Ricardo Augusto Souza Fernandes

\title{
Identificação de Fontes de Correntes Harmônicas por Redes Neurais Artificiais
}

Dissertação apresentada à Escola de Engenharia de São Carlos da Universidade de São Paulo, sendo parte dos requisitos para obtenção do título de Mestre em Engenharia Elétrica.

Orientador: Prof. Dr. Ivan Nunes da Silva

São Carlos 

"Porque dele e por meio dele, e para ele, são todas as coisas. Glória, pois a ele eternamente. Amém."

Romanos 11, 36 



\section{Agradecimentos}

Esta dissertação teve a colaboração de diversas pessoas que gostaria de agradecer mesmo correndo o risco de esquecer algumas delas.

Agradecimentos especiais devem ser feitos à minha família que forneceu suporte em todas as fases de estudo que passei. Ao meu pai por me ensinar a ter muita força e garra mesmo quando nada funciona e por sempre ter me instigado a ir além. À minha mãe pelo carinho e por sempre estar ao meu lado quando mais precisei. Aos meus avós que sempre contribuíram para formar meu caráter de um modo muito carinhoso. E por fim ao meu irmão que mesmo sendo mais novo, sempre me ensinou muito sobre como aproveitar a vida. Ainda devo agradecer de forma geral a todas estas pessoas, pois, contribuíram para a formação do bem mais precioso que possuo, meu conhecimento.

À minha namorada Cíntia, pelo carinho, companheirismo, compreensão e por todo apoio dado em momentos difíceis.

Seguindo uma linha cronológica, gostaria de agradecer aos amigos que fiz antes mesmo da graduação e que continuam ao meu lado. Dentre estas pessoas, devo ressaltar o amigo Maurício Suzuki que ajudou-me muito no aprendizado da lógica de programação e também por sempre tentar me mostrar que os problemas podem ser visualizados por ângulos diferentes.

Aos professores de graduação da FEB/Barretos, instituição na qual tive o privilégio em adquirir toda base de conhecimento acadêmico. Em especial à professora MSc. Fernanda Maria da Cunha Santos, pelo auxílio dado desde o período da graduação até hoje, quando somos colegas de laboratório. Aos 
professores MSc. Sérgio Ricardo de Jesus Oliveira e MSc. Anderson Luiz Aguiar Vilaça pelos grandiosos ensinamentos.

Aos amigos de graduação, Eng. Karol Voitila Pereira Resende, Eng. Rogério Minoru Tanaka, Eng. Arthur Nogueira, Eng. Rogério Varalda pelos cinco anos bem vividos e que mesmo distantes ainda mantêm contato.

Agradeço também aos amigos de graduação e que prosseguiram para o mestrado aqui na USP, Eng. Yuri Andrey Olivato Assagra e Eng. Samuel Lourenço Nogueira pelo companheirismo e amizade, sem esquecer das risadas que demos na república, pois, isto é o que faz com que verdadeiras amizades sejam construídas.

Ao Prof. Dr. Mário Oleskovicz, por possibilitar a execução deste projeto vinculado à bancada experimental de seu laboratório (LSEE), pelas sugestões e correções de artigos científicos, pelo auxílio nos conceitos relativos à Qualidade da Energia e pela orientação sobre os inúmeros problemas encontrados durante a confecção desta dissertação.

Ao Prof. Dr. Paulo José Amaral Serni, pelas sugestões e contribuições conceituais fornecidas.

Ao Prof. Dr. Azauri pela grande contribuição quando de sua participação na banca do exame de qualificação.

Ao Prof. Dr. Ivan Nunes da Silva que, desde o começo sempre deu liberdade para pesquisar assuntos que fossem de meu interesse, pela grandiosa contribuição para a conclusão do trabalho e pela confiança depositada na pesquisa de mestrado. Agradeço ainda pela orientação acadêmica, pela revisão dos artigos publicados em eventos científicos e pelos ensinamentos para elaboração de projetos.

Aos colegas de laboratório (LAIPS): Eng. Dr. Antônio Vanderlei Ortega, MSc. Rodrigo Antonio Faccioli, Eng. MSc. Sérgio Ferreira da Silva, Eng. MSc. Cristiano 
Minotti, Eng. MSc. Fernando Ranieri, Eng. MSc. Danilo Hernane Spatti, Eng. MSc. Marcelo Suetake, Eng. Renato Flor e aos bacharéis em ciência da computação Eduardo Sacogne Fraccaroli, Luciano Carli Moreira de Andrade pelas inúmeras contribuições, sugestões e ensinamentos.

E aos colegas dos demais laboratórios: Eng. Patrick Oliveira dos Santos, Eng. Etienne Biasotto, Eng. MSc. Daniel Barbosa, além de muitos outros.

Aos funcionários da Universidade de São Paulo (USP/EESC/SEL), em especial às secretárias de Pós-Graduação, Marisa Fortulan e Rosane Aranda.

À CAPES (Coordenação de Aperfeiçoamento de Pessoal de Nível Superior), pelo auxílio financeiro concedido no período de realização deste trabalho na forma de bolsa de estudos e por possibilitar o acesso a inúmeras revistas e periódicos renomados gratuitamente.

À Escola de Engenharia de São Carlos (EESC/USP) que acolheu este trabalho de mestrado, por meio da destinação de espaço físico e apoio administrativo, traduzindo assim a grandiosidade da instituição e visão de futuro. 



\section{SUMÁRIO}

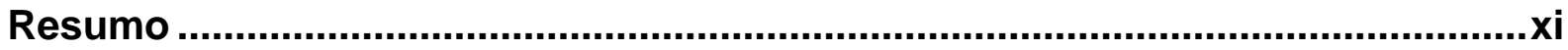

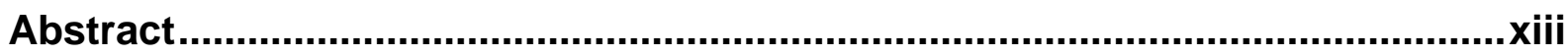

Lista de Siglas e Abreviaturas .....................................................................



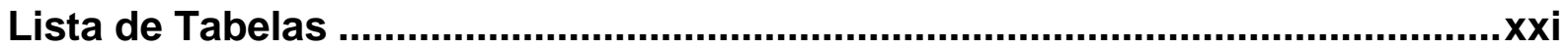

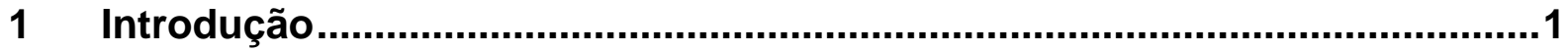

1.1 Motivação e Relevância do Trabalho …………..................................

1.2 Objetivo e Justificativa da Dissertação ................................................

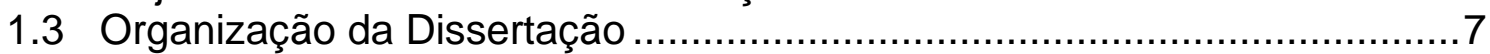

1.4 Trabalhos Publicados em Eventos Científicos ........................................

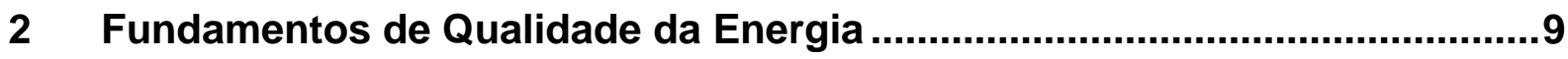

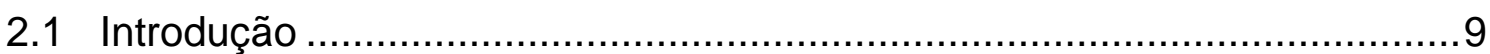

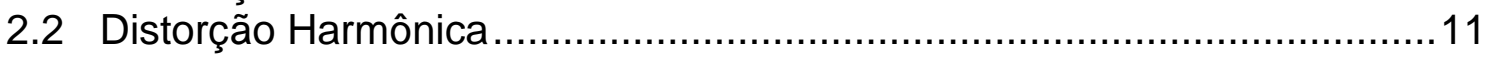

2.2.1 Extração de Harmônicas .............................................................13

2.2.2 Tensões e Correntes Harmônicas ................................................14

2.2.3 Seqüências e Ordens das Harmônicas ........................................17

2.2.4 Indicadores de Distorção Harmônica...........................................20

2.2.5 Distúrbios Acarretados por Distorções Harmônicas .......................24

2.2.6 Técnicas para Mitigação das Harmônicas ....................................26

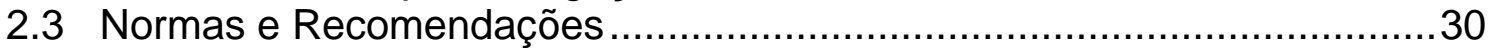

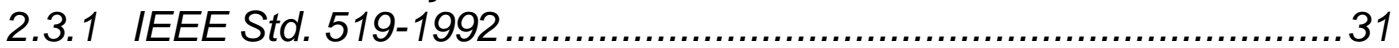

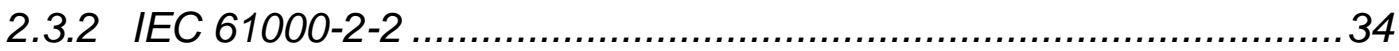



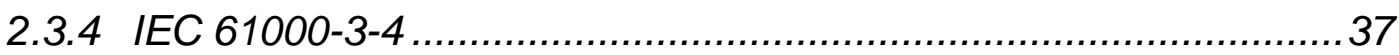

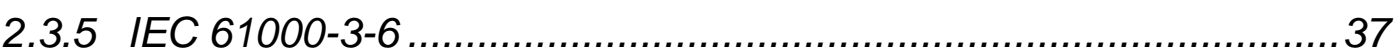



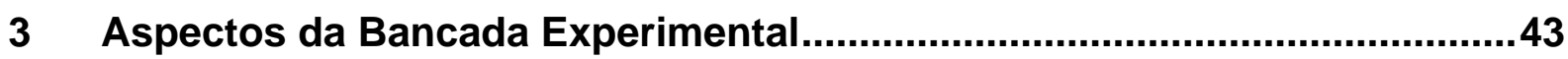

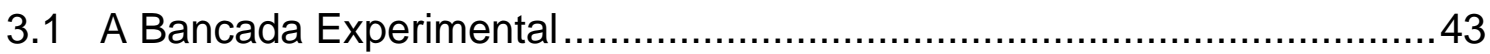

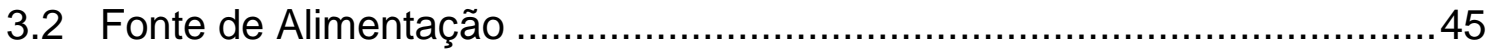

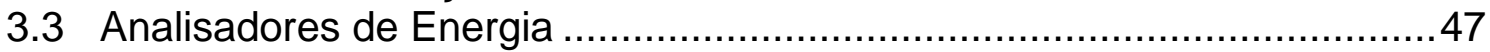

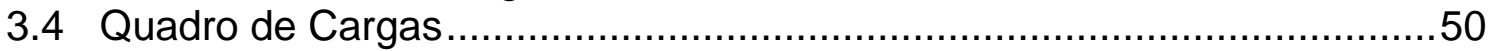

3.4.1 Lâmpada Incandescente .................................................... 51

3.4.2 Lâmpada Fluorescente com Reator Convencional........................52

3.4.3 Lâmpada Fluorescente Compacta..............................................53

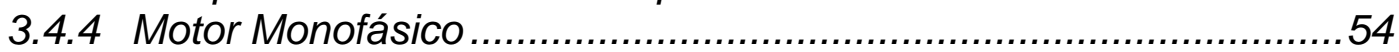



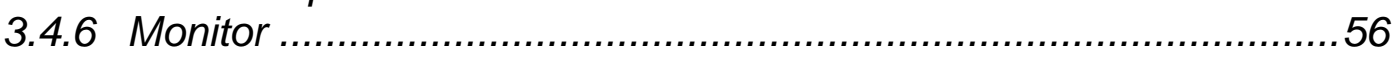

4 Fundamentos de Seleção de Atributos e Mineração de Dados ...................57 


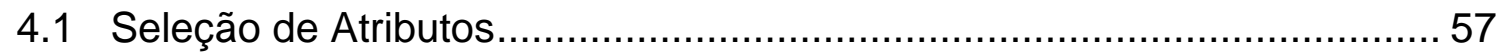

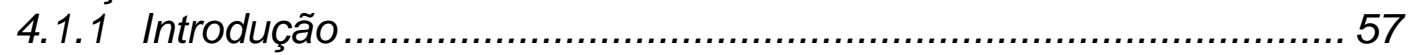

4.1.2 Métodos Wrapper .............................................................. 59

4.1.3 Método CFS (Correlation-based Feature Selection) ....................... 60

4.1.4 Método CF (Consistency-based Filter)......................................... 61

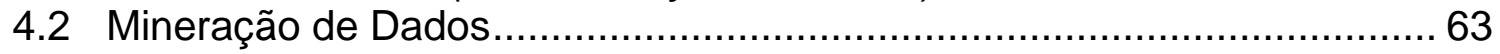

4.2.1 Introdução à Mineração de Dados .............................................. 63

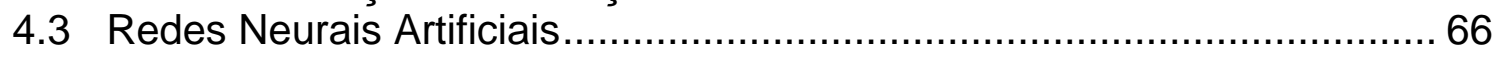

4.3.1 Estado da Arte de Redes Neurais Artificiais ...............................6 67

4.3.2 Arquiteturas de Redes Neurais Artificiais....................................69 69

4.3.3 Perceptron de Múltiplas Camadas ............................................ 73

4.3.4 Treinamento Backpropagation .............................................. 75

4.3.5 Treinamento Levenberg-Marquardt ......................................... 80

5 Identificação de Fontes de Harmônicas e Resultados ................................. 85

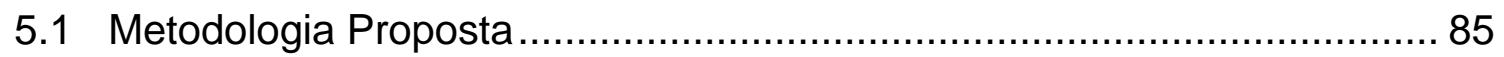

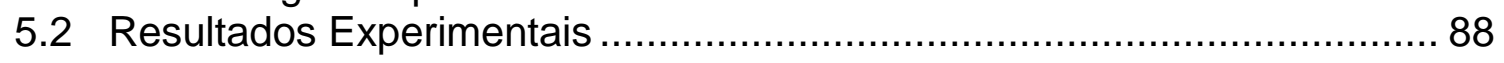

6 Conclusões Gerais e Trabalhos Futuros ................................................. 99



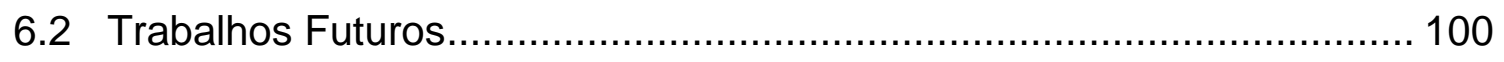

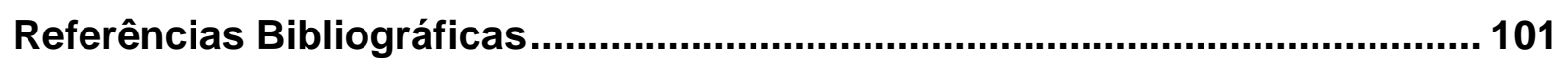




\section{Resumo}

FERNANDES, R. A. S. (2008). Identificação de Fontes de Correntes Harmônicas por Redes Neurais Artificiais. Dissertação (Mestrado) - Escola de Engenharia de São Carlos, Universidade de São Paulo, 2008.

Este trabalho consiste em apresentar um método alternativo para a identificação de fontes de correntes harmônicas comumente encontradas em sistemas elétricos residenciais. Desta identificação, soluções viáveis poderão ser aplicadas com o intuito de mitigar os níveis de emissão das correntes harmônicas geradas, principalmente, por cargas com características não lineares. Para a identificação empregou-se Redes Neurais Artificiais (RNAs), sendo esta técnica inteligente, apresentada como uma alternativa aos métodos convencionais. Os resultados reportados neste contexto procuram validar a proposta apresentada com dados experimentais obtidos em ensaios laboratoriais.

Palavras Chave: Identificação de Fontes Harmônicas, Componentes Harmônicas, Redes Neurais Artificiais. 



\section{Abstract}

FERNANDES, R. A. S. (2008). Identification of Harmonic Current Sources with Artificial Neural Networks. Dissertation (Master's Degree) - Escola de Engenharia de São Carlos, Universidade de São Paulo, 2008.

This work presents an alternative method for the identification of current harmonic sources commonly encountered in residential electrical systems. For this purpose, feasible solutions can be applied to minimize the levels of harmonic currents emission caused by nonlinear loads. Artificial Neural Networks are employed as alternative to conventional methods. The experimental results will be reported in order to validate the proposal presented with the experimental data obtained in laboratory.

Keywords: Identification of Harmonic Sources, Harmonic Components, Artificial Neural Networks. 



\section{Lista de Siglas e Abreviaturas}

\begin{tabular}{|c|c|}
\hline$C F$ & Consistency-based Filter \\
\hline CFS & Correlation-based Feature Selection \\
\hline$D C$ & Direct Current \\
\hline DDT & Distorção de Demanda Total \\
\hline $\mathrm{DHI}$ & Distorção Harmônica Individual \\
\hline DHT & Distorção Harmônica Total \\
\hline$E N$ & European Norm \\
\hline EQM & Erro Quadrático Médio \\
\hline IEC & International Electrotechnical Commission \\
\hline IEEE & Institute of Electrical and Electronics Engineers \\
\hline$K D D$ & Knowledge Discovery in Databases \\
\hline MLP & Multilayer Perceptron \\
\hline MD & Mineração de Dados \\
\hline PAC & Ponto de Acoplamento Comum \\
\hline QEE & Qualidade da Energia Elétrica \\
\hline RBF & Radial Basis Function \\
\hline RMS & Root Mean Square \\
\hline RNA & Rede Neural Artificial \\
\hline$R S-232$ & Recommended Standard-232 \\
\hline SEP & Sistema Elétrico de Potência \\
\hline SVM & Support Vector Machine \\
\hline $\mathrm{TF}$ & Transformada de Fourier \\
\hline TRF & Transformada Rápida de Fourier \\
\hline
\end{tabular}


TWD

UPS

USB

Transformada Wavelet Discreta

Uninterruptible Power Supply

Universal Serial Bus 


\section{Lista de Figuras}

Figura 2.1 - Representação de distorções harmônicas em corrente e tensão considerando a impedância do sistema e o conceito de PAC.

Figura 2.2 - Conjunto de Seqüência Positiva..........................................18

Figura 2.3 - Conjunto de Seqüência Negativa. ........................................... 18

Figura 2.4 - Conjunto de Seqüência Zero..............................................19

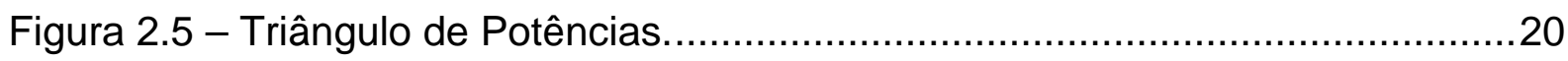

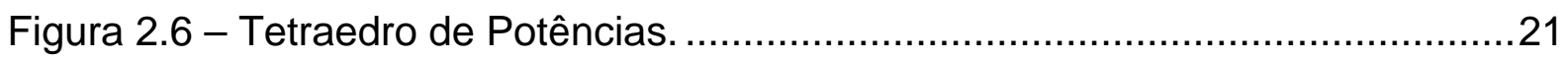

Figura 2.7 - Exemplo de conexão de um transformador em zig-zag para mitigação das correntes harmônicas de seqüência zero. .............................28

Figura 3.1 - Diagrama de blocos representando a bancada experimental utilizada nos ensaios laboratoriais. ................................................43

Figura 3.2 - Organização do laboratório para a realização dos ensaios.................44

Figura 3.3 - Fonte de alimentação / analisador de energia modelo 5001iX da California Instruments.

Figura 3.4 - Software CiguiSII iX Series $₫$........................................... 46

Figura 3.5 - Analisador de energia modelo 435 da Fluke. ...............................4 47

Figura 3.6 - Exemplo de como os dados são disponibilizados pelo equipamento da California Instruments.

Figura 3.7 - Exemplo de como os dados são obtidos pelo equipamento da Fluke.

Figura 3.8 - Exemplo dos arquivos criados pelo analisador de energia modelo 5001iX da California Instruments na aquisição dos dados.

Figura 3.9 - Exemplo dos arquivos criados pelo analisador de energia modelo 435 da Fluke na aquisição dos dados.............................................50

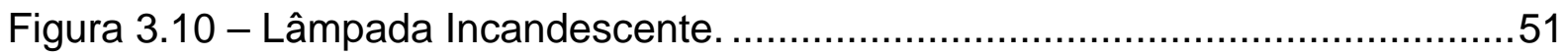

Figura 3.11 - Espectro de freqüências referente à lâmpada incandescente............51

Figura 3.12 - Lâmpada Fluorescente com reator convencional...........................52

Figura 3.13 - Espectro de freqüências referente à lâmpada fluorescente com reator convencional. 
Figura 3.14 - Lâmpada Fluorescente Compacta.

Figura 3.15 - Espectro de freqüências adquirido da lâmpada fluorescente compacta.

Figura 3.16 - Motor monofásico.

Figura 3.17 - Espectro de freqüências referente ao motor.

Figura 3.18 - Computador Pessoal. ............................................................. 55

Figura 3.19 - Espectro de freqüências adquirido do computador pessoal. ..............55

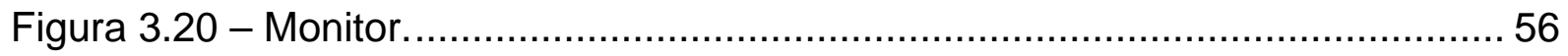

Figura 3.21 - Espectro de freqüências adquirido do monitor............................ 56

Figura 4.1 - Representação geral de seletores de atributos do tipo Wrapper......... 60

Figura 4.2 - Representação geral de filtros para seleção de atributos.................... 62

Figura 4.3 - Visão geral do sistema computacional, partindo-se da base de dados consolidada até a identificação das fontes de correntes harmônicas.

Figura 4.4 - Representação do neurônio artificial modelado por McCulloch e

Pitts comparado a um neurônio biológico.

Figura 4.5 - Representação da função de ativação do tipo degrau bipolar............. 70

Figura 4.6 - Representação da função de ativação do tipo degrau........................ 71

Figura 4.7 - Ilustração da função de ativação do tipo linear.

Figura 4.8 - Representação gráfica da função de ativação do tipo tangente hiperbólica.

Figura 4.9 - Ilustração da função de ativação do tipo logística (sigmóide)...............72

Figura 4.10 - Representação gráfica da função de ativação do tipo rampa. ............72

Figura 4.11 - Ilustração da função de ativação de base radial (gaussiana)............ 73

Figura 4.12 - Arquitetura de uma rede neural do tipo MLP............................. 74

Figura 5.1 - Visão geral da metodologia proposta. ....................................... 85

Figura 5.2 - Espaço de busca antes de selecionar os atributos mais relevantes.... 90

Figura 5.3 - Espaço de busca contendo apenas os atributos selecionados.

Figura 5.4 - Arquitetura das RNAs empregadas à tarefa de identificação das fontes de harmônicas. 
Figura 5.5 - Gráfico de treinamento da RNA especializada na identificação do



Figura 5.6 - Representação gráfica do treinamento realizado pela RNA responsável pela identificação do monitor. .93

Figura 5.7 - Treinamento da RNA especializada na identificação da lâmpada fluorescente. .93

Figura 5.8 - Treinamento da RNA especialista na identificação da lâmpada incandescente.

Figura 5.9 - Treinamento da RNA responsável pela identificação da lâmpada fluorescente compacta.

Figura 5.10 - Gráfico de treinamento da RNA especializada na identificação do motor 



\section{Lista de Tabelas}

Tabela 2.1 - Limites de correntes harmônicas para consumidores de distintas classes de tensão.

Tabela 2.2 - Indicadores (DHI e DHT) para limitação da distorção harmônica de tensão até o PAC.

Tabela 2.3 - Níveis de distorção harmônica individual para sistemas elétricos de baixa tensão conforme o IEC 61000-2-2. ..............................................34

Tabela 2.4 - Máximas correntes harmônicas admissíveis para equipamentos da Classe A.

Tabela 2.5 - Máximas correntes harmônicas admissíveis para equipamentos da Classe B.

Tabela 2.6 - Máximas correntes harmônicas admissíveis para equipamentos da Classe C.

Tabela 2.7 - Máximas correntes harmônicas admissíveis para equipamentos da Classe D

Tabela 2.8 - Níveis de corrente harmônica permitidos pela IEC 61000-3-4.

Tabela 2.9 - Níveis de distorção harmônica de tensão para sistemas de baixa e média tensão.

Tabela 2.10 - Limites de distorção harmônica de tensão para sistemas de média tensão.

Tabela 2.11 - Níveis de distorção harmônica de tensão aceitáveis para sistemas de alta e extra alta tensão.

Tabela 2.12 - Limites de distorção harmônica de tensão até os terminais do alimentador.

Tabela 3.1 - Características das cargas empregadas nos ensaios laboratoriais......50

Tabela 5.1 - Desempenho dos seletores de atributos do ponto de vista do esforço computacional e relevância dos atributos.

Tabela 5.2 - Desempenho das RNAs responsáveis pela identificação de cada carga.

Tabela 5.3 - Instâncias do conjunto de validação que as RNAs responsáveis pela lâmpada fluorescente e pelo motor apresentaram respostas errôneas. 



\section{Introdução}

\subsection{Motivação e Relevância do Trabalho}

Com as instalações residenciais utilizando cada vez mais cargas não lineares como computadores, televisores, refrigeradores, condicionadores de ar, circuitos de iluminação dentre outros, nota-se um aumento dos níveis de emissão das correntes harmônicas que podem acarretar em uma maior degradação da qualidade da energia elétrica (QEE). Apenas como fato ilustrativo, hoje, tem-se a preocupação com o uso racional da energia, onde, em certos casos, ocorre a substituição de cargas praticamente lineares (alto consumo) por cargas não lineares (baixo consumo). Como exemplo, pode-se citar a substituição de lâmpadas incandescentes por lâmpadas fluorescentes compactas.

A partir da observação do sistema elétrico como um todo, constatar-se-á que as residências possuem uma densidade de correntes harmônicas muitas vezes aceitável, porém, quando estas somam-se com as correntes harmônicas geradas por grandes consumidores, a densidade de certas harmônicas pode elevar-se além do esperado e assim causar diversos problemas relacionados à energia elétrica.

Como resultado, tem-se a má qualidade da energia que pode ser refletida para concessionárias, consumidores próximos à fonte geradora de harmônicas e ao próprio estabelecimento gerador. Muitas das vezes, os próprios consumidores são os maiores prejudicados, devido à maior sensibilidade de suas cargas. Neste contexto, caso não haja meios específicos de controle, qualquer sistema com alta 
densidade de cargas não lineares estará vulnerável a problemas refletidos na qualidade da energia. Desta situação, poder-se-ia evidenciar um mau funcionamento de equipamentos, baixo fator de potência, distorção na forma de onda da tensão e/ou corrente, aquecimento de cabos, dentre outros (Dugan et al., 2004).

As pesquisas relacionadas com harmônicas em sistemas elétricos encontram-se divididas em duas áreas principais como denominado por Kumar et al. (2004): análise direta de harmônicas e análise reversa das harmônicas.

A análise direta de harmônicas é frequentemente utilizada para quantificar as distorções de tensão e/ou corrente em diversos pontos do sistema elétrico que encontra-se sob análise. Estas técnicas também são empregadas para verificar o quanto determinada freqüência harmônica está prejudicando o sistema.

No entanto, durante a última década as pesquisas estão mais voltadas aos métodos de análise reversa de harmônicas, pois, estes são responsáveis pela localização e identificação de fontes de harmônicas, seja em sistemas de distribuição, barramentos, sistemas elétricos industriais e até mesmo em residências. É neste contexto que o presente projeto encaixa-se, onde será realizada a identificação das fontes de correntes harmônicas em sistemas elétricos residenciais.

Os primeiros métodos de análise reversa foram propostos sobre barramentos (Heydt, 1989), pois, as cargas não lineares ainda começavam a se proliferar. Com o passar dos anos, tais estudos voltaram-se também para os sistemas de distribuição (Islam e Samra, 1997; Nguyen e Lee, 2000), entretanto, os sistemas elétricos industriais, comerciais e residenciais não necessitavam tanto deste tipo de análise e por este motivo, atualmente, são alvos dos estudos mais recentes. Consequentemente, os primeiros métodos desenvolvidos apenas podiam 
identificar uma carga por vez, assim, Varadan e Makram (1996) propuseram um método para estimação de estados das harmônicas que tinha como base a aplicação de mínimos quadrados, e que por meio da composição harmônica estimada podia identificar quais cargas encontravam-se conectadas ao barramento sob análise. Como as cargas possuíam características particulares, houve a necessidade de determinar três classes de cargas, sendo que a classe A possuía predominância das harmônicas de $5^{\mathrm{a}}, 7^{\mathrm{a}}, 11^{\mathrm{a}}$ e $13^{\mathrm{a}}$ ordens; a classe $\mathrm{B}$ era determinada por cargas com maior predominância de harmônicas de $3^{a}, 5^{a}$ e $7^{a}$ ordens; e a classe C constituída por cargas com harmônicas predominantes de $3^{\mathrm{a}} \mathrm{e}$ $5^{\mathrm{a}}$ ordens.

Alammari et al. (2004) propõem um método para a identificação de cargas não lineares em barramentos, onde as cargas são classificadas conforme determinado por Varadan e Makram (1996); e a identificação das fontes de harmônicas é realizada por um método baseado também em mínimos quadrados.

Outro método para identificação de fontes de harmônicas em barramentos é proposto em Kumar et al. (2004), onde duas etapas são realizadas. Na primeira etapa são encontrados os possíveis barramentos onde estão conectadas as fontes de harmônicas por um método de estimação baseado em mínimos quadrados. A segunda etapa elege um dos barramentos selecionados pela primeira etapa empregando um método baseado na norma Euclidiana.

Observa-se que muitas pesquisas até então utilizavam técnicas convencionais como o método de mínimos quadrados para estimar o estado das harmônicas e por conseqüência identificar as fontes de harmônicas, porém, alguns trabalhos já faziam uso de sistemas inteligentes como as redes neurais artificiais (Varadan e Makram, 1994). A partir destes novos estudos, a aplicação de RNAs à 
identificação de fontes de harmônicas se proliferou (Chan et al., 2000; Niekerk et al., 2002; Lin et al., 2005), assim como, os sistemas fuzzy (Nawi et al., 2003; Ferrero et al., 2007).

As RNAs tornaram-se ferramentas muito empregadas aos problemas de identificação de fontes de harmônicas devido à sua capacidade de generalizar soluções, mapear sistemas não lineares e, também, por agrupar e classificar padrões.

Em Varadan e Makram (1994), empregou-se uma RNA com algoritmo de treinamento backpropagation para a identificação de fontes de harmônicas conforme as classes determinadas pelo IEEE Std. 519-1992. No referido trabalho as cargas foram separadas em lineares e não lineares de acordo com o ângulo de fase das correntes, onde concluíram que o ângulo de fase é um atributo irrelevante para tarefas de identificação de fontes de harmônicas, pois, não se consegue caracterizar distintos tipos de cargas não lineares.

Já em Niekerk et al. (2002), utilizou-se uma rede neural do tipo MLP (Multilayer Perceptron), onde os algoritmos de treinamento foram variados entre bayesian regularisation e resilient backpropagation. No trabalho em questão foram identificadas as classes de cargas presentes no sistema elétrico conforme o IEEE Std. 519-1992.

Já os sistemas fuzzy foram muito empregados à identificação das cargas não lineares pela sua capacidade em lidar com as incertezas e imprecisões das variáveis envolvidas no sistema elétrico. Os sistemas denominados fuzzy exploram os aspectos qualitativos do problema para mapear uma melhor solução, isto é feito mediante a construção de regras do tipo "Se-Então" que formarão sua base de conhecimento. 
Em Nawi et al. (2003), sistemas fuzzy são aplicados com o intuito de se identificar cargas industriais como inversores de freqüência, controladores de velocidade para máquinas elétricas e fornos a arco. As cargas são identificadas com suas harmônicas de $3^{\mathrm{a}}, 5^{\mathrm{a}}, 7^{\mathrm{a}}, 9^{\mathrm{a}}$ e $11^{\mathrm{a}}$ ordens, onde as regras lingüísticas do sistema fuzzy são determinadas conforme o nível de cada uma destas harmônicas.

As pesquisas mais recentes ainda trabalham com sistemas de distribuição e sistemas elétricos industriais, porém, começam a crescer os estudos correlatos à identificação de cargas não lineares em sistemas elétricos residenciais. Dentro deste contexto, Umeh e Mohamed (2005) propõem um sistema fuzzy, porém, com regras lingüísticas baseadas nos níveis percentuais da distorção harmônica total de corrente.

Por fim, Srinivasan et al. (2006) propõem um método a partir da aplicação da Transformada Rápida de Fourier (TRF) para a extração do espectro de freqüências das correntes, considerando-se o ângulo de fase e a amplitude apenas das componentes de ordem ímpar até a $15^{\mathrm{a}}$ ordem. Neste mesmo trabalho, modelos baseados em RNAs (MLP - Multilayer Perceptron, RBF - Radial Basis Function e SVM - Support Vector Machines) são utilizados para a identificação das cargas presentes em um sistema elétrico residencial.

\subsection{Objetivo e Justificativa da Dissertação}

Os objetivos gerais desse projeto de pesquisa consistem na investigação, desenvolvimento, projeto, implementação e validação de arquiteturas de sistemas inteligentes para a identificação de fontes de correntes harmônicas presentes em sistemas elétricos residenciais, focando nas cargas comumente encontradas nestes sistemas. Assim, por meio das ferramentas desenvolvidas e implementadas torna-se 
possível a construção de modelos capazes de realizar a identificação destas cargas de forma bastante confiável. Dentro desse contexto, os objetivos gerais deste projeto de pesquisa são relacionados como se segue:

- Criar e disponibilizar um banco de dados que possa ser utilizado por outras pesquisas relacionadas às correntes harmônicas de cargas residenciais;

- Selecionar os atributos mais relevantes à identificação das cargas, isto é, selecionar as ordens das correntes harmônicas de maior relevância, por métodos automatizados;

- Aplicar sistemas inteligentes para a mineração dos dados adquiridos experimentalmente, de forma a extrair os padrões de assinaturas harmônicas das cargas e suas combinações;

- Automatizar ou semi-automatizar o processo de identificação das cargas geradoras de correntes harmônicas;

- Permitir que novas técnicas, desenvolvidas mediante a aplicação de sistemas inteligentes, possam ser testadas e validadas experimentalmente.

- Comparar a metodologia para identificação de fontes de correntes harmônicas empregada nesta dissertação com as abordagens convencionais já existentes.

Conforme os resultados obtidos nessa pesquisa, esta pode ser expandida de forma a aplicar as mesmas técnicas em sistemas de distribuição das concessionárias de energia elétrica, de forma a identificar os estabelecimentos que estejam gerando altos níveis de distorção harmônica, visando melhorias na qualidade da energia elétrica. 


\subsection{Organização da Dissertação}

A dissertação está organizada em seis capítulos principais. O Capítulo 1 apresenta a motivação e relevância, o estado da arte referente à identificação de fontes de harmônicas, bem como os principais objetivos deste trabalho.

No Capítulo 2 são tratados os conceitos e fundamentos relativos às tensões e correntes harmônicas. Consistindo de uma breve descrição das principais características referentes à qualidade da energia elétrica, os efeitos das harmônicas em sistemas elétricos de potência, as principais recomendações para se limitar os níveis de harmônicas e finalizando com as técnicas para mitigação de harmônicas em sistemas elétricos.

No Capítulo 3, as cargas utilizadas na bancada experimental são descritas, bem como os equipamentos empregados para a extração das assinaturas harmônicas das cargas e suas possíveis combinações.

No Capítulo 4, os conceitos fundamentais das técnicas para seleção de atributos e da mineração de dados são apresentados, onde são descritos os aspectos das redes neurais.

No Capítulo 5, discute-se a metodologia empregada para a identificação das fontes de harmônicas conectadas ao sistema, assim como os resultados experimentais.

No Capítulo 6, são dadas as conclusões gerais e os possíveis trabalhos que podem ser desenvolvidos no futuro. Por fim, são apresentadas as referências bibliográficas desta dissertação. 


\subsection{Trabalhos Publicados em Eventos Científicos}

No decorrer do período de mestrado, os seguintes trabalhos foram publicados em anais de congressos científicos:

- FERNANDES, R. A. S.; SILVA, I. N.; OLESKOVICZ, M. Sistema neurogenético aplicado à identificação de cargas não-lineares. In: 7th Brazilian Conference on Dymanics, Control and Their Applications, 2008, Presidente Prudente. Proceedings of the 7th Brazilian Conference on Dymanics, Control and Their Applications, 2008. p. 955-960.

- FERNANDES, R. A. S.; SILVA, I. N.; OLESKOVICZ, M. Identificação de fontes harmônicas por redes neurais artificiais. In: VIII Conferência Internacional de Aplicações Industriais, 2008, Poços de Caldas. Anais do VIII INDUSCON, 2008.

- FERNANDES, R. A. S.; SILVA, I. N.; OLESKOVICZ, M.; SANTOS, F. M. C. Extração de características harmônicas para a identificação de cargas não-lineares aplicando sistemas inteligentes. In: XVIII Congresso Brasileiro de Automática, 2008, Juiz de Fora. Anais do XVIII Congresso Brasileiro de Automática, 2008. 


\section{Fundamentos de Qualidade da Energia}

\subsection{Introdução}

A descrição dos conceitos fundamentais de qualidade da energia elétrica faz-se necessária devido ao principal enfoque desta dissertação consistir da identificação de fontes de correntes harmônicas comumente encontradas em sistemas elétricos residenciais.

O tema "qualidade da energia" vem sendo discutido desde o final da década de 80 , sendo este um assunto de interesse tanto das concessionárias quanto dos consumidores finais, pois, é um tópico que abrange uma série de fenômenos que podem vir a ocorrer sobre os sistemas elétricos, sejam estes de baixa, média ou alta tensão. Estes fenômenos já vinham sendo discutidos antes mesmo de surgir o termo "qualidade da energia", porém, tornaram-se ainda mais evidentes com a proliferação de equipamentos como: televisores, aparelhos de som, microcomputadores, refrigeradores, condicionadores de ar, impressoras, dentre outros.

O interesse sobre o tema "qualidade da energia" começou a crescer após a propagação dos equipamentos acima exemplificados, devido a estes serem cargas não lineares e também muito sensíveis aos distúrbios ocorridos no Sistema Elétrico de Potência (SEP) (Dugan et al., 2004).

Visto que este novo padrão de cargas que começou a surgir não era tão robusto quanto às cargas antes empregadas nos mais diversos estabelecimentos (residenciais, comerciais e/ou industriais), surgiu então a necessidade de tratar a 
"qualidade da energia" com sua devida importância. Assim, estudos correlatos a este tema começaram a se expandir, pois, os distúrbios provenientes de uma má qualidade da energia elétrica poderiam prejudicar o funcionamento destes equipamentos e, por fim, paralisar linhas de produção e outros serviços empresariais, afetando a economia dos mais diversos setores de atividades.

Outro fator que vem fazendo com que muitas cargas sejam substituídas, principalmente em ambientes residenciais e comerciais é o uso racional da energia elétrica, pois, com o passar do tempo os consumidores finais começaram a se preocupar mais com a eficiência energética de seus estabelecimentos, de forma a reduzir os custos associados ao consumo da energia elétrica e assim passaram a dar preferência por cargas de baixo consumo, as quais, em sua maioria apresentam correntes harmônicas de alta densidade que tornam os distúrbios bastante evidentes. Este é um fator que preocupa muito as concessionárias, pois com a interconexão dos consumidores finais, dependendo da alta densidade de correntes harmônicas produzida por um dado consumidor, estas podem causar uma variedade de distúrbios na tensão ao passarem pela impedância do sistema. Desta forma, mesmo que a concessionária forneça uma tensão adequada, as correntes harmônicas destas cargas podem distorcer a alimentação do sistema e por conseqüência outros consumidores conectados ao mesmo ramal serão prejudicados.

Em conformidade com a alteração no perfil das cargas elétricas encontradas em estabelecimentos residenciais, comerciais e/ou industriais, houve a necessidade de se determinar limites para que fosse realizado o controle da QEE. Até então controlava-se apenas a demanda e o fator de potência, no entanto, hoje as concessionárias devem garantir que a tensão e freqüência da rede também 
estejam dentro de limites aceitáveis, onde a tensão deve ser aproximadamente uma forma de onda senoidal, simétrica e com magnitude limitada; já a freqüência deve ser mantida dentro de um desvio de $\pm 0,5 \mathrm{~Hz}$ com relação à freqüência nominal da rede, no caso do Brasil entre 60,5Hz e 59,5Hz (Dugan et al., 2004).

De acordo com as limitações impostas pelas cargas, podemos dizer que o termo "qualidade da energia" é definido pelos consumidores finais como as características da energia fornecida pela concessionária que faz com que seus equipamentos funcionem corretamente. No entanto, em termos gerais, Dugan et al. (2004) definem a má qualidade da energia como qualquer problema manifestado na tensão e/ou corrente, assim como desvios de freqüência, que resultem em qualquer tipo de falha ou má operação dos equipamentos pertencentes aos consumidores finais.

Entretanto, a alimentação do sistema, mesmo que esteja dentro dos limites previamente citados pode ser prejudicada devido aos distúrbios ocorridos nos SEPS, como: afundamentos de tensão, elevações de tensão, flutuações de tensão, oscilações, ruídos, sobretensões, subtensões, distorções harmônicas de corrente e/ou tensão, dentre outros (Dugan et al., 2004; Sankaran, 2002).

Dentre esta grande quantidade de distúrbios, este trabalho irá tratar com maior amplidão as distorções harmônicas, visto que o foco principal desta dissertação é a identificação das fontes de correntes harmônicas presentes em sistemas elétricos residenciais.

\subsection{Distorção Harmônica}

Em Arrillaga et al. (2000), as harmônicas são definidas como tensões ou correntes senoidais que possuem freqüências múltiplas inteiras da fundamental, 
sendo que no caso do sistema elétrico brasileiro a freqüência fundamental é dada por $60 \mathrm{~Hz}$. No entanto, as harmônicas não devem ser confundidas com os transitórios. Para isto, basta observar que estas ocorrem continuamente no sistema por um tempo muito maior que os fenômenos transitórios, pois, estão relacionadas à operação contínua das cargas. Contudo, no caso da energização de transformadores, pode-se verificar uma distorção da forma de onda com duração maior que os transitórios comumente encontrados, mas este evento não deixa de ser considerado um fenômeno transitório.

Os distúrbios causados por distorções harmônicas são considerados uns dos mais complexos problemas enfrentados pela QEE, pois, nos projetos e operação de sistemas elétricos apenas a componente de freqüência fundamental é considerada, isto porque dificilmente tem-se idéia das cargas que estarão conectadas ao sistema, bem como a densidade de suas componentes harmônicas (Das, 2002).

A discussão sobre as distorções harmônicas não é novidade, porém, este tema foi bastante confrontado com problemas de interferência eletromagnética em linhas telefônicas e problemas encontrados na saturação e energização de transformadores. Um dos fatores que impulsionou este assunto foi a grande quantidade de cargas não lineares hoje utilizadas, como citado previamente. Quando se realiza a análise de harmônicas em SEPs, deve-se levar em consideração a demanda do sistema, pois, mesmo que o SEP esteja projetado para suportar a demanda requisitada, cuidados especiais devem ser tomadas quanto à ressonância entre a capacitância do sistema e determinada componente harmônica que seja considerada crítica, pois, a distorção harmônica será maximizada além do 
normal e poderá ultrapassar a demanda suportada pelo sistema (Dugan et al., 2004).

\subsubsection{Extração de Harmônicas}

A extração de componentes harmônicas em qualquer âmbito, usualmente, é realizada pela Transformada de Fourier (TF), pois, esta foi uma das primeiras técnicas aplicadas à caracterização das freqüências dominantes em ondas eletromagnéticas que viajam através do tempo por uma função periódica. Assim, o mesmo princípio pode ser aplicado à extração de harmônicas das correntes e/ou tensões em SEPs, proporcionando uma análise individual de cada componente (Sankaran, 2002).

A série de Fourier, desenvolvida pelo matemático Jean Baptiste Fourier, foi formulada sobre a hipótese de que qualquer função periódica não senoidal com freqüência fundamental $f$ pode ser expressa como a soma de infinitas funções periódicas senoidais com freqüências múltiplas da fundamental (Sankaran, 2002; Arrillaga et al., 2000). A Equação (2.1) mostra o cálculo da série de Fourier para uma função periódica $x(t)$.

$$
x(t)=a_{0}+\sum_{n=1}^{\infty}\left(a_{n} \cos \left(\frac{2 \pi n t}{T}\right)+b_{n} \sin \left(\frac{2 \pi n t}{T}\right)\right)
$$

onde, $a_{0}$ representa o valor médio da função periódica $x(t)$ e tanto $a_{n}$ quanto $b_{n}$ são os coeficientes da série, os quais se estendem até a $n$-ésima ordem harmônica.

Em SEPs a série de Fourier pode ser simplificada como apresentado por Wakileh (2001) e Sankaran (2002), devido à forma de onda distorcida geralmente possuir seus lados negativo e positivo simétricos. A simplificação é válida somente 
para casos como este. Assim, tem-se que a expressão da Equação (2.1) com seus termos de senos e cossenos pode ser alterada conforme segue:

- Caso a função seja ímpar e simétrica com relação à origem, isto é, $f(-t)=-f(t)$, então podemos utilizar apenas os termos com senos;

- Caso contrário, isto é, dada uma função par $f(-t)=f(t)$, então apenas os termos com cossenos necessitam serem utilizados.

Existem casos onde a simetria aparece somente em meio ciclo, isto é, $f\left(t \pm \frac{T}{2}\right)=-f(t)$, então esta não apresenta a componente $D C$ e resultará no cancelamento de harmônicas de ordem par.

Como mostrado, o método desenvolvido por Fourier é um dos mais empregados na extração de componentes harmônicas, porém não é o único. Outros métodos mais novos, como a Transformada Wavelet Discreta (TWD), também podem ser utilizados como mostrado por Chan et al. (2000), além de métodos que fazem uso de ferramentas inteligentes como RNAs (Nascimento et al., 2007; Lin, 2007). No entanto, estes novos métodos ainda não são tão aplicados quanto os métodos convencionais baseados tanto na série de Fourier como na Transformada Discreta de Fourier (TDF) ou na Transformada Rápida de Fourier (TRF).

\subsubsection{Tensões e Correntes Harmônicas}

Como visto até o momento, as distorções harmônicas são causadas por cargas que apresentam comportamento não linear, isto é, cargas que requerem correntes com componentes harmônicas de alta densidade. Em geral, este comportamento não linear pode ser observado pela não conformidade da forma de 
onda de corrente quando relacionada com a forma de onda de alimentação da carga (Dugan et al., 2004).

Normalmente, quando a análise de componentes harmônicas de tensão e/ou corrente é realizada sobre os SEPs, não leva-se em consideração a extração das freqüências harmônicas acima da $63^{a}$ ordem, pois, os equipamentos necessitariam de maior precisão, a qual viria acompanhada por um alto custo associado ao hardware (Dugan et al., 2004).

Outra conclusão que pode ser considerada é que geralmente os grandes responsáveis pelas distorções harmônicas são os usuários finais, devido à grande quantidade de cargas não lineares empregadas em seus estabelecimentos, porém, não pode-se dizer que todo ou qualquer consumidor irá gerar altos níveis de distorção harmônica para o sistema.

Como mostrado anteriormente, as concessionárias são responsáveis por garantir que a alimentação dos consumidores finais esteja livre de distorções, entretanto, as cargas dos consumidores ou a combinação delas faz com que as correntes que passam pelo sistema possam estar distorcidas, e por conseqüência, poderão distorcer a alimentação do sistema.

Para exemplificar as responsabilidades dos consumidores finais e concessionárias quanto às harmônicas, sejam estas de tensão ou corrente, deve-se analisar o caso de uma determinada carga não linear estar conectada em paralelo com a alimentação do sistema, como mostrado pela Figura 2.1. 


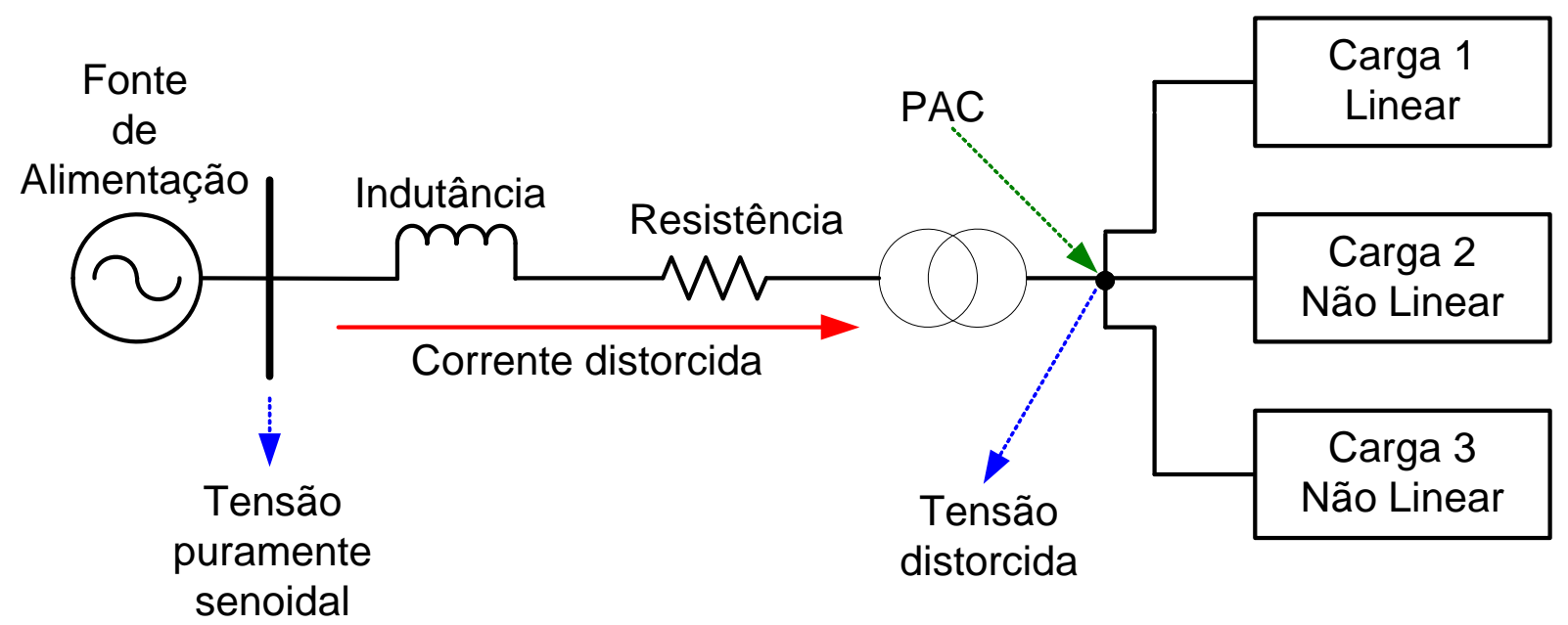

Figura 2.1 - Representação de distorções harmônicas em corrente e tensão considerando a impedância do sistema e o conceito de PAC.

Pela Figura 2.1 pode-se considerar a fonte de alimentação como sendo a concessionária e as cargas sendo os consumidores finais. Ainda neste exemplo, poder-se-ia dizer que cada carga representa uma fonte de corrente, e mesmo que a carga 1 possua uma característica linear, esta será afetada pela distorção harmônica provocada pelas cargas 2 e 3 , as quais possuem alta densidade de correntes harmônicas que por conseqüência distorcem a tensão de alimentação do sistema. De acordo com o exemplo acima ilustrado, a recomendação IEEE Std. 519-1992 determinou que:

- O controle das correntes harmônicas deve ser realizado no estabelecimento dos consumidores;

- Ao se assumir que as correntes harmônicas injetadas no sistema estejam dentro de limites aceitáveis, pode-se dizer que caso haja distorção harmônica de tensão, a responsabilidade por estas distorções será atribuída à entidade que controla a impedância do sistema, geralmente a concessionária. 
Portanto, no que se refere às harmônicas, deve-se observar que, em geral quando se leva em consideração apenas a corrente do sistema, estar-se-á comentando sobre as distorções causadas por consumidores; quando leva-se em consideração as distorções harmônicas de tensão passar-se-á a se referir à concessionária.

Por meio da figura pode-se também definir o PAC como sendo um ponto de conexão comum tanto à concessionária quanto aos consumidores. Neste caso, o ponto encontra-se localizado no lado secundário de um transformador, pois, é este enrolamento que se conecta às cargas, ou seja, aos consumidores.

\subsubsection{Seqüências e Ordens das Harmônicas}

Até então destacou-se que as harmônicas são correntes e/ou tensões independentes que podem compor uma forma de onda distorcida. Neste trabalho serão tratadas apenas harmônicas presentes em sistemas monofásicos, porém, os aspectos inerentes às harmônicas presentes em sistemas trifásicos também serão apresentados para uma maior abrangência do assunto. Ao se tratar de sistemas trifásicos, poder-se-á dizer que as harmônicas de cada fase têm relacionamento com as harmônicas de outra fase. Para visualizar o comportamento deste relacionamento entre fases, utilizam-se normalmente as componentes simétricas, onde um sistema trifásico é transformado em três sistemas monofásicos seja para correntes ou tensões, os quais proporcionarão menor complexidade na análise do sistema. Estes três sistemas monofásicos obtidos são denominados de conjuntos de seqüência positiva, negativa e zero. Deve-se lembrar que para este tipo de análise toma-se a componente fundamental como referência (Sankaran, 2002). 
O conjunto de seqüência positiva irá conter três formas de onda senoidais defasadas de $120^{\circ}$ entre elas, assim como ocorre em sistemas trifásicos balanceados, com rotação de fase normal (Sankaran, 2002). Adotar-se-á como normal a seqüência de fase $A B C$ em sentido anti-horário. A representação do conjunto de seqüência positiva pode ser visualizada pela Figura 2.2.

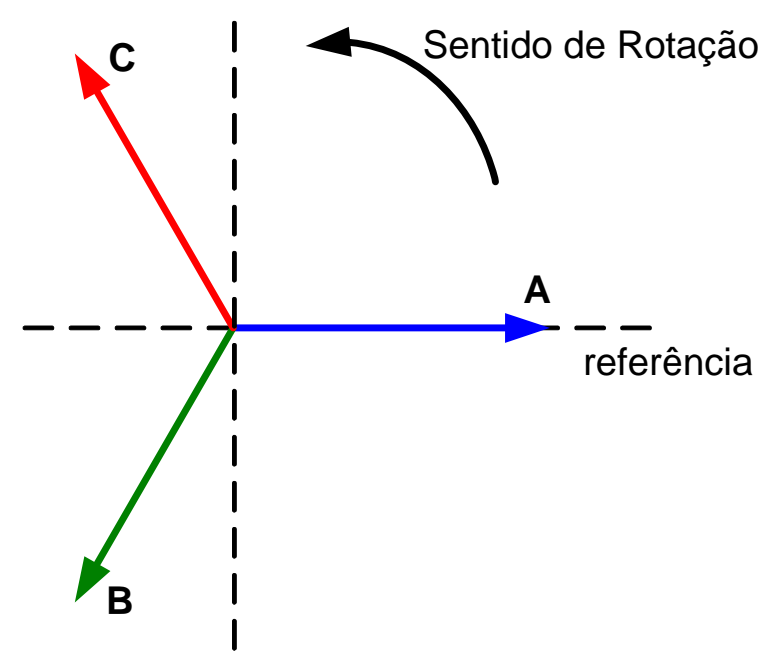

Figura 2.2 - Conjunto de Seqüência Positiva.

O conjunto de seqüência negativa, assim como o positivo, apresenta três formas de onda senoidais defasadas em $120^{\circ}$, porém, com rotação de fase oposta, ACB, como mostrado na Figura 2.3.

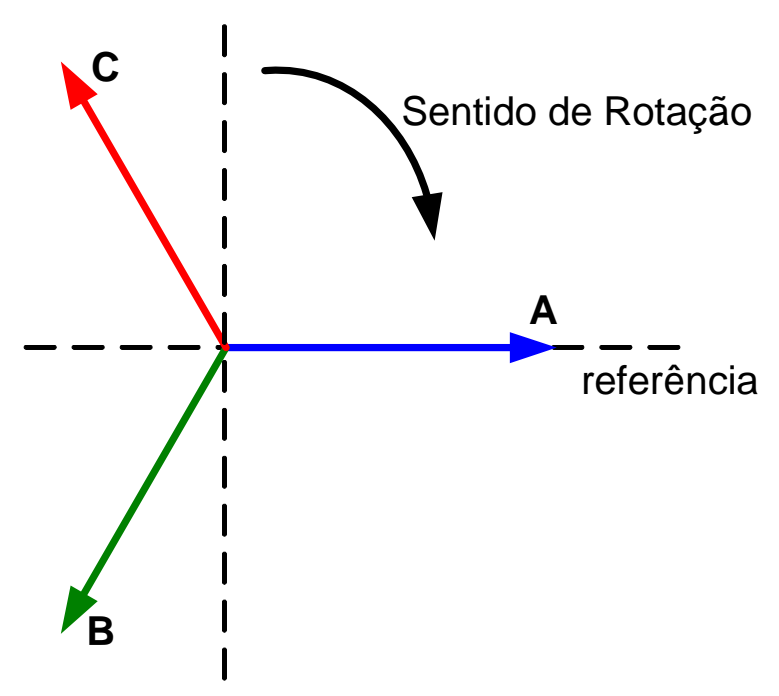

Figura 2.3 - Conjunto de Seqüência Negativa. 
Já o conjunto de seqüência zero possui também as três formas de onda senoidais, porém, todas em fase, como podem ser visualizadas por meio da Figura 2.4 .

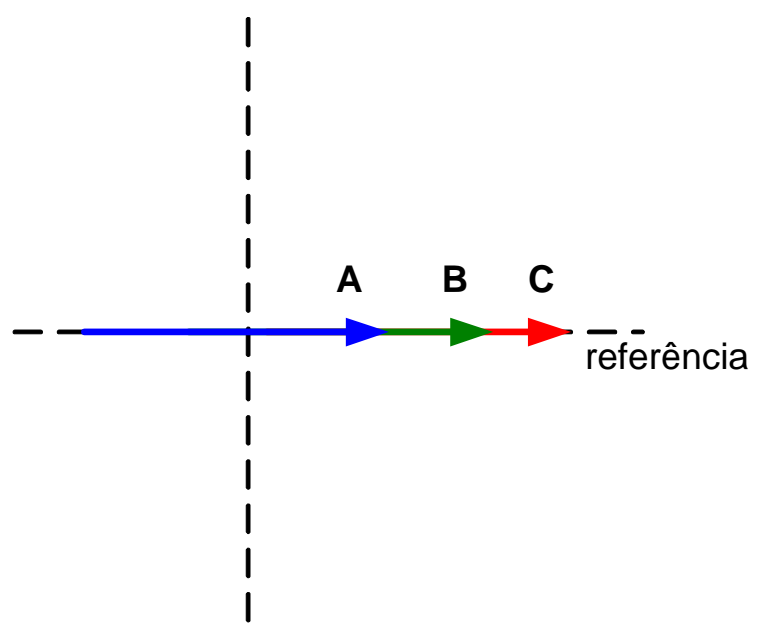

Figura 2.4 - Conjunto de Seqüência Zero.

Em função da ordem das componentes harmônicas, pode-se determinar a seqüência de fase das mesmas. Partindo-se desta premissa, pode-se verificar que as harmônicas múltiplas de 3 são de seqüência zero e, como mostrado por Dugan et al. (2004), estas são muito importantes, pois, quando estão presentes nas fases de um sistema trifásico em estrela a quatro condutores, as harmônicas de seqüência zero, ao circularem pelo condutor de neutro, podem contribuir para as distorções nas tensões do sistema.

A ordem das harmônicas, como mostrado, pode ser utilizada para determinar a seqüência de fase de qualquer componente harmônica do sistema. As ordens das harmônicas são utilizadas de forma a facilitar e generalizar certos cálculos e análises, pois, alguns SEPS se diferenciam quanto à freqüência da componente fundamental (Sankaran, 2002). Com relação às ordens das harmônicas nota-se que a harmônica de ordem zero representa a componente $D C$ inserida na forma de onda analisada. Em alguns casos esta componente deve ser identificada, 
pois, pode apresentar efeitos indesejáveis, tais como a saturação do núcleo de transformadores.

\subsubsection{Indicadores de Distorção Harmônica}

Nos sistemas elétricos de potência, até então, poucas variáveis eram mensuradas como: tensões e correntes eficazes, fator de potência, seqüências de fase e as potências ativa, reativa e aparente, sendo que todas estas grandezas são obtidas partindo-se do pressuposto que apenas a componente de freqüência fundamental está presente no sistema. Mas, quando o mesmo encontra-se sob influência de distorções harmônicas deve-se levar em consideração as demais freqüências encontradas no sistema (Dugan et al., 2004). Para estes casos, algumas modificações em certos cálculos devem ser adotadas, como é o caso das potências, pois, há a necessidade de realizar o cálculo da potência de distorção, que está relacionada às correntes com componentes de freqüência diferentes da fundamental (Dugan et al., 2004).

Assim, o triângulo de potências previamente utilizado para o cálculo das potências será substituído por um tetraedro de potências, onde a potência de distorção pode ser obtida. Estas modificações podem ser visualizadas pelas Figuras 2.5 e 2.6 .

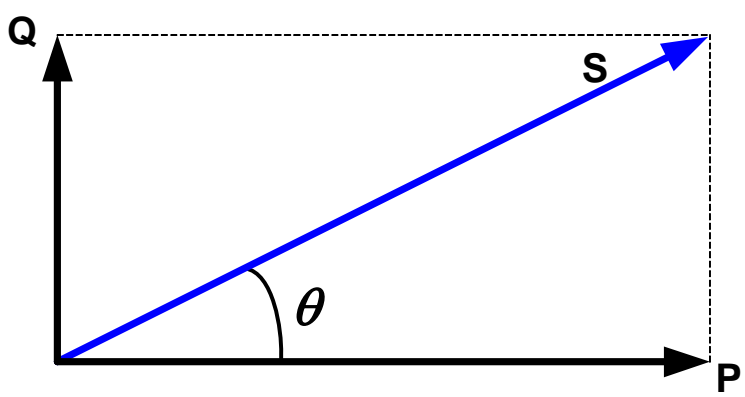

Figura 2.5 - Triângulo de Potências. 


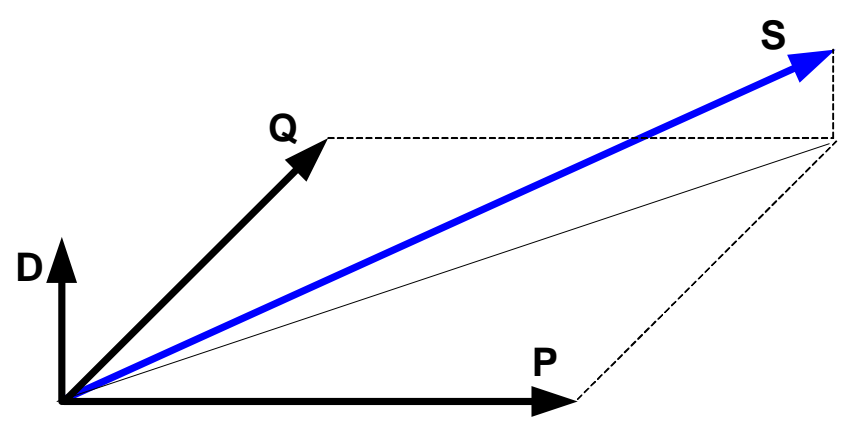

Figura 2.6 - Tetraedro de Potências.

No que se segue serão apresentados os cálculos para estas potências de acordo com o novo contexto. A potência ativa passa a ser calculada como sendo a soma das potências para cada uma das freqüências encontradas no sinal. Tal cálculo é apresentado por Dugan et al. (2004) para denotar um sistema onde haja componentes de freqüência diferentes da fundamental. O mesmo pode ser verificado por meio da Equação (2.2):

$$
P=\sum_{k=1}^{N} V_{k} \cdot I_{k} \cdot \cos \left(\theta_{k}\right)
$$

onde $N$ denota um número inteiro e positivo relacionado com a ordem da harmônica e $\theta_{k}$ representa o ângulo de defasagem entre a tensão e a corrente da $k$-ésima componente.

A potência reativa, também em conformidade com os cálculos apresentados por Dugan et al. (2004) pode ser verificada por meio da Equação (2.3).

$$
Q=\sum_{k=1}^{N} V_{k} \cdot I_{k} \cdot \operatorname{sen}\left(\theta_{k}\right)
$$

No entanto, quanto ao cálculo da potência aparente, na literatura pode-se encontrar uma diversidade de cálculos propostos, porém, foi adotado o cálculo de acordo com Dugan et al. (2004). Este método foi adotado devido a estar em conformidade com o tetraedro de potências citado anteriormente. Assim, a potência 
aparente é representada pela soma das potências ativa, reativa e de distorção como mostrado pela Equação (2.4).

$$
S=\sqrt{P^{2}+Q^{2}+D^{2}}
$$

A potência de distorção, por sua vez, é calculada para que possam ser incluídas as tensões e correntes das harmônicas com freqüências diferentes da fundamental.

$$
D=\sum_{k=2}^{N} V_{k} \cdot I_{k}
$$

Com a inserção da potência de distorção no cálculo da potência aparente, outras grandezas como o fator de potência $(F P)$ do sistema terá seu valor alterado, no entanto, sua definição é mantida como mostrado pela Equação (2.6).

$$
F P=\frac{P}{S}
$$

Além da potência de distorção, outros índices que medem harmônicas podem ser calculados. Assim, outros três índices serão apresentados, para que se possa quantificar o conteúdo harmônico de uma forma de onda distorcida. Estes índices são conhecidos como distorção harmônica total $(D H T)$, distorção harmônica individual $(D H I)$ e distorção de demanda total $(D D T)$, podendo ser aplicados tanto para correntes quanto para tensões.

O cálculo da DHT é utilizado para medir o nível de "poluição" causado por um conjunto de harmônicas presentes em um sistema elétrico, os cálculos da DHT para tensão e corrente são apresentados pelas Equações (2.7) e (2.8) respectivamente.

$$
D H T \%=\frac{\sqrt{\sum_{k=2}^{N} V_{k}^{2}}}{V_{1}} \cdot 100
$$


onde, $V_{k}$ denota a tensão RMS da harmônica de ordem $k$ e $V_{1}$ representa a tensão RMS da fundamental.

$$
D H T \%=\frac{\sqrt{\sum_{k=2}^{N} I_{k}^{2}}}{I_{1}} \cdot 100
$$

onde, $I_{k}$ denota a corrente RMS da harmônica de ordem $k$ e $I_{1}$ representa a corrente RMS da fundamental.

Para o cálculo da $D H I$ pode-se utilizar dois métodos, sendo o primeiro deles convencionado pelo IEEE e o segundo pelo IEC. Este índice apenas mede o quanto uma certa componente harmônica está contribuindo para a "poluição" do sistema elétrico. Por meio do cálculo convencionado pelo IEEE, dado pela Equação (2.9), pode-se dizer que para a fundamental o $D H I$ será sempre $100 \%$, isto porque todas as harmônicas utilizam a fundamental como referência.

$$
D H I_{k}=\frac{I_{k}}{I_{1}}
$$

Já por meio do cálculo convencionado pelo IEC, pode-se notar que primeiro quantifica-se as harmônicas tomando como base seus valores RMS, assim, a corrente RMS será dada pela Equação (2.10), para depois realizar o cálculo do DHI mostrado pela Equação (2.11).

$$
\begin{aligned}
& I_{r m s}=\sqrt{\sum_{k=1}^{N} I_{k}^{2}} \\
& D H I_{k}=\frac{I_{k}}{I_{r m s}}
\end{aligned}
$$

Ambos os métodos podem ser empregados para o cálculo da $D H I$ de tensão, bastando substituir as correntes $I_{k}, I_{1}$ e $I_{r m s}$ pelas tensões $V_{k}, V_{1}$ e $V_{r m s}$, onde $V_{r m s}$ é calculado de forma análoga a $I_{r m s}$. 
Em sistemas onde a demanda de corrente é baixa, empregam-se os cálculos de $D H T$ e $D H I$ apresentados anteriormente, pois, a distorção da forma de onda é muito evidente. Porém, em sistema onde a demanda de corrente é alta, as harmônicas apresentam maior manifestação sobre a distorção da demanda de corrente. Assim, o cálculo da $D D T$ é apresentado a seguir:

$$
D D T=\frac{\sqrt{\sum_{k=2}^{N} I_{k}^{2}}}{I_{L}}
$$

onde, $I_{k}$ denota a corrente $R M S$ da harmônica de ordem $k$ e $I_{L}$ representa a máxima corrente de demanda para a componente fundamental medida no ponto de acoplamento comum (PAC).

Estes índices supracitados são calculados por equipamentos comumente utilizados pelas concessionárias, pois, estas necessitam verificar a integridade do sistema elétrico de forma a garantir uma tensão de alimentação com pouca distorção harmônica até o PAC.

\subsubsection{Distúrbios Acarretados por Distorções Harmônicas}

Uma diversidade de distúrbios provenientes de distorções harmônicas podem ocorrer sobre os sistemas elétricos. Nesta subseção alguns destes distúrbios serão apresentados, talvez os mais comuns em sistemas elétricos.

Quando se analisa as distorções harmônicas a nível industrial, os problemas são maiores, pois, os altos níveis de correntes harmônicas podem interagir com equipamentos como: motores, bancos de capacitores, transformadores etc.

Os transformadores são equipamentos do sistema elétrico que sofrem perdas tanto por tensões quanto por correntes harmônicas. No caso de tensões harmônicas, estas aumentam as perdas no ferro. Mas, as correntes harmônicas, 
estas são altamente prejudiciais aos transformadores, pois, aumentam as perdas no cobre associadas ao efeito pelicular. Tal efeito ocorre pela redução da área de condução do cobre à medida que a freqüência da corrente aumenta. Com este aumento na freqüência outro fator que se altera é a reatância de dispersão que é ampliada em função da freqüência (Das, 2002).

Assim como nos transformadores, as máquinas elétricas rotativas sofrem perdas de mesma natureza, pois, possuem o mesmo princípio de funcionamento. Com o aumento das perdas no cobre e no ferro, eleva-se a temperatura destes equipamentos reduzindo sua vida útil. Os motores de indução trifásicos podem ser prejudicados pela presença de harmônicas que possuem seqüência de fase oposta à fundamental, fazendo com que seus acionamentos não sejam satisfatórios.

O efeito das harmônicas sobre transformadores serve de base para a verificação de efeitos sobre outros componentes do sistema elétrico. Como mostrado nos transformadores, as harmônicas podem gerar o efeito pelicular que irá reduzir a área do condutor. De forma análoga, pode-se dizer que estes mesmos efeitos podem ser vistos sobre os cabos de alimentação de qualquer sistema que esteja sob influência de harmônicas de alta densidade. Além disso, caso este cabeamento seja de longa distância, poderão surgir sobretensões na linha, associadas à ressonância por componentes harmônicas e, como conseqüência, poderá ocorrer a degradação do cabeamento.

A ressonância por componentes harmônicas pode também amplificar os níveis de correntes e tensões em bancos de capacitores (Das, 2002).

Um aspecto que deve ser ressaltado é que nem sempre as distorções de tensão são ocasionadas por conta das correntes harmônicas que fluem pela 
impedância do sistema, muito pode-se atribuir aos sistemas de UPS devido às suas conversões de tensão (Sankaran, 2002).

Como pôde ser observado, muitos efeitos são causados por distorções harmônicas sobre os elementos do SEP. Mas as harmônicas além de afetarem os componentes do sistema elétrico de potência, podem também causar danos aos sistemas de telecomunicação, pois, caso existam altas freqüências harmônicas com densidades consideráveis, estas podem gerar interferências sobre estes sistemas, como por exemplo, danos no sistema de telefonia, os quais prejudicariam muito os consumidores e empresas do setor (Sankaran, 2002; Wakileh, 2001).

A nível residencial ou comercial pode-se observar um problema nos medidores de energia que são encontrados na entrada do sistema elétrico destes estabelecimentos. Caso estes consumidores possuam cargas com alta densidade de correntes harmônicas, estas poderão ocasionar numa medida de energia imprecisa nos medidores baseados no princípio de funcionamento de motores de indução. Neste caso, o disco do medidor que gira com velocidade proporcional ao fluxo de potência tenderá a gerar um erro para freqüências harmônicas, já que estes medidores são calibrados para a freqüência fundamental. Ainda quanto às interferências eletromagnéticas, verifica-se que muitos equipamentos eletrônicos poderiam ter seu funcionamento normal prejudicado (Das, 2002).

\subsubsection{Técnicas para Mitigação das Harmônicas}

Em Dugan et al. (2004) são citadas três situações nas quais as harmônicas devem ser mitigadas e três métodos para a solução destes problemas. Os problemas relacionados são: 
- Quando o sistema possui uma grande quantidade de fontes de harmônicas;

- Quando o caminho por onde a corrente harmônica flui é eletricamente longo e pode resultar em distorções de tensão ou interferências eletromagnéticas;

- Ou quando a resposta do sistema interfere nas correntes harmônicas de forma a amplificá-las.

As três medidas que podem ser tomadas para a resolução dos problemas acima citados são:

- Reduzir as correntes harmônicas que as cargas estão produzindo, porém, geralmente este método é empregado para cargas que estejam nitidamente em má operação;

- Bloquear determinadas correntes harmônicas por meio de filtros sintonizados na freqüência que se deseja eliminar do sistema;

- Modificar a resposta em freqüência do sistema para que não haja ressonância entre certas harmônicas que poderiam ser prejudiciais ao próprio sistema, normalmente por meio do emprego de filtros paralelo, reatores ou até mesmo a modificação do banco de capacitores.

No que se segue serão apresentados alguns dos equipamentos mais comumente empregados para a mitigação de harmônicas como transformadores em zig-zag, filtros passivos e filtros ativos.

Os transformadores com conexão em zig-zag normalmente são alocados em estabelecimentos que possuam correntes harmônicas de seqüência zero. A conexão de transformadores em zig-zag pode ser visualizada pela Figura 2.7. 


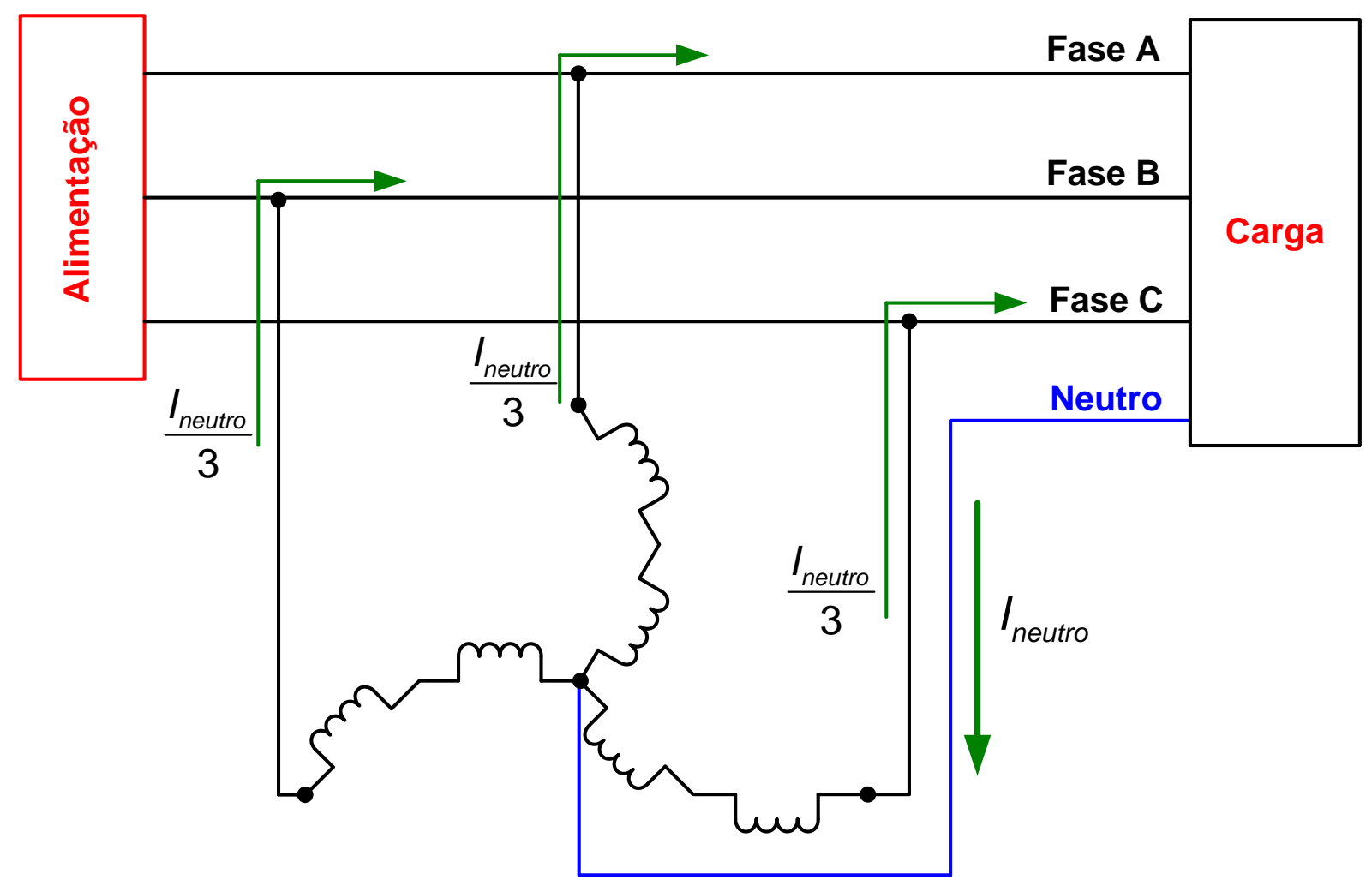

Figura 2.7 - Exemplo de conexão de um transformador em zig-zag para mitigação das correntes harmônicas de seqüência zero.

De acordo com a figura anterior, pode-se observar que a conexão em zigzag possibilita que o transformador trabalhe como um filtro para as correntes de seqüência zero, ou seja, aquelas correntes que circulam pelo neutro do sistema. Isto ocorre porque o transformador conectado em zig-zag apresenta uma baixa impedância ao neutro, fazendo com que estas correntes de seqüência zero circulem entre a carga e o transformador zig-zag, mantendo, portanto, as harmônicas de ordem tripla longe da fonte. Para ser eficaz, o transformador zig-zag deve ser instalado o mais próximo possível da carga. Este tipo de filtragem muitas vezes é feita sobre estabelecimentos comerciais, devido a normalmente possuírem muitos computadores, onde espera-se a presença de harmônicas de terceira ordem, as quais, geralmente causam sobrecarga de neutro e aquecimento de transformadores (Sankaran, 2002). 
Já os filtros passivos são comumente utilizados devido ao seu baixo custo quando comparados a outros dispositivos para controle de harmônicas. Como o próprio nome diz estes filtros fazem uso de elementos passivos como indutores, capacitores e resistores, que são devidamente sintonizados para a freqüência da harmônica que se deseja bloquear. Os filtros passivos podem ser configurados em paralelo ou em série com o SEP (Das, 2002; Dugan et al., 2004).

Normalmente, os filtros passivos alocados em paralelo com SEP, são os de única freqüência de sintonia. Estes filtros são construídos com seus elementos passivos em série, de forma que apresente uma baixa impedância para a corrente harmônica sintonizada, fazendo com que esta seja desviada de seu fluxo normal. Estes filtros além de bloquear a harmônica, muitas vezes têm a função de corrigir o fator de potência do sistema, pois, como analisado anteriormente, o fator de potência está vinculado ao cálculo da potência de distorção (Das, 2002).

No caso de se utilizar filtros passivos em série com o SEP, sua construção deve ser feita de modo a dispor seus elementos indutivos e capacitivos em paralelo e assim sintonizados para a freqüência da harmônica em questão. Com o filtro sintonizado, este deve ser conectado em série com a carga e o SEP, onde irá prover uma alta impedância responsável por bloquear a corrente harmônica. Estes filtros podem ser projetados de forma a apresentar uma baixa impedância para a freqüência fundamental, de modo a permitirem que a corrente fundamental passe com baixa perda. Filtros passivos em série com o SEP são comumente empregados para sistemas monofásicos (Das, 2002; Dugan et al., 2004).

Quando as harmônicas presentes no sistema se propagam por uma larga faixa de freqüências, há a necessidade de se empregar filtros que consigam bloquear esta faixa ao invés de aplicar um filtro para cada freqüência. Neste 
contexto, os filtros passa-faixa e os filtros do tipo C são os mais aplicados. Os filtros passa-faixa, quando aplicados à mitigação de harmônicas, são sintonizados de forma a deixar passar apenas a faixa das freqüências que estejam abaixo da freqüência de corte, normalmente a fundamental. No entanto, os filtros do tipo C são dados como uma alternativa aos filtros passa-faixa, porém, estes têm configuração semelhante a um filtro passa-altas de segunda ordem (Dugan et al., 2004).

Os últimos tipos de filtros a serem discutidos são os filtros ativos, considerados relativamente novos para as tarefas de mitigação de harmônicas. Estes filtros têm um alto custo associado por serem construídos à base dos dispositivos da eletrônica de potência. Entretanto, possuem a grande vantagem de não entrarem em ressonância com o sistema como é o caso dos filtros passivos. Com estas vantagens apresentadas, normalmente são empregados em circunstâncias onde os filtros passivos não podem ser aplicados. Assim como os filtros passivos, também podem ser configurados para eliminarem múltiplas harmônicas e para a correção do fator de potência (Das, 2002; Sankaran, 2002).

\subsection{Normas e Recomendações}

Nesta seção as recomendações de diversas organizações mundiais sobre os limites de harmônicas em sistemas elétricos serão apresentadas. Todas estas recomendações são desenvolvidas com o auxílio de diversos fabricantes de equipamentos, concessionárias e instituições de pesquisa.

Pode-se dizer que de um modo geral as recomendações são criadas com o objetivo de fornecer uma referência comum para todas as partes envolvidas de forma que haja compatibilidade entre as instalações dos consumidores e das concessionárias. 
Portanto, algumas das principais recomendações serão tratadas, como é o caso da IEEE Std. 519-1992 e de algumas IEC 61000-X-X.

Apenas deve ser observado que o IEC definiu uma vasta quantidade de recomendações sobre a relação da compatibilidade eletromagnética com a qualidade da energia e, diferentemente da recomendação do IEEE sobre harmônicas, o IEC é dividido em seis partes. Sendo que a segunda e terceira partes estão mais relacionadas ao controle e limitação das harmônicas. Seguindo este contexto, apresentar-se-á somente as recomendações nas quais o IEC enfatiza os aspectos referentes às distorções harmônicas.

\subsubsection{IEEE Std. 519-1992}

O IEEE Std. 519-1992 (Práticas recomendadas e requisitos para controle de harmônicas em sistemas elétricos de potência) propõe um compartilhamento de responsabilidades para a manutenção das harmônicas no PAC, onde os consumidores devem garantir que as correntes harmônicas estejam limitadas e as concessionárias, por sua vez, garantam os limites das distorções harmônicas de tensão. Esta recomendação propõe a avaliação das harmônicas no PAC, pois assim, pode-se determinar como um consumidor afeta tanto a concessionária quanto outro consumidor conectado ao mesmo alimentador.

A seguir são mostrados pela Tabela 2.1 os limites para as correntes harmônicas que podem ser injetadas no sistema elétrico pelos diferentes tipos de consumidores. 
Tabela 2.1 - Limites de correntes harmônicas para consumidores de distintas classes de tensão.

\begin{tabular}{|c|c|c|c|c|c|c|}
\hline \multicolumn{7}{|c|}{$V_{n} \leq 69 k V$} \\
\hline$\frac{I_{S C}}{I_{L}}$ & $h<11$ & $11 \leq h<17$ & $17 \leq h<23$ & $23 \leq h<35$ & $35 \leq h$ & DDT \\
\hline$<20$ & 4.0 & 2.0 & 1.5 & 0.6 & 0.3 & 5.0 \\
\hline $20-50$ & 7.0 & 3.5 & 2.5 & 1.0 & 0.5 & 8.0 \\
\hline 50-100 & 10.0 & 4.5 & 4.0 & 1.5 & 0.7 & 12.0 \\
\hline $100-1000$ & 12.0 & 5.5 & 5.0 & 2.0 & 1.0 & 15.0 \\
\hline$>1000$ & 15.0 & 7.0 & 6.0 & 2.5 & 1.4 & 20.0 \\
\hline \multicolumn{7}{|c|}{$69 k V<V_{N} \leq 161 k V$} \\
\hline$<20$ & 2.0 & 1.0 & 0.75 & 0.3 & 0.15 & 2.5 \\
\hline $20-50$ & 3.5 & 1.75 & 1.25 & 0.5 & 0.25 & 4.0 \\
\hline 50-100 & 5.0 & 2.25 & 2.0 & 0.75 & 0.35 & 6.0 \\
\hline $100-1000$ & 6.0 & 2.75 & 2.5 & 1.0 & 0.5 & 7.5 \\
\hline$>1000$ & 7.5 & 3.5 & 3.0 & 1.25 & 0.7 & 10.0 \\
\hline \multicolumn{7}{|c|}{$V_{n}>161 \mathrm{kV}$} \\
\hline$<50$ & 2.0 & 1.0 & 0.75 & 0.3 & 0.15 & 2.5 \\
\hline$=50$ & 3.0 & 1.5 & 1.15 & 0.45 & 0.22 & 3.75 \\
\hline
\end{tabular}

Fonte:(IEEE Std. 519-1992)

Com os limites mencionados na Tabela 2.1, pode-se garantir que as correntes harmônicas até o PAC estão delimitadas e que, caso haja alguma distorção harmônica de tensão, esta será responsabilidade da concessionária, por isto, a seguir são apresentados pela Tabela 2.2 os limites para a distorção harmônica de tensão. 
Tabela 2.2 - Indicadores (DHI e DHT) para limitação da distorção harmônica de tensão até o PAC.

\begin{tabular}{|ccc|}
\hline \hline $\begin{array}{c}\text { Tensão até o PAC } \\
(\mathbf{k V})\end{array}$ & $\begin{array}{c}\text { DHI } \\
\text { (\%) }\end{array}$ & $\begin{array}{c}\text { DHT } \\
\text { (\%) }\end{array}$ \\
\hline$V_{n} \leq 69$ & 3.0 & 5.0 \\
$69<V_{n} \leq 161$ & 1.5 & 2.5 \\
$V_{n}>161$ & 1.0 & 1.5 \\
\hline \hline
\end{tabular}

Fonte: (IEEE Std. 519-1992)

Devido a esta recomendação limitar as correntes harmônicas de acordo com a tensão de alimentação de cada consumidor, a mesma garante um maior rigor aos consumidores que detêm uma maior porção da quantidade de carga suportada pelo sistema.

Uma última observação deve ser feita quanto à utilização do IEEE Std. 5191992, onde esta pode ser empregada dentro do estabelecimento de consumidores, que nestes casos um novo PAC deve ser definido, podendo ser qualquer ponto do sistema que interligue suas cargas.

Com a aplicação das recomendações apresentadas pelo IEEE Std. 5191992 espera-se que o SEP em questão forneça energia elétrica de excelente qualidade.

De forma sumária, pode-se definir a IEEE Std. 519-1992 como um consenso de diretrizes e práticas recomendadas que podem ser aplicadas às concessionárias e seus consumidores para controlar e/ou minimizar o impacto das harmônicas geradas por cargas não lineares. 


\subsubsection{IEC 61000-2-2}

O IEC 61000-2-2 limita distorções harmônicas de tensão para consumidores com tensão de alimentação entre $240 \mathrm{~V}$ e $450 \mathrm{~V}$ para sistema trifásicos ou monofásicos que estejam operando com freqüência nominal de $50 \mathrm{~Hz}$ ou $60 \mathrm{~Hz}$. Os níveis de harmônicas aceitáveis são mostrados pela Tabela 2.3, onde observa-se que os níveis são dados como um percentual da fundamental.

Tabela 2.3 - Níveis de distorção harmônica individual para sistemas elétricos de baixa tensão conforme o IEC 61000-2-2.

\begin{tabular}{|cccc|cc|}
\hline \hline \multicolumn{3}{c|}{ Harmônicas não múltiplas de 3 } & \multicolumn{2}{c|}{ Harmônicas múltiplas de 3 } \\
\hline $\begin{array}{c}\text { Ordem } \\
\text { İmpar } \\
h\end{array}$ & $\begin{array}{c}\text { Harmônica } \\
\text { de Tensão } \\
(\%)\end{array}$ & $\begin{array}{c}\text { Ordem } \\
\text { Par }\end{array}$ & $\begin{array}{c}\text { Harmônica } \\
\text { de Tensão } \\
(\%)\end{array}$ & $\begin{array}{c}\text { Ordem } \\
h\end{array}$ & $\begin{array}{c}\text { Harmônica } \\
\text { de Tensão } \\
(\%)\end{array}$ \\
\hline 5 & 6.0 & 2 & 2.0 & 3 & 5.0 \\
7 & 5.0 & 4 & 1.0 & 9 & 1.5 \\
11 & 3.5 & 6 & 0.5 & 15 & 0.3 \\
13 & 3.0 & 8 & 0.5 & 21 & 0.2 \\
17 & 2.0 & 10 & 0.2 & $>21$ & 0.2 \\
19 & 1.5 & 12 & 0.2 & & \\
23 & 1.5 & $>12$ & 0.2 & & \\
25 & 1.5 & & & & \\
$>25$ & $0.2+1.3 * 25 / h$ & & & & \\
\hline \hline
\end{tabular}

Fonte:(Dugan et al., 2004)

Estes níveis não são rígidos, pois, esta recomendação aplica-se a usuários de baixo consumo de energia e que provavelmente não terão grande influência nas distorções harmônicas.

\subsubsection{IEC 61000-3-2}

O IEC 61000-3-2 visa limitar as correntes harmônicas dos equipamentos de baixa tensão conectados à rede pública de energia, isto em conformidade com o IEC 61000-2-2 apresentado anteriormente e que define as limitações para as distorções 
harmônicas de tensão. A recomendação 61000-3-2 do IEC ainda divide as limitações de correntes de acordo com quatro classes de equipamentos, as quais são as seguintes:

- Classe A - Equipamentos trifásicos balanceados e todos os demais equipamentos que não pertençam às classes B, C e D;

- Classe B - Ferramentas portáteis;

- Classe C - Equipamentos de iluminação e dispositivos para controle dos mesmos;

- Classe D - Equipamentos que possuam corrente de entrada com forma de onda especial e com potência ativa menor que 600W.

A seguir são mostradas as Tabelas 2.4 à 2.7 que representam cada uma das classes acima relacionadas com seus devidos limites de correntes harmônicas.

Tabela 2.4 - Máximas correntes harmônicas admissíveis para equipamentos da Classe A.

\begin{tabular}{|cccc|}
\hline $\begin{array}{c}\text { Ordem } \\
\text { Impar } \\
h\end{array}$ & $\begin{array}{c}\text { Corrente } \\
\text { Harmônica } \\
(\%)\end{array}$ & $\begin{array}{c}\text { Ordem } \\
\text { Par } \\
h\end{array}$ & $\begin{array}{c}\text { Corrente } \\
\text { Harmônica } \\
(\%)\end{array}$ \\
\hline 3 & 2.3 & 2 & 1.08 \\
5 & 1.14 & 4 & 0.43 \\
7 & 0.77 & 6 & 0.3 \\
9 & 0.4 & $8-40$ & $0.23 * 8 / h$ \\
11 & 0.33 & & \\
13 & 0.21 & & \\
$15-39$ & $0.15 * 15 / h$ & & \\
\hline \hline
\end{tabular}

Fonte:(Dugan et al., 2004) 
Tabela 2.5 - Máximas correntes harmônicas admissíveis para equipamentos da Classe B.

\begin{tabular}{|cccc|}
\hline \hline $\begin{array}{c}\text { Ordem } \\
\text { Impar } \\
h\end{array}$ & $\begin{array}{c}\text { Corrente } \\
\text { Harmônica } \\
(\%)\end{array}$ & $\begin{array}{c}\text { Ordem } \\
\text { Par } \\
h\end{array}$ & $\begin{array}{c}\text { Corrente } \\
\text { Harmônica } \\
(\%)\end{array}$ \\
\hline 3 & 3.45 & 2 & 1.62 \\
5 & 1.71 & 4 & 0.645 \\
7 & 1.155 & 6 & 0.45 \\
9 & 0.60 & $8=h=40$ & $2.76 / h$ \\
11 & 0.495 & & \\
13 & 0.315 & & \\
$15=h=39$ & $3.375 / h$ & & \\
\hline \hline
\end{tabular}

Fonte:(Schaffner, 2006)

Tabela 2.6 - Máximas correntes harmônicas admissíveis para equipamentos da Classe C.

\begin{tabular}{|cc|}
\hline \hline $\begin{array}{c}\text { Ordem } \\
h\end{array}$ & $\begin{array}{c}\text { Corrente Harmônica } \\
(\%)\end{array}$ \\
\hline 2 & 2 \\
3 & 30 * fator de potência do circuito \\
5 & 10 \\
7 & 7 \\
9 & 5 \\
$11-39$ & 3 \\
\hline \hline
\end{tabular}

Fonte:(Dugan et al., 2004)

Tabela 2.7 - Máximas correntes harmônicas admissíveis para equipamentos da Classe $D$.

\begin{tabular}{|c|cc|}
\hline \hline & \multicolumn{2}{|c|}{ Corrente Máxima } \\
\hline $\begin{array}{c}\text { Ordem } \\
h\end{array}$ & $(\mathrm{~mA} / \mathrm{W})$ & $(\mathrm{A})$ \\
\hline 2 & 3.4 & 2.3 \\
5 & 1.9 & 1.14 \\
7 & 1.0 & 0.77 \\
9 & 0.5 & 0.4 \\
13 & 0.35 & 0.33 \\
$11-39$ & $3.86 / \mathrm{h}$ & Tabela $(2.4)$ \\
\hline \hline
\end{tabular}

Fonte:(Dugan et al., 2004) 


\subsubsection{IEC 61000-3-4}

A recomendação IEC 61000-3-4, da mesma forma que a IEC 61000-3-2, define os limites de harmônicas sobre as correntes emitidas pelos equipamentos. Sendo que a principal diferença é que esta trabalha com equipamentos que operam com correntes de entrada acima de 16A, podendo chegar até 75A. A Tabela 2.8 mostra os limites permissíveis para estas correntes harmônicas.

Tabela 2.8 - Níveis de corrente harmônica permitidos pela IEC 61000-3-4.

\begin{tabular}{|cccc|}
\hline \hline $\begin{array}{c}\text { Ordem } \\
h\end{array}$ & $\begin{array}{c}\text { Corrente } \\
\text { Harmônica } \\
(\%)\end{array}$ & $\begin{array}{c}\text { Ordem } \\
h\end{array}$ & $\begin{array}{c}\text { Corrente } \\
\text { Harmônica } \\
(\%)\end{array}$ \\
\hline 3 & 21.6 & 19 & 1.1 \\
5 & 10.7 & 21 & 0.6 \\
7 & 7.2 & 23 & 0.9 \\
9 & 3.8 & 25 & 0.8 \\
11 & 3.1 & 27 & 0.6 \\
13 & 2.0 & 29 & 0.7 \\
15 & 0.7 & 31 & 0.7 \\
17 & 1.2 & 33 & 0.6 \\
\hline \hline
\end{tabular}

Fonte:(Dugan et al., 2004)

\subsubsection{IEC 61000-3-6}

Até agora foram mostrados os limites de harmônicas para consumidores conectados em baixa tensão. No entanto, o IEC 61000-3-6 foi desenvolvido para abranger a porção restante do sistema, que são os consumidores de média e alta tensão. Por esta recomendação, considera-se como média tensão os consumidores alimentados com tensões entre $1 \mathrm{kV}$ e $35 \mathrm{kV}$; para alta tensão, alocam-se os consumidores com tensões de alimentação entre 35kV e 230kV; para tensões acima de $230 \mathrm{kV}$, o sistema é considerado de extra alta tensão e os consumidores que necessitam de tensões menores que $1 \mathrm{kV}$ são considerados de baixa tensão. De 
acordo com estes limites de tensão de entrada de cada consumidor, o IEC 61000-36 determinou níveis de compatibilidade para harmônicas de tensão apenas aplicados à baixa e média tensão, isto é, os limites admitidos pelo IEC para esta classe de consumidores. Já para consumidores de média, alta e extra-alta tensão, não são determinados níveis de admissibilidade, no entanto, são determinados os níveis de planejamento; desta forma, tais níveis irão depender das cargas que estes consumidores pretendem instalar em seus respectivos estabelecimentos. Os níveis de compatibilidade são apresentados na Tabela 2.9 e os níveis de planejamento podem ser visualizados pelas Tabelas 2.10 e 2.11 .

Tabela 2.9 - Níveis de distorção harmônica de tensão para sistemas de baixa e média tensão.

\begin{tabular}{|c|c|c|c|c|c|}
\hline \multicolumn{4}{|c|}{ Harmônicas não múltiplas de 3} & \multicolumn{2}{|c|}{ Harmônicas múltiplas de 3} \\
\hline $\begin{array}{l}\text { Ordem } \\
\text { Împar }\end{array}$ & $\begin{array}{l}\text { Harmônica } \\
\text { de Tensão }\end{array}$ & $\begin{array}{l}\text { Ordem } \\
\text { Par }\end{array}$ & $\begin{array}{l}\text { Harmônica } \\
\text { de Tensão }\end{array}$ & Ordem & $\begin{array}{l}\text { Harmônica } \\
\text { de Tensão }\end{array}$ \\
\hline$h$ & $(\%)$ & $h$ & $(\%)$ & & $(\%)$ \\
\hline 5 & 6.0 & 2 & 2.0 & 3 & 5.0 \\
\hline 7 & 5.0 & 4 & 1.0 & 9 & 1.5 \\
\hline 11 & 3.5 & 6 & 0.5 & 15 & 0.3 \\
\hline 13 & 3.0 & 8 & 0.5 & 21 & 0.2 \\
\hline 17 & 2.0 & 10 & 0.5 & $>21$ & 0.2 \\
\hline 19 & 1.5 & 12 & 0.2 & & \\
\hline 23 & 1.5 & $>12$ & 0.2 & & \\
\hline 25 & 1.5 & & & & \\
\hline$>25$ & $0.2+1.3 * 25 / h$ & & & & \\
\hline
\end{tabular}


Tabela 2.10 - Limites de distorção harmônica de tensão para sistemas de média tensão.

\begin{tabular}{|cccc|cc|}
\hline \hline \multicolumn{5}{c|}{ Harmônicas não múltiplas de 3 } & \multicolumn{2}{c|}{ Harmônicas múltiplas de 3 } \\
\hline Ordem & Harmônica & Ordem & Harmônica & Ordem & Harmônica \\
İmpar & de Tensão & Par & de Tensão & $h$ & densão \\
$h$ & $(\%)$ & $h$ & $(\%)$ & 3 & $(\%)$ \\
5 & 5.0 & 2 & 1.6 & 9 & 1.2 \\
7 & 4.0 & 4 & 1.0 & 15 & 0.3 \\
11 & 3.0 & 6 & 0.5 & 21 & 0.2 \\
13 & 2.5 & 8 & 0.4 & $>21$ & 0.2 \\
17 & 1.6 & 10 & 0.4 & & \\
19 & 1.2 & 12 & 0.2 & & \\
23 & 1.2 & $>12$ & 0.2 & & \\
25 & 1.2 & & & & \\
$>25$ & $0.2+0.5$ * $25 / \mathrm{h}$ & & & & \\
\hline \hline
\end{tabular}

Fonte:(Dugan et al., 2004)

Tabela 2.11 - Níveis de distorção harmônica de tensão aceitáveis para sistemas de alta e extra alta tensão.

\begin{tabular}{|cccc|cc|}
\hline \hline \multicolumn{5}{c|}{ Harmônicas não múltiplas de 3 } & \multicolumn{2}{c|}{ Harmônicas múltiplas de 3 } \\
\hline Ordem & Harmônica & Ordem & Harmônica & Ordem & $\begin{array}{c}\text { Harmônica } \\
\text { İmpar }\end{array}$ \\
de Tensão & Par & de Tensão & $h$ & $(\%)$ \\
$h$ & $(\%)$ & $h$ & $(\%)$ & 3 & 2.0 \\
5 & 2.0 & 2 & 1.6 & 9 & 1.0 \\
7 & 2.0 & 4 & 1.0 & 15 & 0.3 \\
11 & 1.5 & 6 & 0.5 & 21 & 0.2 \\
13 & 1.5 & 8 & 0.4 & $>21$ & 0.2 \\
17 & 1.0 & 10 & 0.4 & & \\
19 & 1.0 & 12 & 0.2 & & \\
23 & 0.7 & $>12$ & 0.2 & & \\
25 & 0.7 & & & & \\
$>25$ & $0.2+0.5 * 25 / h$ &
\end{tabular}

Fonte:(Dugan et al., 2004)

Além das limitações de tensão harmônica, a IEC 61000-3-6 ainda trata da admissibilidade dos equipamentos a serem instalados no sistema de média e alta tensão, onde alguns critérios devem ser satisfeitos para garantir que o SEP irá fornecer energia de boa qualidade a todos os consumidores conectados a um 
determinado alimentador. Caso alguns critérios não sejam satisfeitos, a concessionária e o consumidor deverão entrar em acordo para rearranjar o sistema de forma a este se adequar à carga em questão.

\subsubsection{EN 50160}

A EN 50160 é uma norma européia que determina os procedimentos utilizados pelas concessionárias européias de forma a garantir uma boa qualidade da tensão que alimenta seus consumidores. Para que estes aspectos sejam atendidos, a EN 50160 especifica os níveis de tensão e suas características até o ponto de conexão dos consumidores ou até os sistemas de distribuição de energia para redes públicas de baixa e média tensão. Assim como nas recomendações anteriormente citadas, a norma EN 50160 fornece limites de tensão harmônica que são dados como um percentual da tensão para a freqüência fundamental, estes limites são mostrados pela Tabela 2.12.

Tabela 2.12 - Limites de distorção harmônica de tensão até os terminais do alimentador.

\begin{tabular}{|cccc|cc|}
\hline \hline \multicolumn{5}{c|}{ Harmônicas não múltiplas de 3 } & \multicolumn{2}{c|}{ Harmônicas múltiplas de 3 } \\
\hline $\begin{array}{c}\text { Ordem } \\
\text { Ímpar }\end{array}$ & $\begin{array}{c}\text { Harmônica } \\
\text { de Tensão }\end{array}$ & $\begin{array}{c}\text { Ordem } \\
\text { Par }\end{array}$ & $\begin{array}{c}\text { Harmônica } \\
\text { de Tensão }\end{array}$ & Ordem & $\begin{array}{c}\text { Harmônica } \\
\text { de Tensão } \\
5\end{array}$ \\
(\%) & 6.0 & $h$ & $(\%)$ & $h$ & $(\%)$ \\
7 & 5.0 & 2 & 2.0 & 3 & 5.0 \\
11 & 3.5 & 4 & 1.0 & 9 & 1.5 \\
13 & 3.0 & $6-24$ & 0.5 & 15 & 0.3 \\
17 & 2.0 & & & 21 & 0.2 \\
19 & 1.5 & & & & \\
23 & 1.5 & & & & \\
25 & 1.5 & & & & \\
\hline \hline
\end{tabular}


Conforme mostrado neste capítulo, uma diversidade de normas e/ou recomendações foram desenvolvidas para um melhor controle e manutenção do sistema elétrico de potência, de forma a garantir que a energia fornecida possua excelente qualidade. Também pôde-se verificar no que diz respeito às cargas residenciais que os limites impostos pelas normas e/ou recomendações supracitadas ainda não são tão rígidos como ocorre no caso de cargas instaladas em média ou alta tensão, isto devido aos consumidores residenciais não possuírem uma quantidade de cargas não lineares que venham a prejudicar o sistema. No entanto, tal controle pode vir a ser aplicado sobre um conjunto de consumidores residenciais, devido à crescente proliferação das cargas não lineares e de sua grande utilização por tais consumidores. 



\section{Aspectos da Bancada Experimental}

Este capítulo abrange todos os aspectos relativos à bancada de ensaios, onde serão descritas todas as cargas empregadas na fase experimental do trabalho bem como a fonte de alimentação e os analisadores de energia envolvidos no processo de aquisição dos dados referentes às assinaturas harmônicas das cargas e suas combinações.

\subsection{A Bancada Experimental}

A bancada experimental foi basicamente composta por uma fonte de alimentação, dois analisadores de energia, as cargas e um microcomputador responsável pelo armazenamento dos dados e por identificar as cargas conectadas ao sistema. Para uma melhor compreensão desta bancada de ensaios, um diagrama de blocos da mesma pode ser visualizada por meio da Figura 3.1.

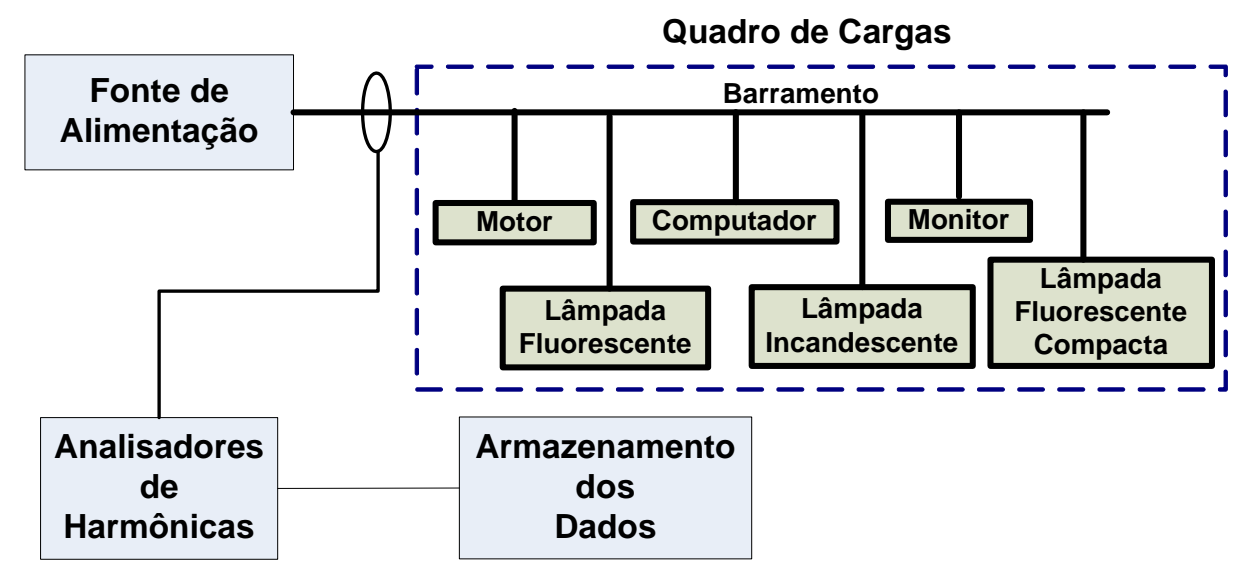

Figura 3.1 - Diagrama de blocos representando a bancada experimental utilizada nos ensaios laboratoriais. 
A princípio foi empregado um total de seis cargas, lineares e não lineares, para que o sistema fosse capaz de identificar qualquer tipo de carga e até mesmo suas combinações.

O sistema foi alimentado com uma forma de onda puramente senoidal afim de que pudessem ser extraídas as assinaturas harmônicas reais de cada carga e suas respectivas combinações.

As assinaturas harmônicas foram extraídas com o auxílio de dois analisadores de energia que serão comentados mais adiante. Com as assinaturas harmônicas das cargas, uma base de dados foi gerada de forma semi-automática e utilizada para o treinamento das RNAs que terão seus aspectos tratados com maior profundidade no Capítulo 4. Por enquanto, dar-se-á maior enfoque aos dispositivos que permitiram realizar os ensaios necessários.

Conforme todas as características apresentadas, na Figura 3.2 pode ser visualizada a organização física do laboratório de ensaios.

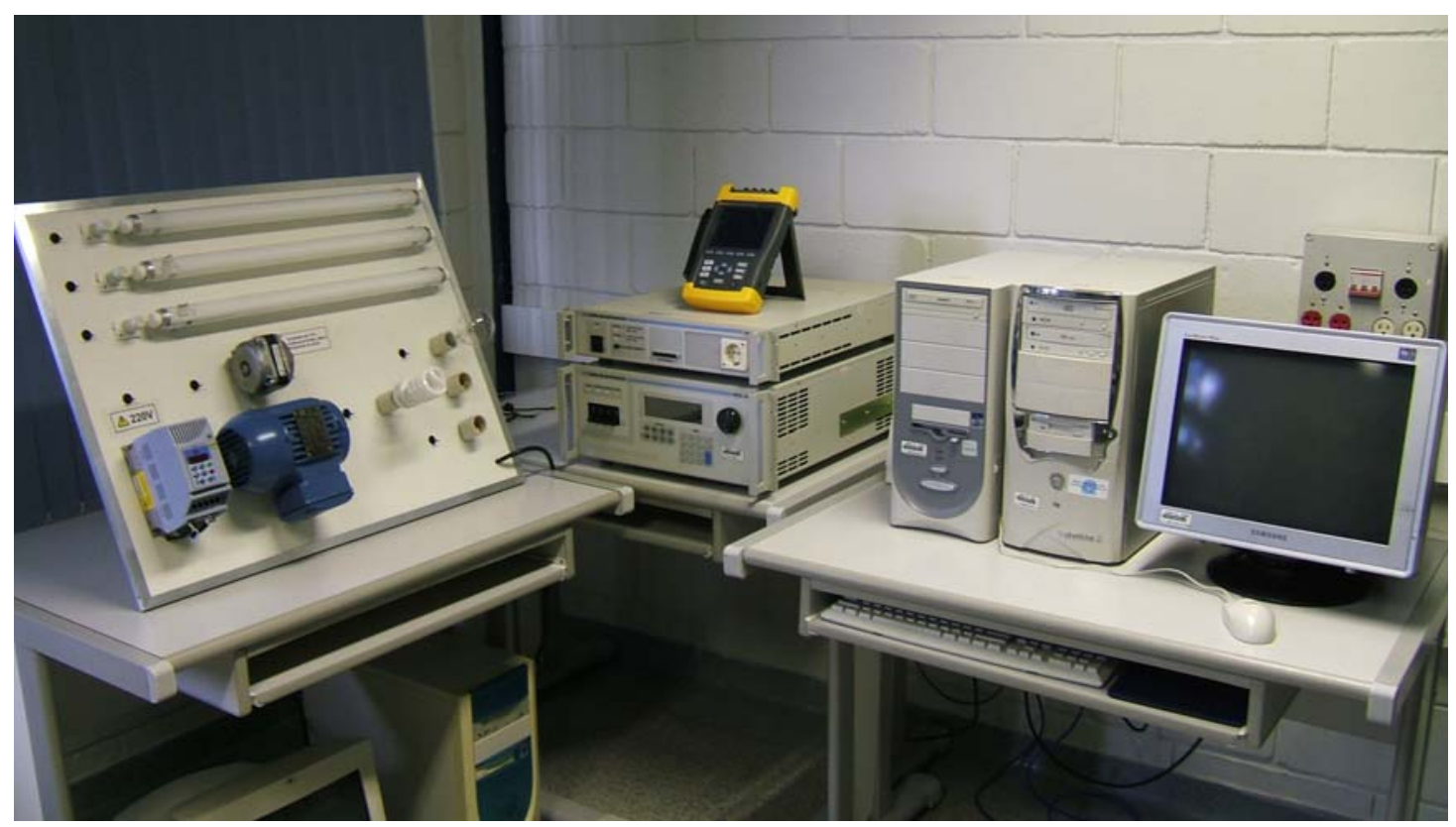

Figura 3.2 - Organização do laboratório para a realização dos ensaios. 


\subsection{Fonte de Alimentação}

Para a alimentação das cargas foi utilizada uma fonte monofásica, modelo 5001iX da California Instruments com potência de 5kVA. Este equipamento pode ser visualizado pela Figura 3.3.

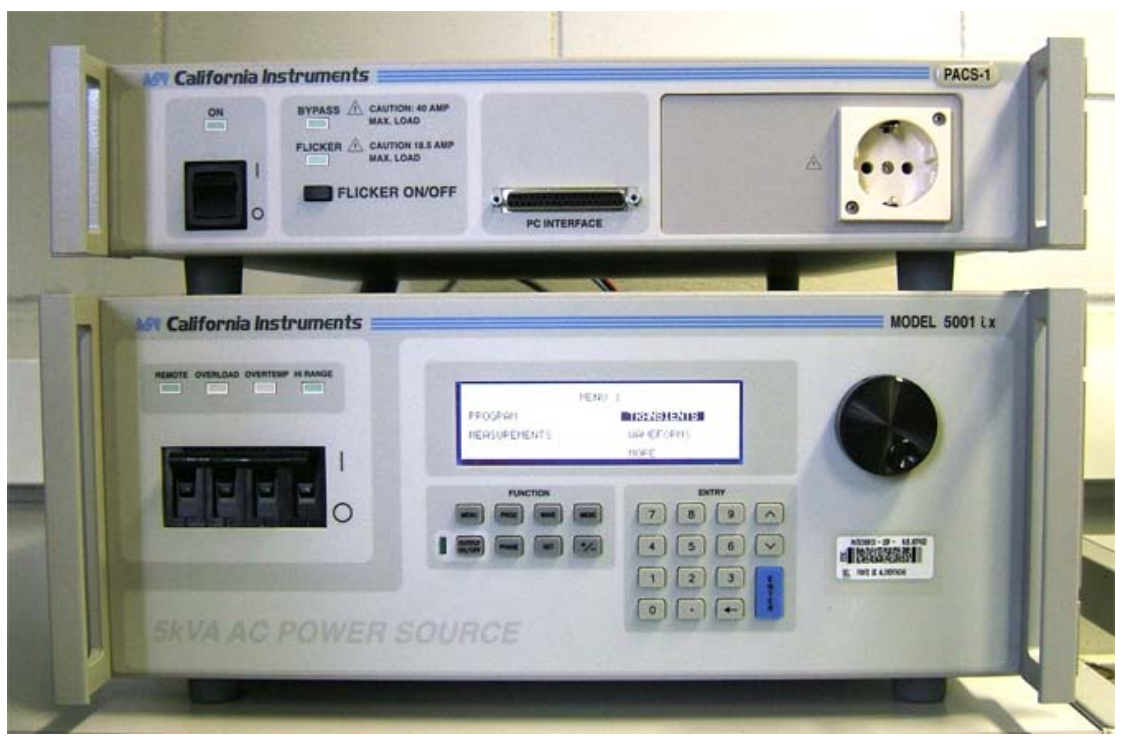

Figura 3.3 - Fonte de alimentação / analisador de energia modelo 5001iX da California Instruments.

A fonte de alimentação foi configurada para fornecer às cargas uma tensão de $127 \mathrm{~V}$ (eficaz) com ângulo de fase em $90^{\circ}$ e freqüência em $60 \mathrm{~Hz}$, concordando com as diretrizes de fornecimento de energia apresentadas no Capítulo 2.

Os ajustes de configuração desta fonte podem ser realizados tanto por meio de seu painel frontal quanto por software. A Figura 3.4 ilustra como seria a configuração da mesma por meio do software CiguiSII iX Series II ${ }^{\circledR}$, onde todos os ajustes são transmitidos à fonte por uma interface serial RS-232.

Além da interface serial RS-232, o equipamento também possui uma interface que possibilita a conexão da mesma a uma placa de aquisição de dados, e desta forma, os dados podem ser tratados em tempo real. Assim, vislumbra-se futuramente realizar tal aquisição para que possa ser verificado o potencial do 
sistema computacional desenvolvido quando aplicado à tarefa de identificação em tempo real. Visto que o tempo real no caso da identificação das fontes de harmônicas depende muito do tempo que as cargas levam para entrarem em regime permanente.

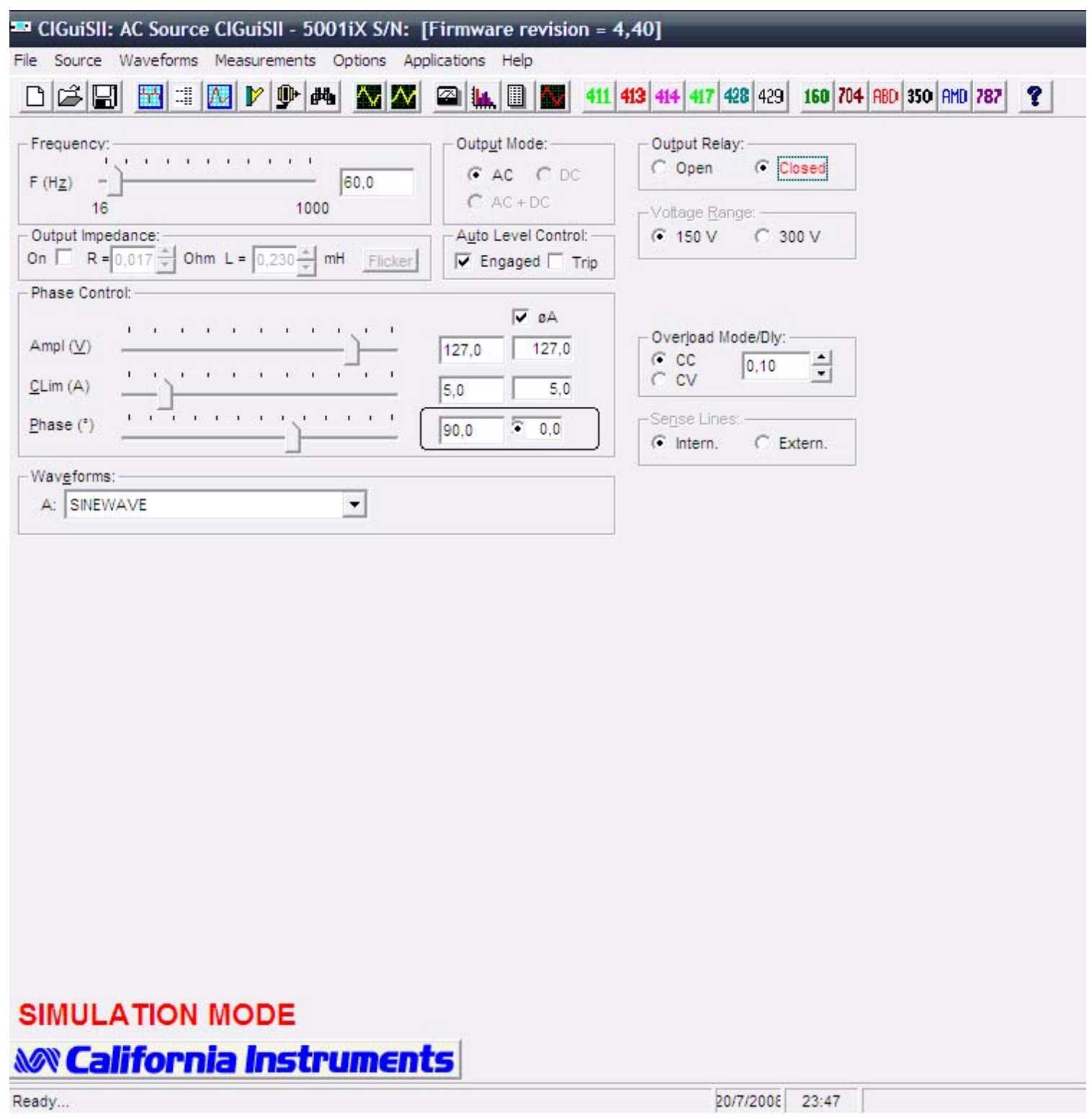

Figura 3.4 - Software CiguiSII iX Series ${ }^{\circledR}$. 


\subsection{Analisadores de Energia}

Os analisadores de energia usados para extração das assinaturas harmônicas foram dois, onde um deles encontra-se sob o mesmo chassi da fonte de alimentação, portanto, o equipamento mostrado pela Figura 3.3 também possui como característica a função de analisador de energia. O segundo analisador utilizado foi um Fluke 435 ilustrado pela Figura 3.5.

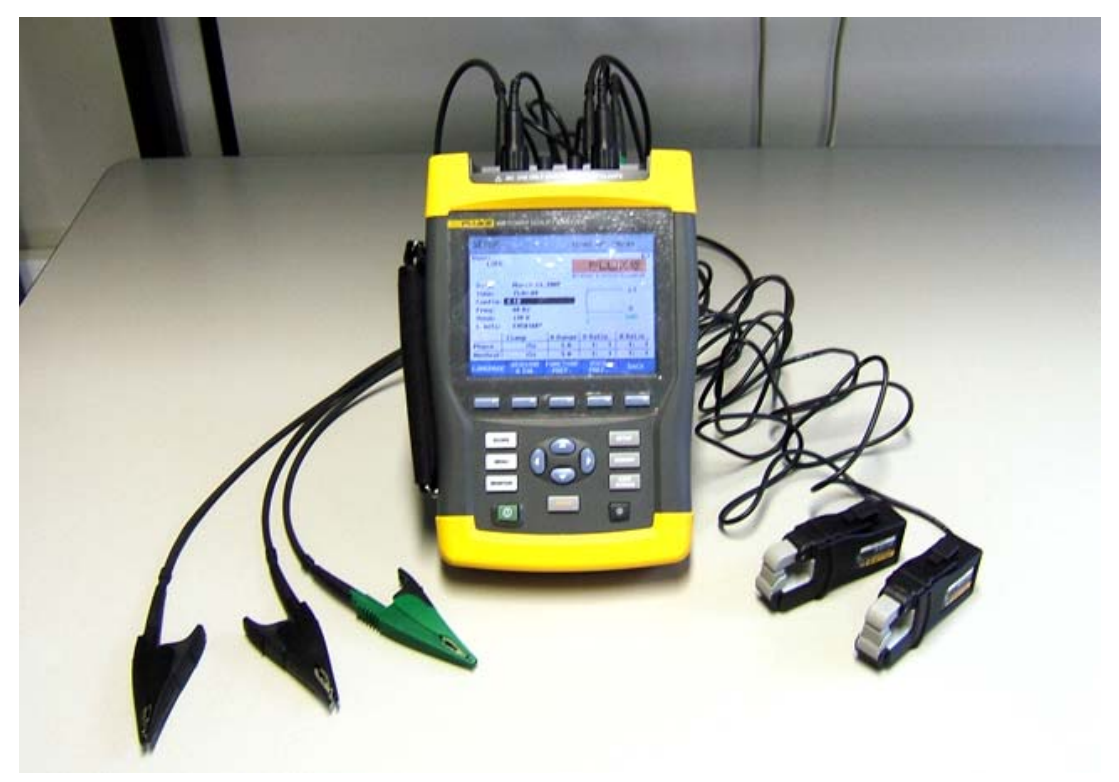

Figura 3.5 - Analisador de energia modelo 435 da Fluke.

Ambos os analisadores foram gerenciados via software para que a aquisição dos dados fosse feita de modo semi-automático. No caso do analisador da California Instruments, estes dados foram obtidos via interface serial e então armazenados no microcomputador. Apresenta-se na Figura 3.6, a tela do software por onde se realiza a aquisição destes dados. 


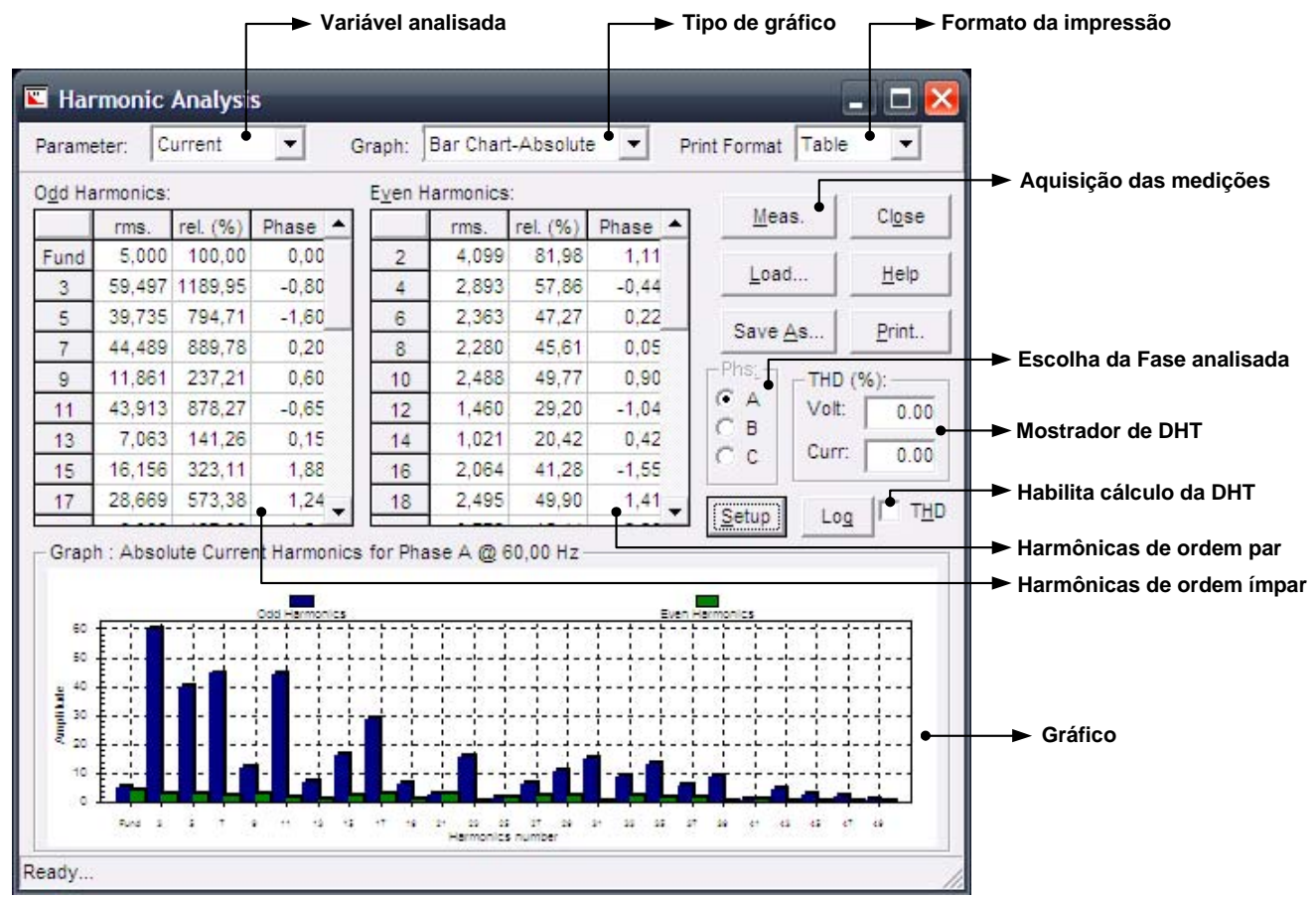

Figura 3.6 - Exemplo de como os dados são disponibilizados pelo equipamento da California Instruments.

Já pelo analisador da Fluke os dados são obtidos via interface serial optoisolada que é convertida para uma interface USB, a qual faz a conexão com o microcomputador. Um exemplo de como os dados são apresentados pelo software FlukeView ${ }^{\circledR}$ é ilustrado pela Figura 3.7.

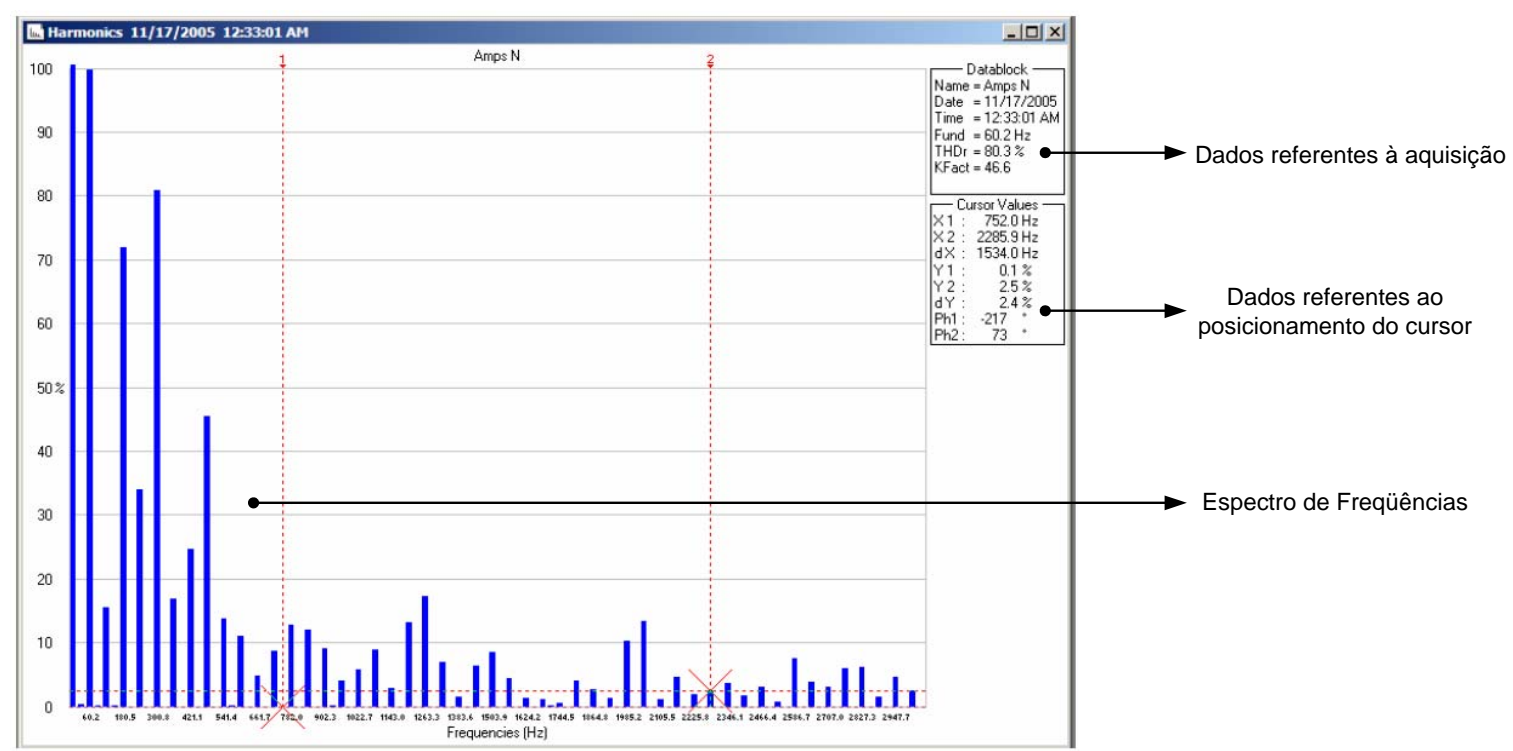

Figura 3.7 - Exemplo de como os dados são obtidos pelo equipamento da Fluke. 
A geração da base de dados contendo as assinaturas harmônicas das cargas é referida como semi-automática, devido à necessidade de um operador ter que executar os procedimentos da aquisição dos dados e também pela necessidade de se adequar os arquivos resultantes das aquisições, pois, estes arquivos contêm cabeçalhos que devem ser extraídos. Para esta finalidade alguns módulos de software foram desenvolvidos utilizando-se a ferramenta computacional Matlab ${ }^{\circledR}$, de forma a realizar estas adequações e manter a base de dados com certa uniformidade. Exemplos destes cabeçalhos são ilustrados nas Figuras 3.8 e 3.9.

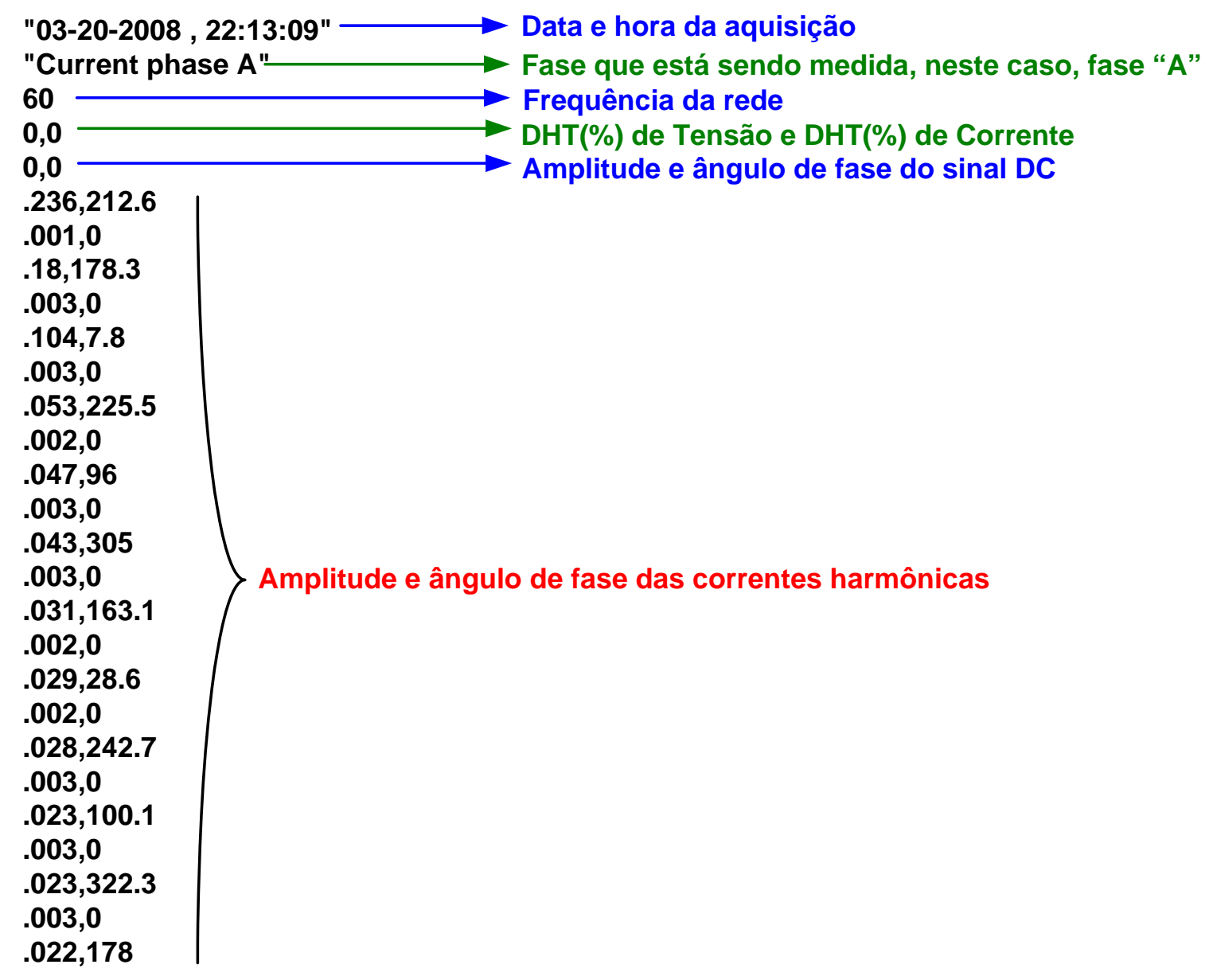

Figura 3.8 - Exemplo dos arquivos criados pelo analisador de energia modelo 5001iX da California Instruments na aquisição dos dados. 


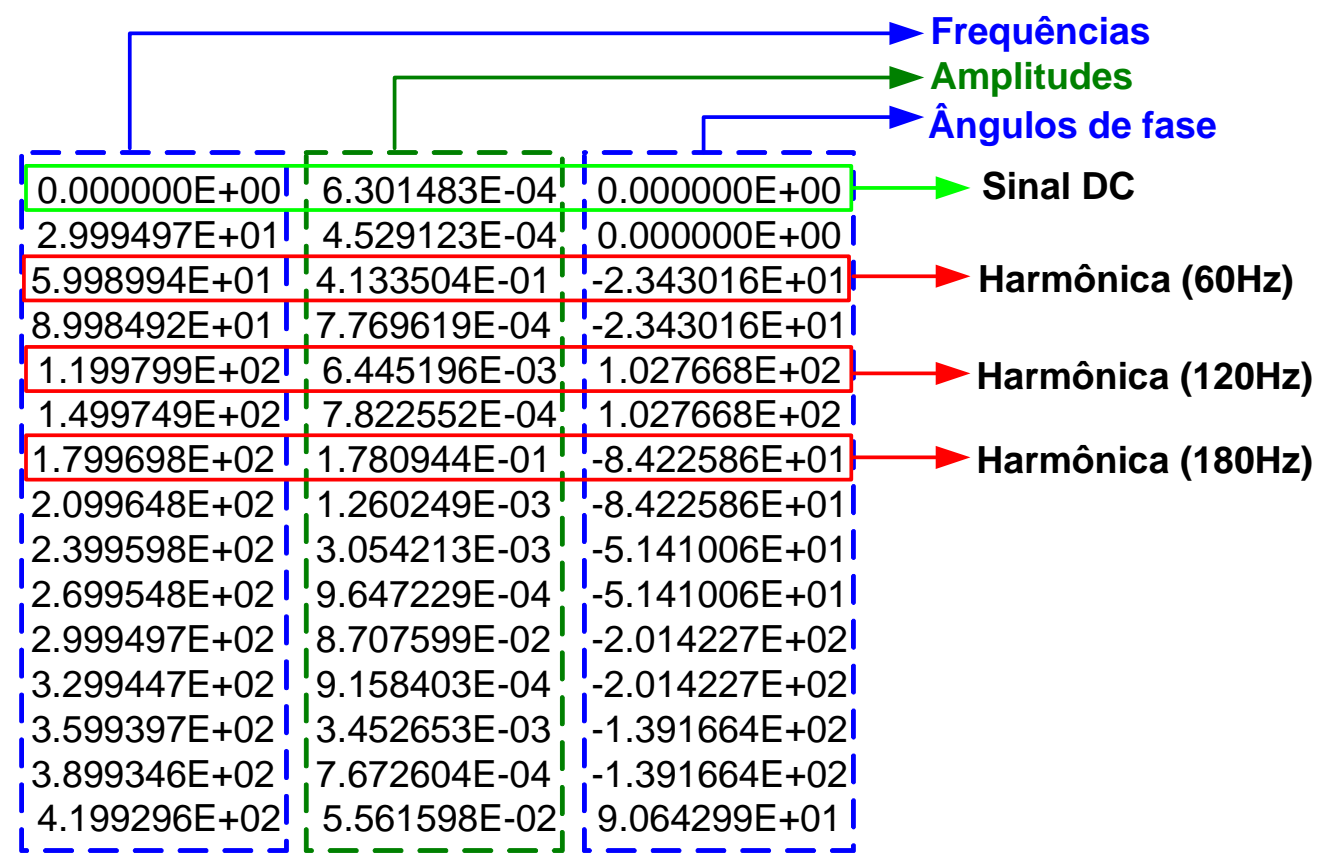

Figura 3.9 - Exemplo dos arquivos criados pelo analisador de energia modelo 435 da Fluke na aquisição dos dados.

\subsection{Quadro de Cargas}

Como enfatizado no início desta dissertação, apenas cargas residenciais foram utilizadas. Estas cargas são descritas pela Tabela 3.1 com suas respectivas características.

Tabela 3.1 - Características das cargas empregadas nos ensaios laboratoriais.

\begin{tabular}{|cccc|}
\hline \hline Carga & $\begin{array}{c}\text { Tensão } \\
\text { (V) }\end{array}$ & $\begin{array}{c}\text { Potência } \\
\text { (W) }\end{array}$ & $\begin{array}{c}\text { Frequência } \\
\text { (Hz) }\end{array}$ \\
\hline Lâmpada Incandescente & 127 & 200 & 60 \\
Lâmpada Fluorescente* & 127 & 20 & 60 \\
Lâmpada Fluorescente Compacta & $110 / 127$ & 23 & $50 / 60$ \\
Motor & $110 / 220$ & $10 / 53$ & $50 / 60$ \\
Computador Pessoal & $115 / 230$ & - & $50 / 60$ \\
Monitor & $110 / 240$ & 450 & $50 / 60$ \\
\hline \hline
\end{tabular}

*reator convencional 
No que se segue serão apresentadas cada uma das cargas mencionadas acima com suas respectivas assinaturas harmônicas individuais.

\subsubsection{Lâmpada Incandescente}

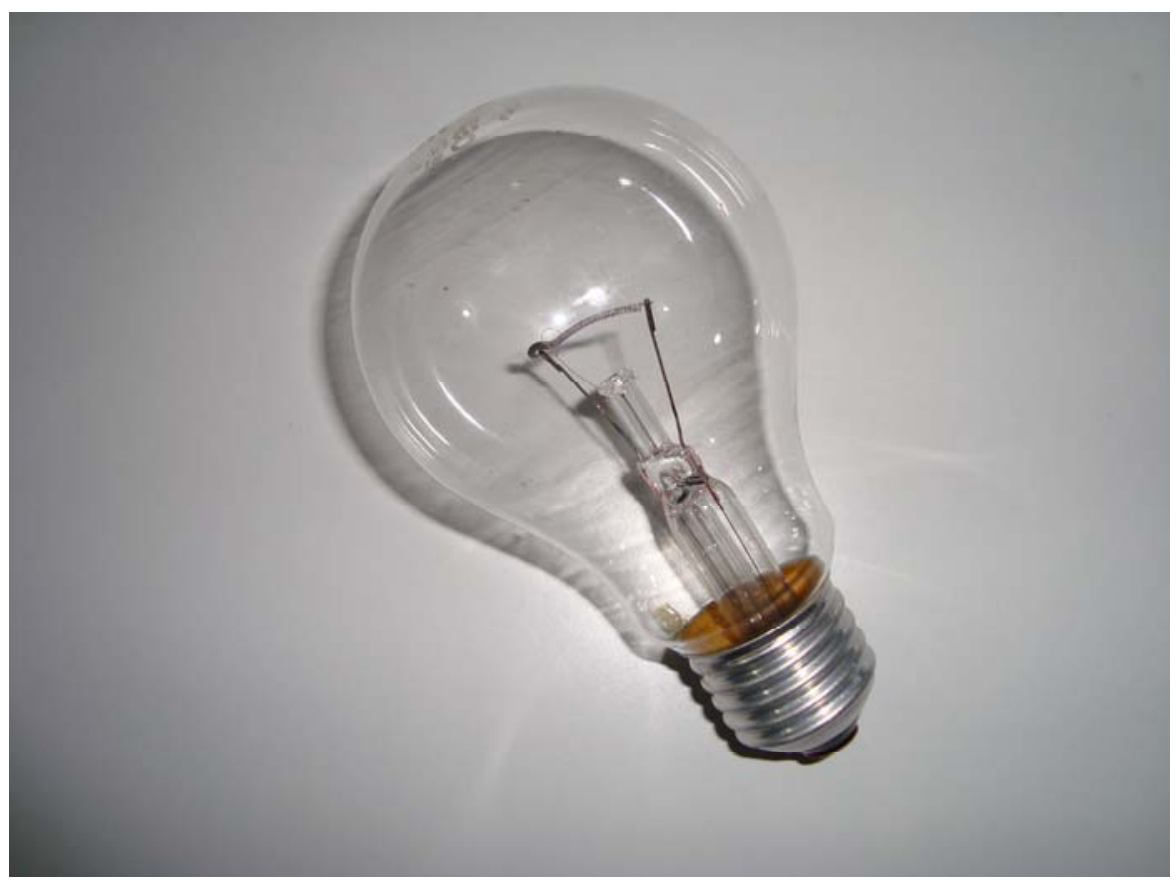

Figura 3.10 - Lâmpada Incandescente.

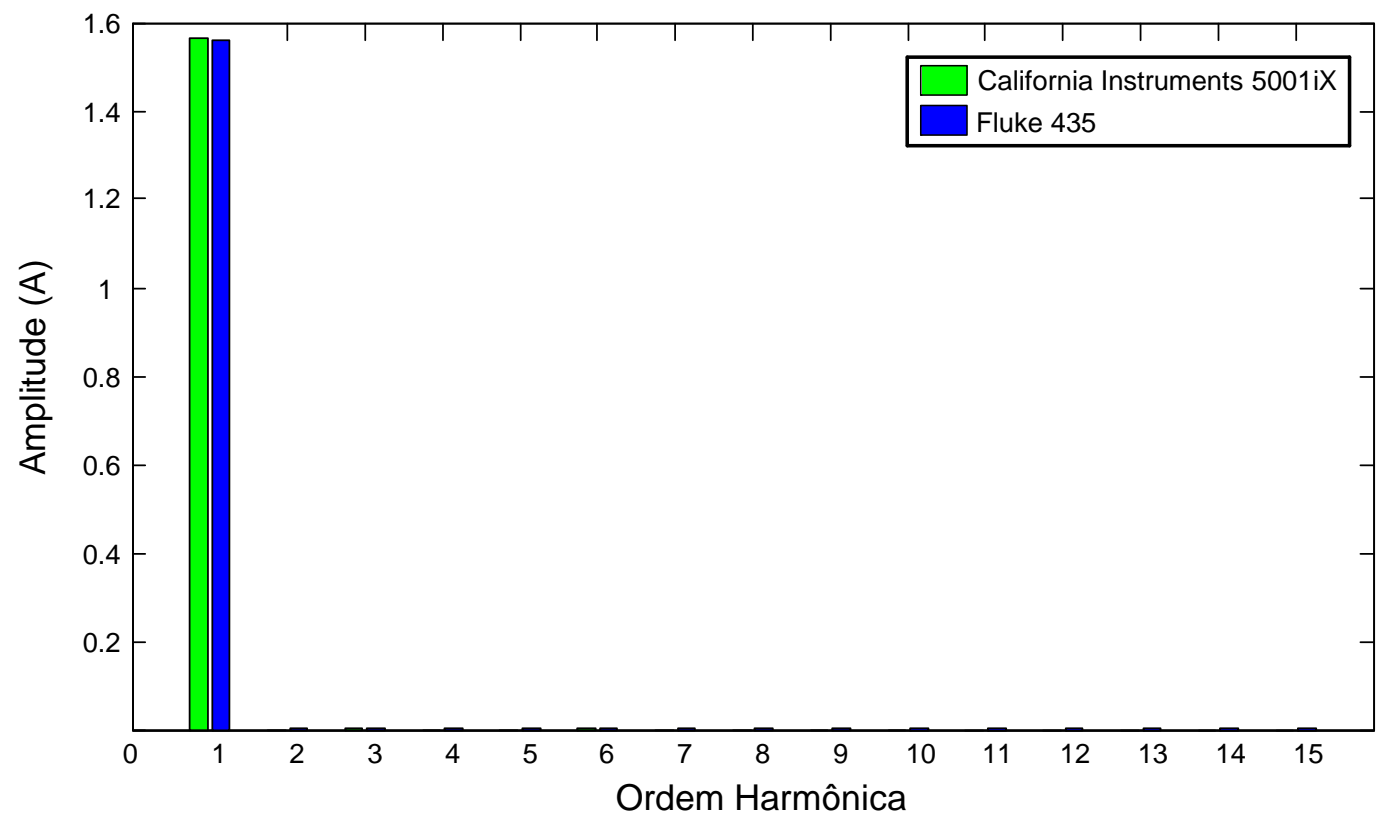

Figura 3.11 - Espectro de freqüências referente à lâmpada incandescente. 


\subsubsection{Lâmpada Fluorescente com Reator Convencional}

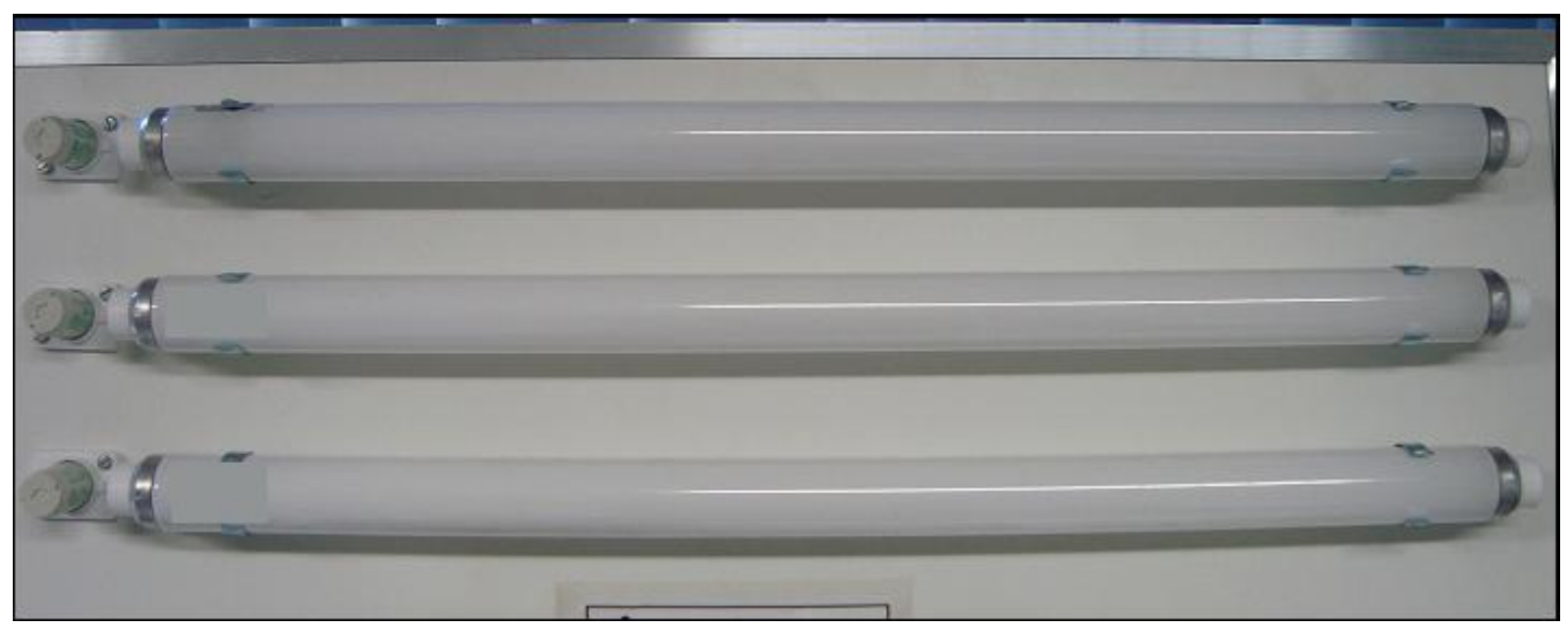

Figura 3.12 - Lâmpada Fluorescente com reator convencional.

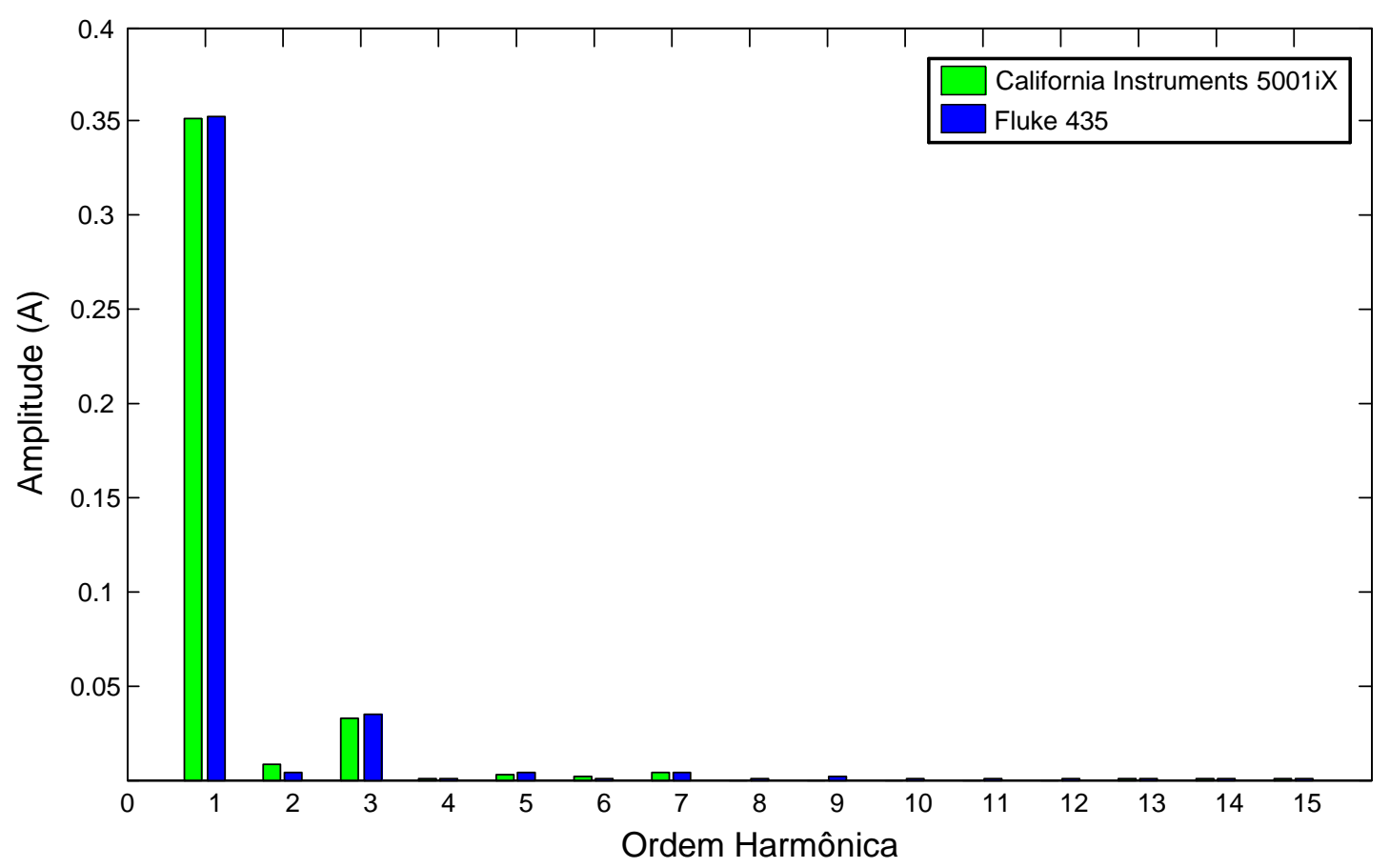

Figura 3.13 - Espectro de freqüências referente à lâmpada fluorescente com reator convencional. 


\subsubsection{Lâmpada Fluorescente Compacta}

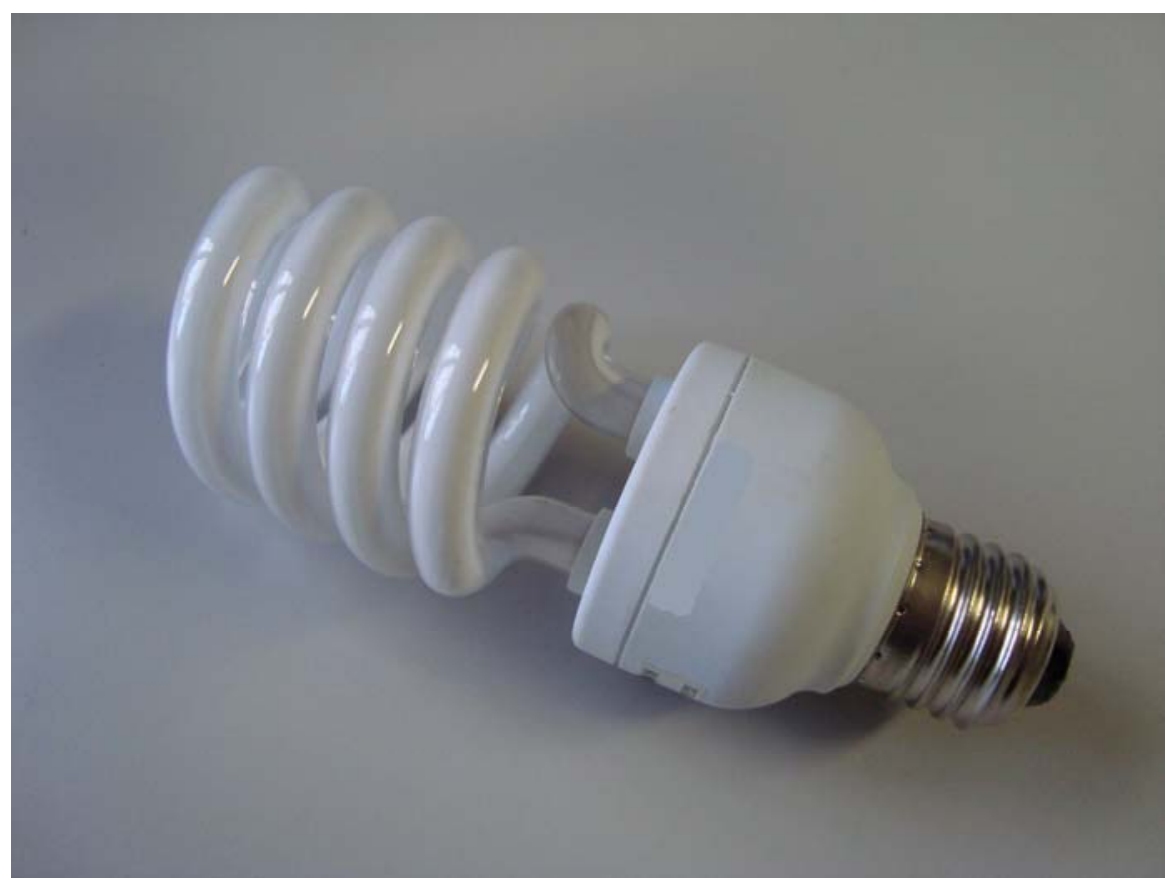

Figura 3.14 - Lâmpada Fluorescente Compacta.

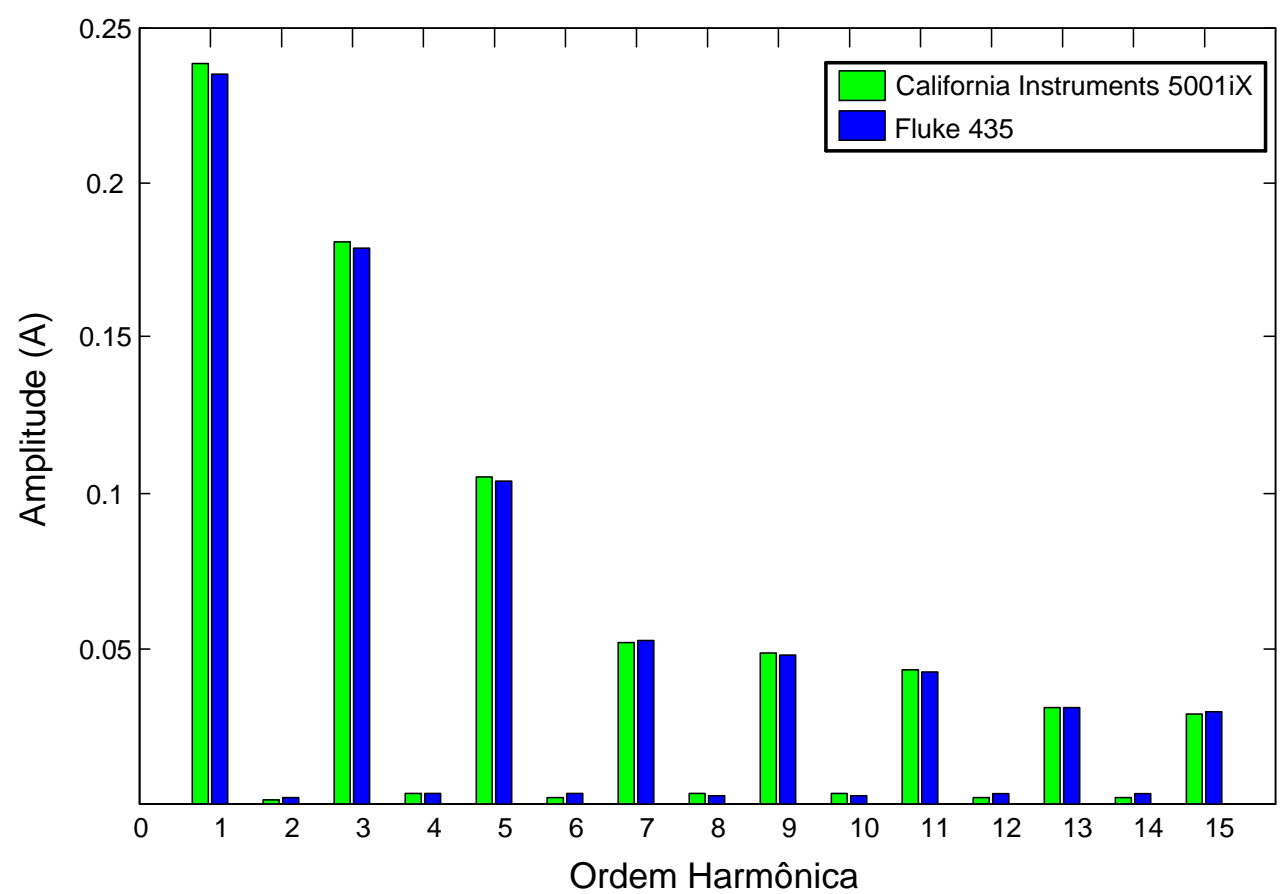

Figura 3.15 - Espectro de freqüências adquirido da lâmpada fluorescente compacta. 


\subsubsection{Motor Monofásico}

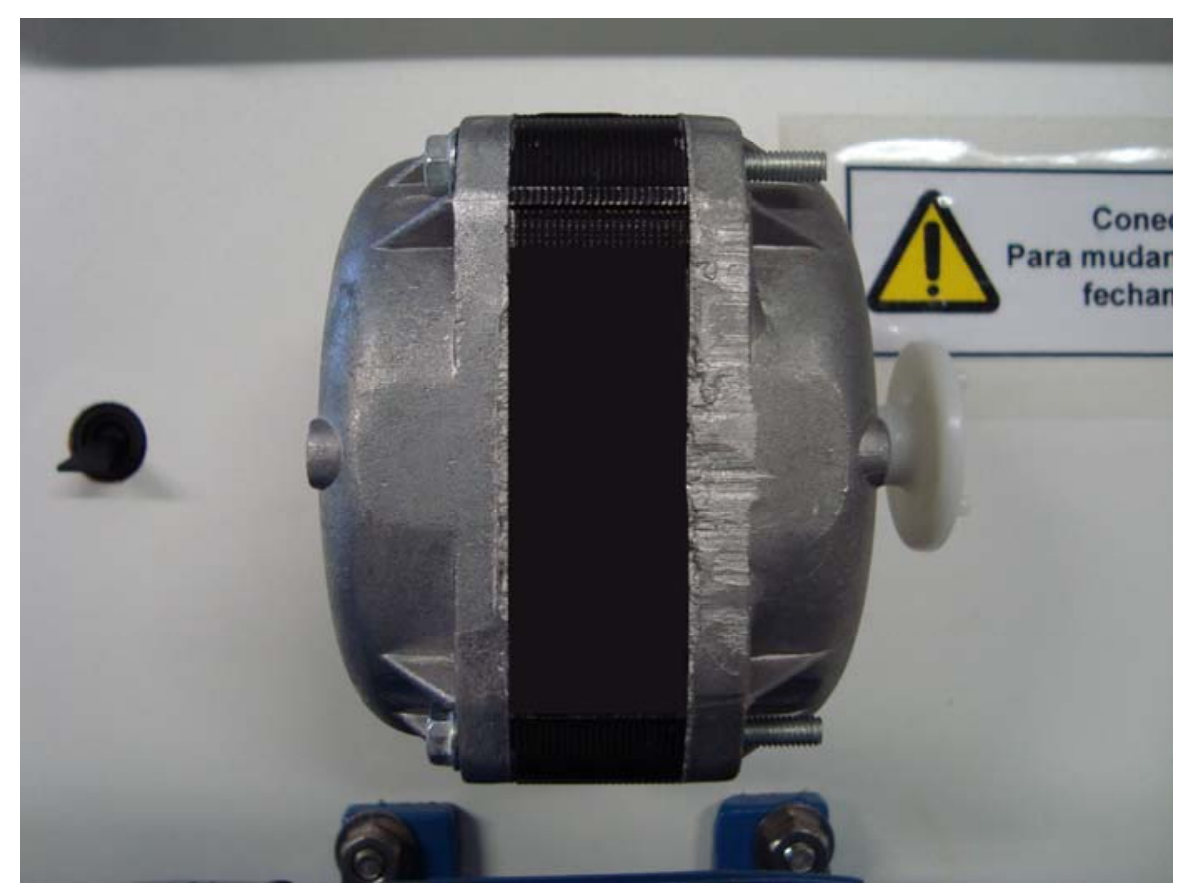

Figura 3.16 - Motor monofásico.

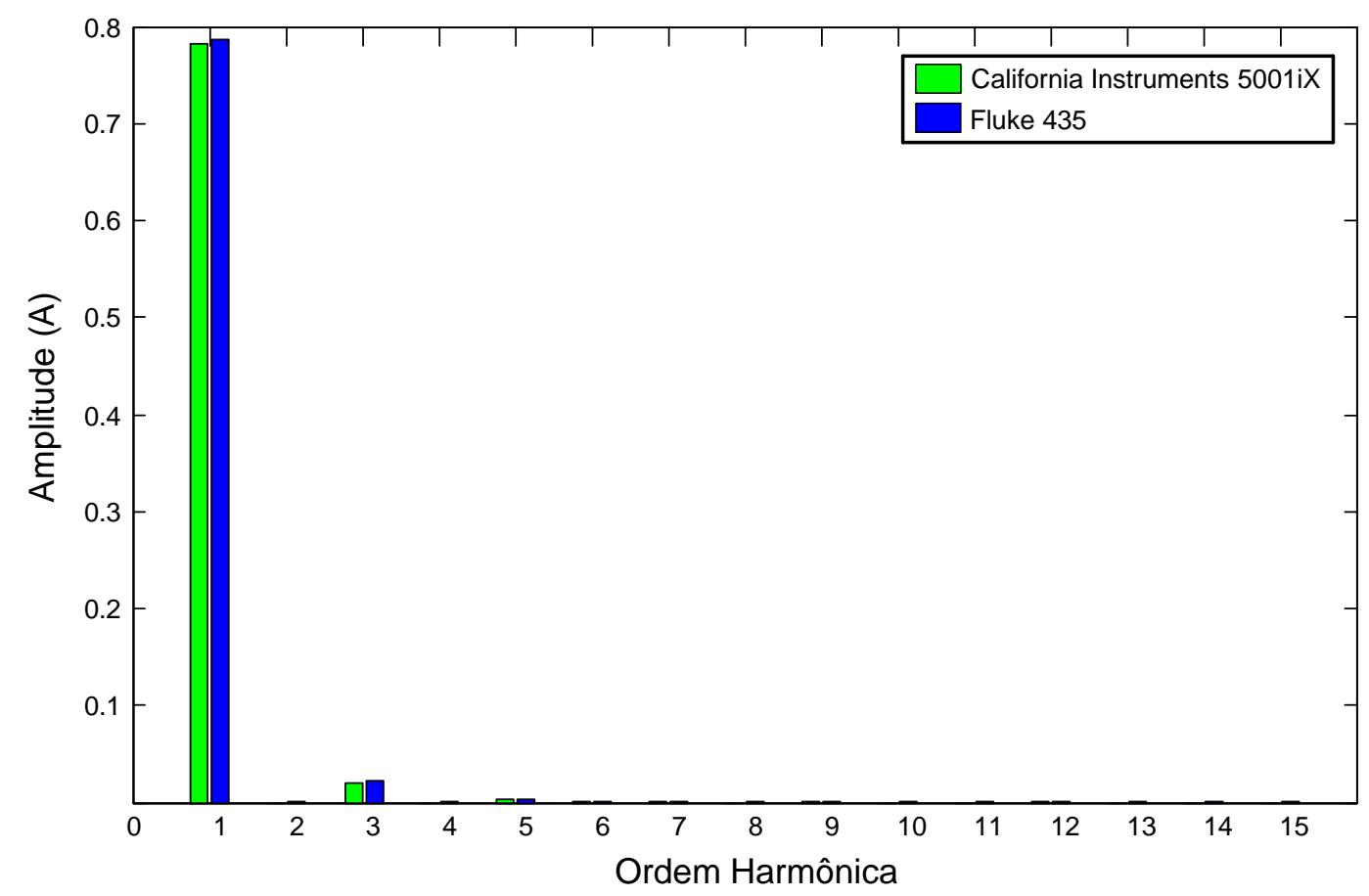

Figura 3.17 - Espectro de freqüências referente ao motor. 


\subsubsection{Microcomputador}

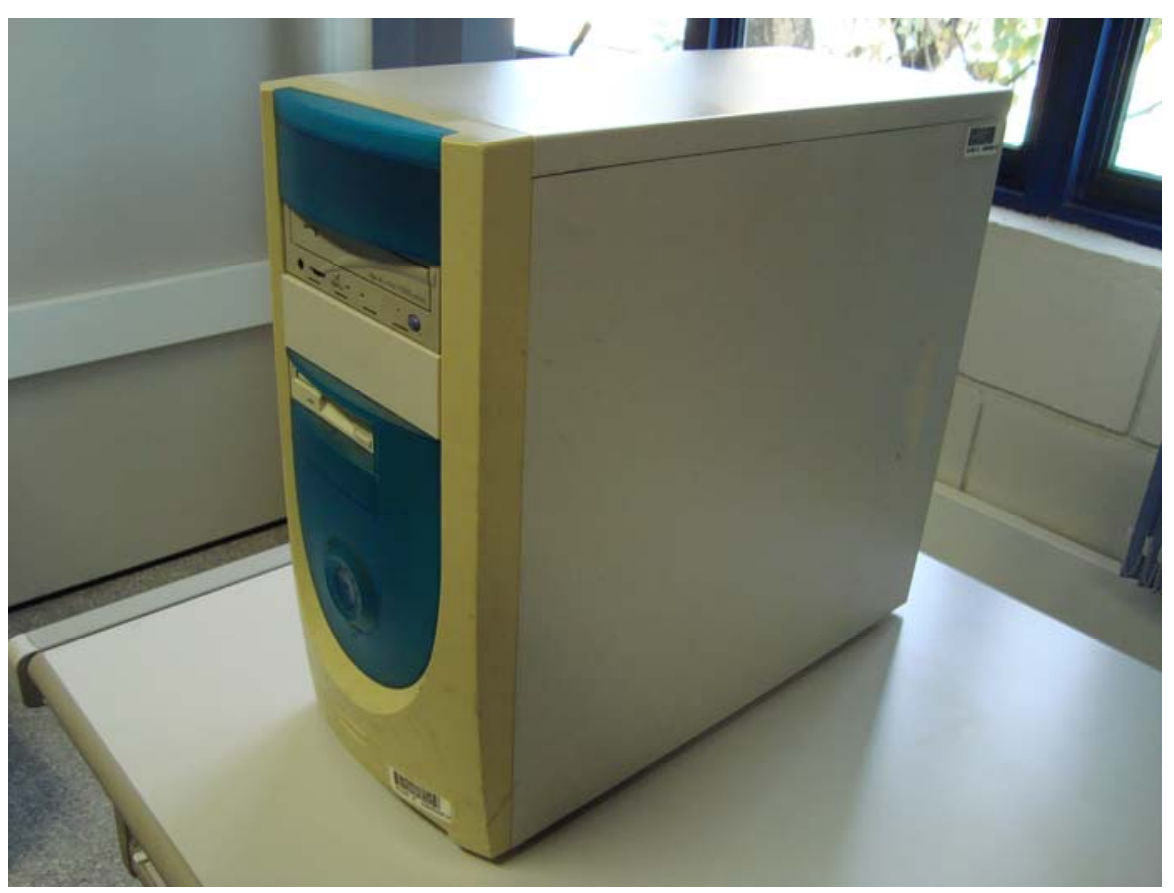

Figura 3.18 - Computador Pessoal.

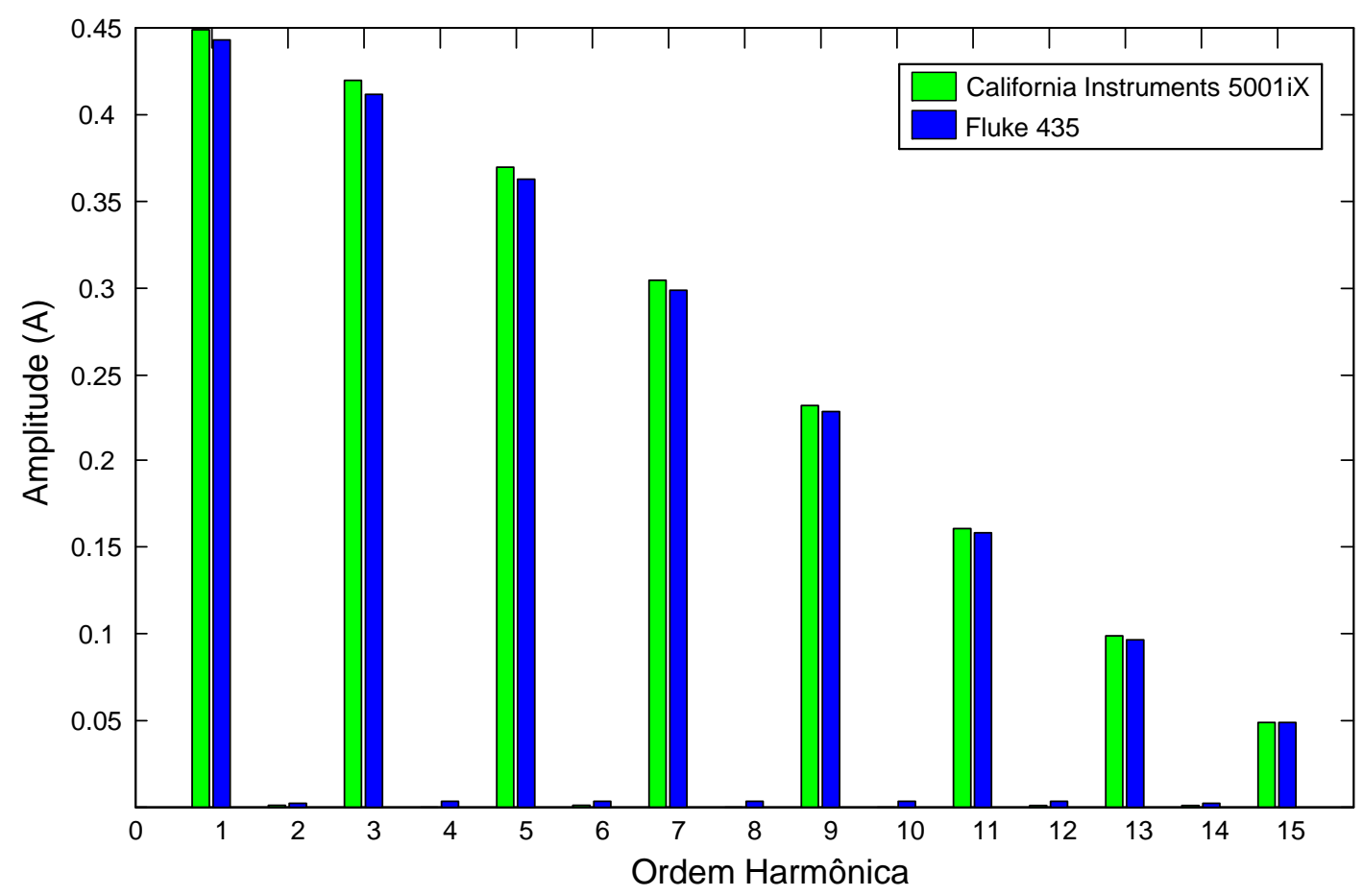

Figura 3.19 - Espectro de freqüências adquirido do computador pessoal. 
3.4.6 Monitor

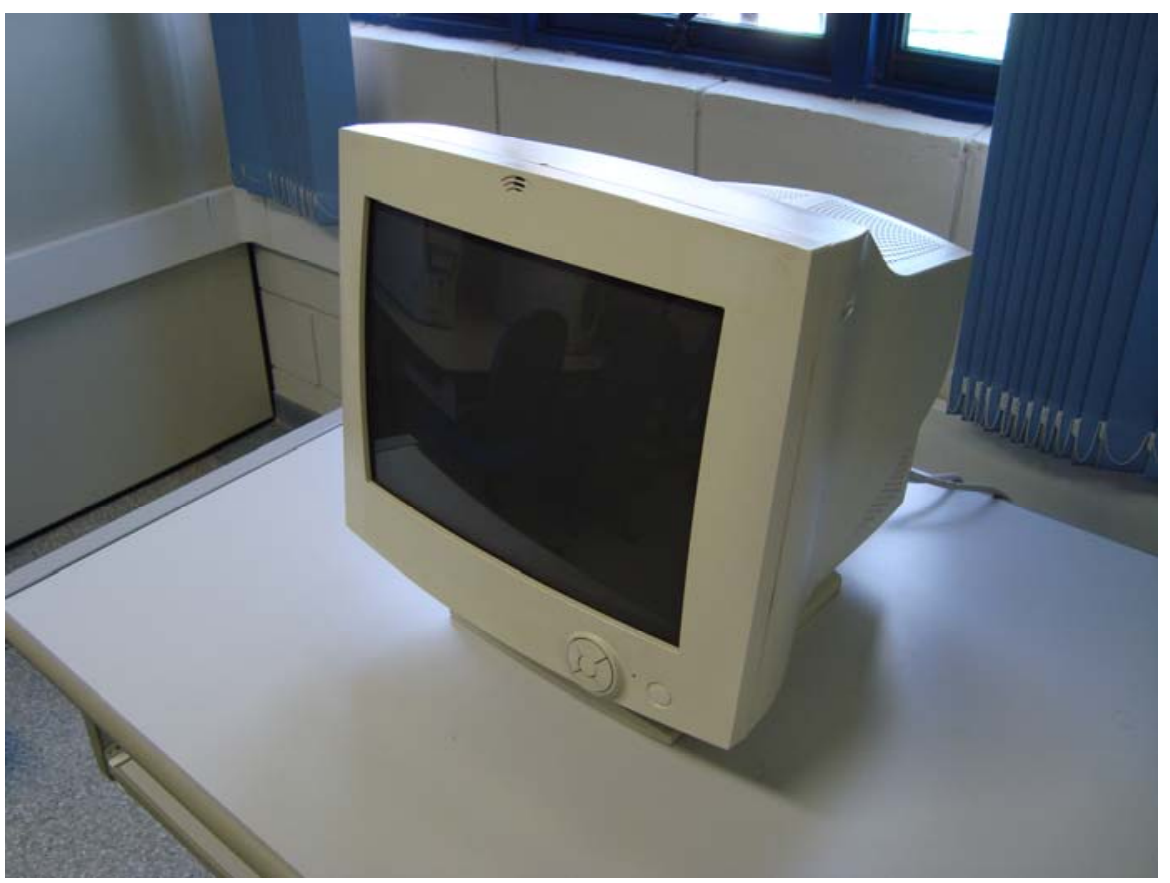

Figura 3.20 - Monitor.

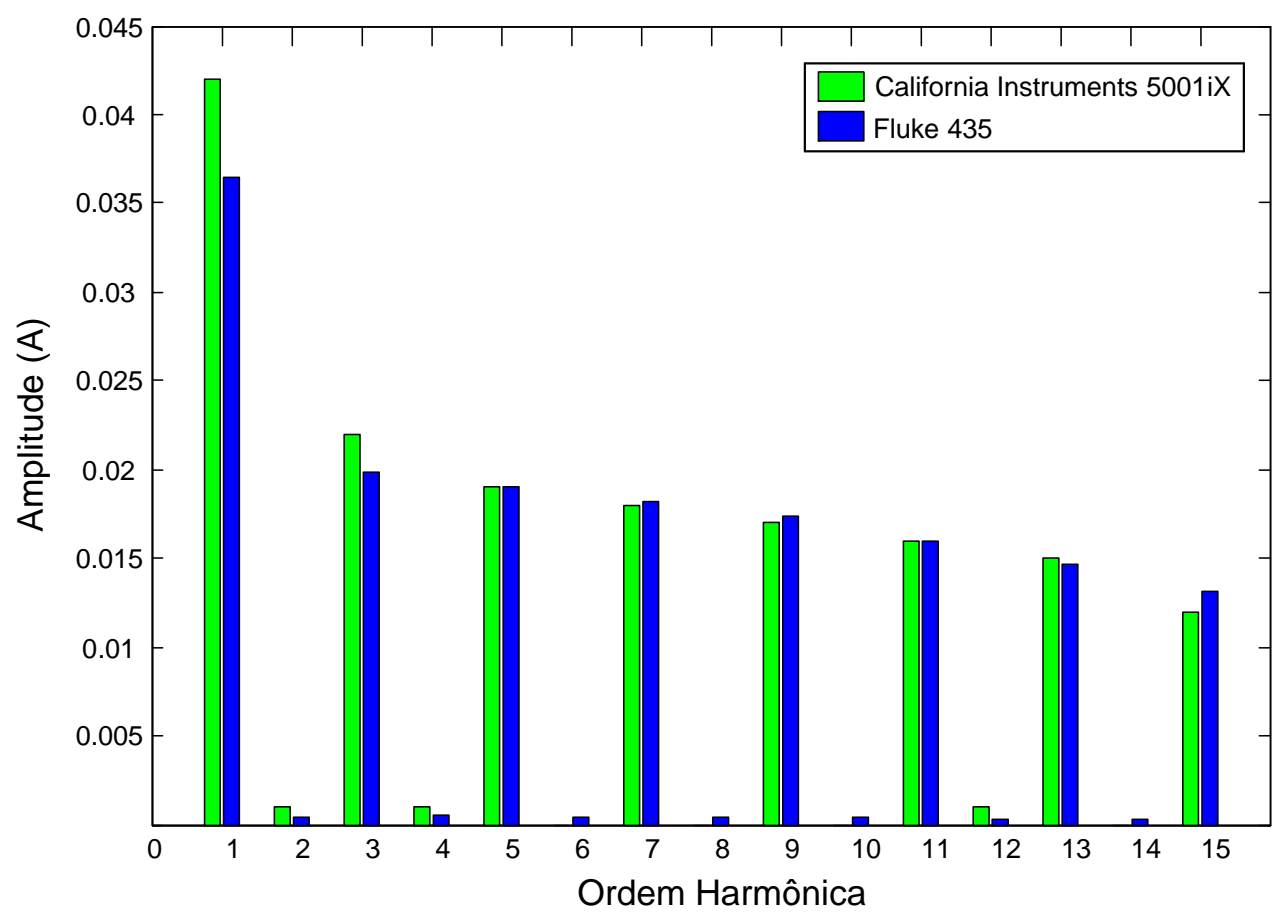

Figura 3.21 - Espectro de freqüências adquirido do monitor. 


\section{Fundamentos de Seleção de Atributos e Mineração de Dados}

\subsection{Seleção de Atributos}

No que se segue será dada uma breve introdução ao processo de seleção de atributos e a algumas das técnicas utilizadas no desenvolvimento deste trabalho, bem como suas vantagens e desvantagens.

\subsubsection{Introdução}

Apenas para situar o leitor quanto ao termo "atributo", Witten e Frank (2005) o definem como:

"Qualquer instância que seja dada como entrada a uma técnica de aprendizado de máquina que possua valores fixos para cada uma de suas características".

Em outras palavras, atributos são as colunas de uma base de dados que representam as diferentes características das diversas instâncias contidas nesta base de dados. As instâncias muitas vezes são conhecidas como registros ou tuplas.

Considerando-se então este conceito de "atributo", Liu e Motoda (1998) definem o processo de seleção de atributos como a determinação de um subconjunto de atributos ótimo que será responsável por generalizar a informação contida na base de dados, conforme a resposta que espera-se obter desta base de 
dados. O subconjunto de atributos obtido deverá necessariamente possuir um tamanho igual ou menor ao conjunto de atributos original.

Algoritmos para seleção de atributos são muito empregados quando os métodos para mineração de dados não conseguem obter a generalização de padrões sem qualquer pré-processamento dos dados ou quando estes algoritmos são inviabilizados devido à grande quantidade de atributos que seriam dados como entrada.

Geralmente utiliza-se a seleção de atributos para evitar estas duas hipóteses anteriormente comentadas, pois, ao se reduzir o número de entradas, minimiza-se também o espaço de busca pela solução ótima.

Apenas para complementar, há casos onde os métodos para seleção de atributos são empregados em conjunto com técnicas para a redução do número de instâncias, como mostrado por Liu e Motoda (2001).

Com relação ao funcionamento dos algoritmos para seleção de atributos, estes normalmente escolhem os atributos por uma avaliação individual ou por subconjuntos de atributos. A avaliação individual de atributos ordena-os com relação às suas relevâncias, assim, estes métodos removem os atributos irrelevantes mas não os atributos redundantes. Já no caso de avaliação por subconjuntos de atributos, tanto os atributos redundantes quanto os irrelevantes serão extraídos do conjunto de atributos (Lee, 2005).

Os métodos para seleção de atributos podem ser divididos em duas classes: wrappers (Kohavi e John, 1997) e filtros (Almuallim e Dietterich, 1991; Liu e Setiono, 1996). Filtros diferenciam-se de wrappers apenas quanto à independência do algoritmo de aprendizado que será utilizado posteriormente (Liu e Setiono, 1996; 
Hall, 2000). Nesta dissertação foram empregados métodos de ambas as classes, tendo o intuito de se comprovar os benefícios fornecidos por cada tipo.

Alguns autores (Hall e Holmes, 2003) defendem a idéia de que a seleção de atributos é um ponto central para tarefas de mineração de dados, visto que muitas das vezes a não seleção dos atributos pode levar os sistemas inteligentes a uma identificação com baixo desempenho e alto custo computacional.

Todos os métodos que serão analisados no decorrer deste capítulo foram empregados por fornecerem como resposta uma lista de atributos ordenados por relevância.

\subsubsection{Métodos Wrapper}

Os métodos do tipo wrapper são muito utilizados quando deseja-se selecionar atributos em problemas de aprendizado supervisionado. A metodologia consiste na entrada de um conjunto de treinamento onde os atributos passam por um método de busca pré-determinado pelo usuário. Após a busca de um subconjunto de atributos, este é avaliado e recebe um custo, porém, para que o método tenha a devida validade, estes subconjuntos devem ser classificados por um algoritmo de indução também pré-definido pelo usuário, que fornecerá como resultado uma estimativa de desempenho. Após todos os subconjuntos de atributos passarem pelo mesmo processo, os melhores subconjuntos são selecionados e deverão novamente passar por um segundo algoritmo de indução que irá extrair os atributos mais relevantes, sendo estes avaliados junto a um conjunto de validação para que os atributos selecionados mostrem seu potencial (Kohavi e John, 1997).

Uma breve representação que generaliza os métodos Wrapper é mostrada pela Figura 4.1 de forma a ilustrar os procedimentos acima comentados. 


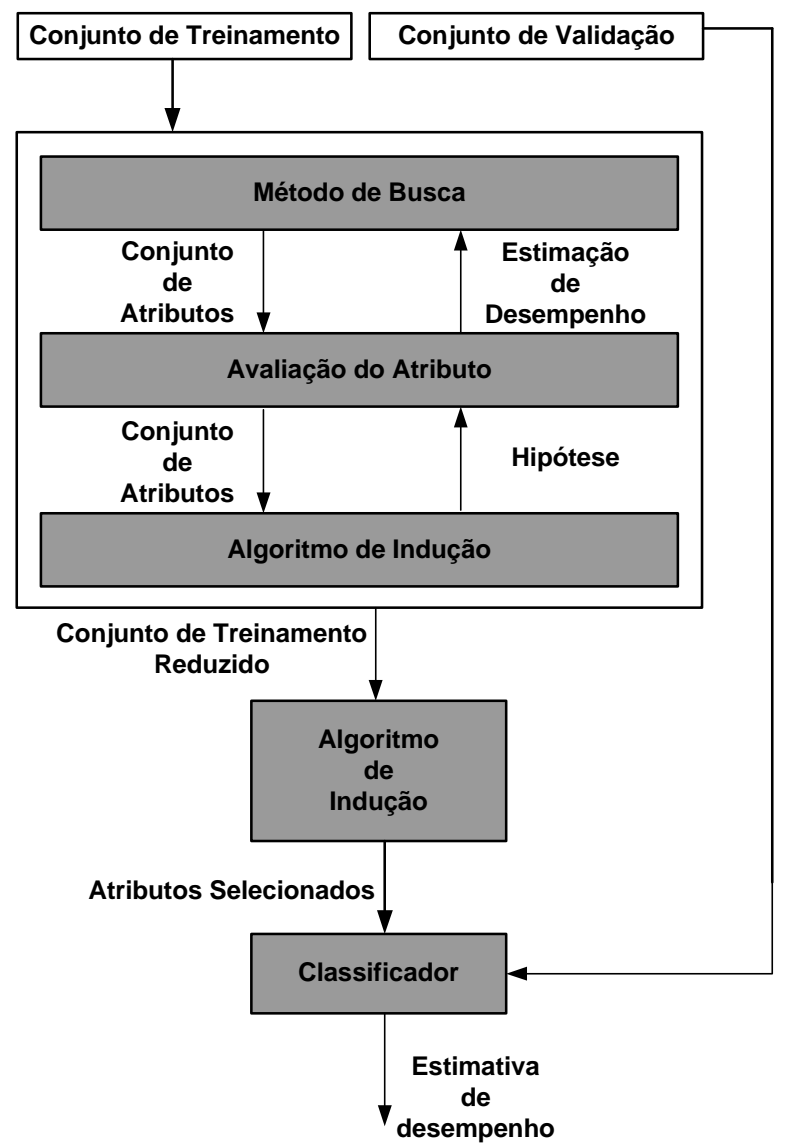

Figura 4.1 - Representação geral de seletores de atributos do tipo Wrapper.

Este algoritmo foi empregado devido ao fato de normalmente fornecer melhores resultados do que filtros, isto porque seu método de busca interage com o algoritmo de indução que realiza uma prévia avaliação dos subconjuntos de atributos. Porém, como mostrado por Hall e Holmes (2003), os métodos wrapper apresentam alto custo computacional devido ao algoritmo de indução ser executado para todo subconjunto analisado.

\subsubsection{Método CFS (Correlation-based Feature Selection)}

O CFS é um método proposto por Hall (1999), onde este pode ser aplicado tanto em conjuntos de dados contínuos quanto discretos, conforme mostrado em Hall (2000). O método faz uso de correlação para avaliar o custo dos atributos, no entanto, uma grande diferença apresentada pelo CFS, quando comparado a outros 
filtros, é que sua seleção começa pela avaliação dos subconjuntos de atributos para depois avaliar os atributos individualmente.

O algoritmo de CFS foi idealizado por Hall (1999) conforme a seguinte hipótese:

"Bons subconjuntos de atributos contêm atributos altamente correlatos com a classe, no entanto, estes não são correlatos a outros atributos".

A busca pelo melhor subconjunto de atributos é finalizada apenas quando o critério de parada é satisfeito, sendo que este critério é obtido quando as últimas cinco iterações retornam o mesmo subconjunto de atributos.

Algumas vantagens apresentadas pelo algoritmo CFS são sua rápida execução, possibilidade de ser aplicado em qualquer tipo de conjunto de atributos e redução de até $50 \%$ da quantidade de atributos.

\subsubsection{Método CF (Consistency-based Filter)}

O método CF, proposto por Liu e Setiono (1996), avalia os subconjuntos de atributos conforme sua consistência em relação às classes que compõem o conjunto de dados e, diferentemente da grande maioria dos métodos para seleção de atributos, não utiliza busca heurística, mas sim uma busca probabilística baseada no algoritmo Las Vegas. Conforme os resultados experimentais obtidos por Liu e Setiono (1996), pode-se verificar que este método geralmente fornece uma rápida resposta, garantindo também a localização do subconjunto de atributos ótimo, além de ser facilmente implementado.

O algoritmo Las Vegas faz escolhas probabilísticas que auxiliam no processo de busca, assim, encontra-se rapidamente o melhor subconjunto de atributos. Esta busca é executada até que um número máximo de tentativas seja 
alcançado, sendo que ao final das tentativas avalia-se tanto o tamanho do subconjunto de atributos quanto a sua inconsistência com relação à classe. O subconjunto selecionado será o de menor tamanho e inconsistência, visto que a consistência de um subconjunto de atributos é inversamente proporcional à sua inconsistência.

Uma desvantagem apresentada pela busca probabilística, quando comparada a uma busca heurística, é o seu custo computacional ser um pouco mais alto. No entanto, sua maior vantagem é que não possui a mesma vulnerabilidade apresentada pela busca heurística quando submetido a conjuntos de dados com muitos atributos correlatos.

Apenas de forma ilustrativa, um diagrama de blocos representando o funcionamento generalizado de filtros empregados na tarefa de seleção de atributos pode ser visualizado na Figura 4.2.

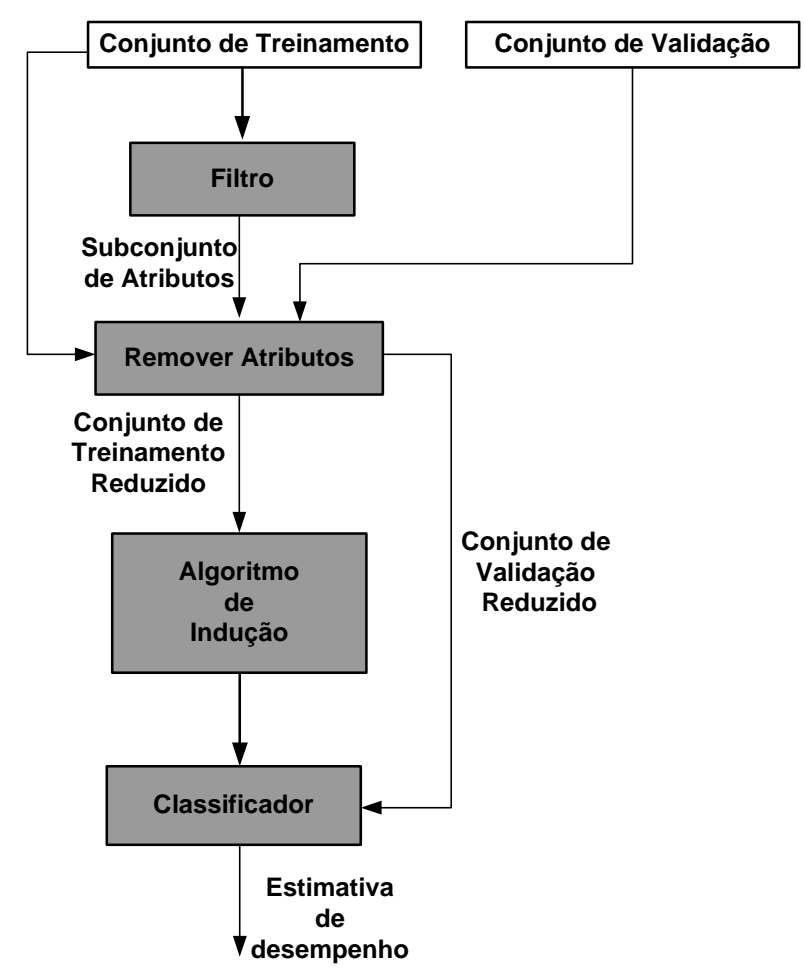

Figura 4.2 - Representação geral de filtros para seleção de atributos. 


\subsection{Mineração de Dados}

\subsubsection{Introdução à Mineração de Dados}

Antes de começar a debater sobre as RNAs utilizadas na busca pelos padrões das assinaturas harmônicas presentes na base de dados adquirida, uma breve introdução à Mineração de Dados será dada a seguir.

A Mineração de Dados (MD) surgiu com a necessidade de extrair padrões em bases de dados na tentativa de se obter informações valiosas e que pudessem fazer com que empresas se tornassem ainda mais competitivas dentro do setor de atividade ao qual se encaixavam. Principalmente hoje, quando nos encontramos na era da informação, este tipo de ferramenta torna-se essencial para o desenvolvimento empresarial, sendo que um exemplo é a previsão de mercado para daqui alguns anos, de modo que a empresa em questão direcione-se melhor conforme o mercado caminha.

Outro fator que levou ao surgimento da MD é a grande quantidade de dados que as empresas conseguem armazenar por dia ou até mesmo por hora, em que esta alta capacidade de armazenamento foi fruto da crescente evolução dos computadores. Esta grande quantidade de dados faz com que os analistas e pesquisadores não consigam analisar tais dados em tempo hábil, pois, não basta apenas analisá-los, porque estes ainda devem ser transformados em informações úteis para que sejam devidamente agregados pelas organizações empresariais.

Porém, a definição do termo "Mineração de Dados" ainda é alvo de discussões. Hoje, pode-se encontrar diversas definições para a MD. Alguns autores (Han e Kamber, 2001; Oliveira, 2004) referem-se à MD como sendo o processo de descoberta de conhecimento em bases de dados, também conhecido por KDD 
(Knowledge Discovery in Database), no entanto, Fayyad et al. (1996) a definem como uma "etapa" do processo de KDD e que consiste de uma diversidade de algoritmos para extração de padrões.

Nesta dissertação abordar-se-á o assunto como definido por Fayyad et al. (1996), onde serão utilizadas RNAs para o processo de identificação de padrões. Todas as etapas que constituem o sistema computacional até chegar à MD podem ser observadas por meio da Figura 4.3.

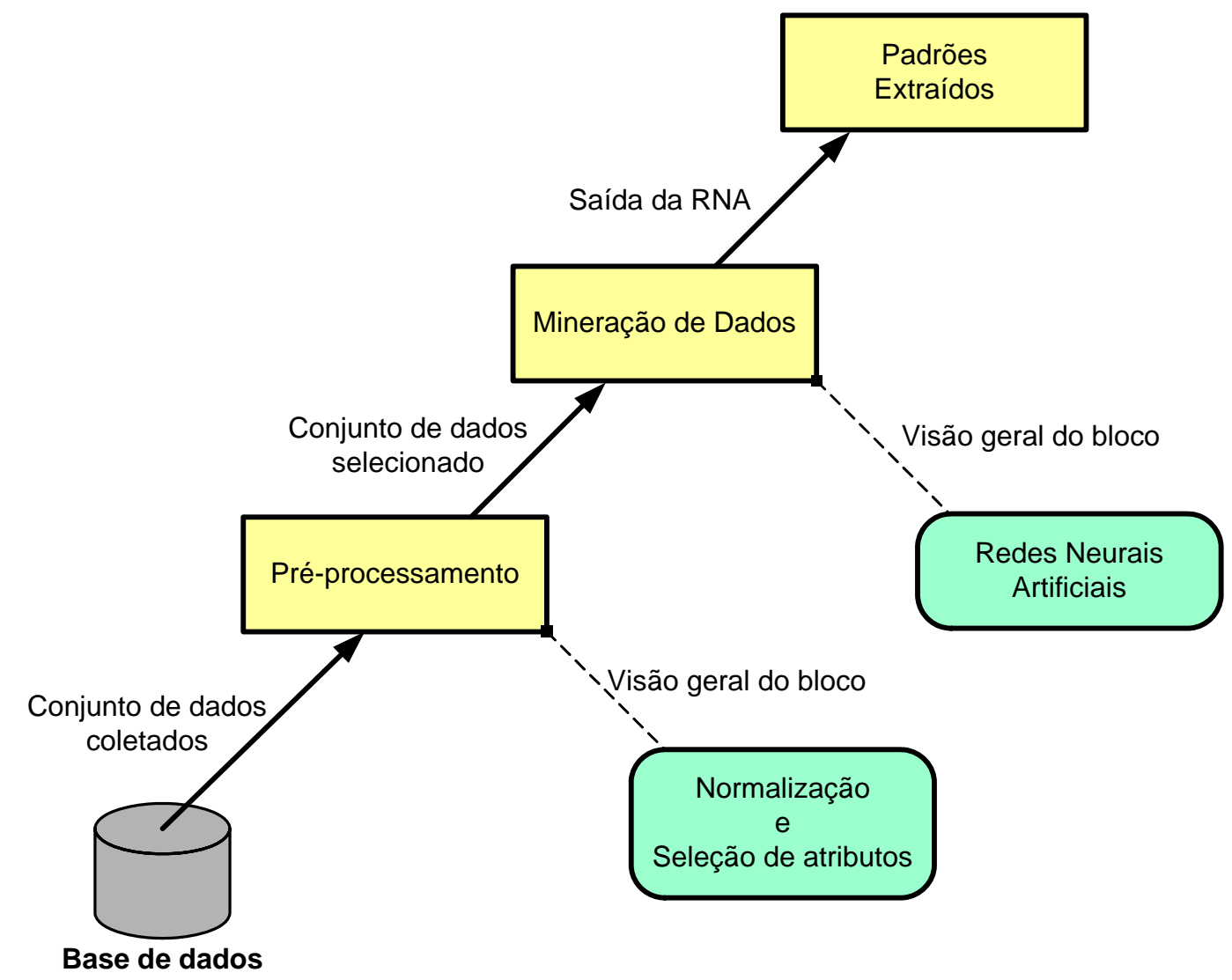

Figura 4.3 - Visão geral do sistema computacional, partindo-se da base de dados consolidada até a identificação das fontes de correntes harmônicas.

Conforme mostrado nesta figura, pode-se verificar que o sistema é dividido em quatro etapas sumarizadas a seguir:

- Etapa 1 - criação da base de dados que será constituída das assinaturas harmônicas das cargas; 
- Etapa 2 - a normalização e seleção dos atributos mais relevantes que constituem a base de dados;

- Etapa 3 - a partir da base de dados com os atributos selecionados e normalizados, aplica-se mineração dos dados propriamente dita e que será realizada por RNAs;

- Etapa 4 - os padrões encontrados pelo algoritmo empregado na mineração dos dados serão validados.

A MD normalmente é usada para especificar grupos de padrões que podem ser encontrados em bases de dados sem que haja algum conhecimento prévio de qual padrão poderá fornecer informações de interesse (Han e Kamber, 2001; Fayyad et. al., 1996; Oliveira, 2004).

No entanto, há casos em que já se tem idéia do tipo de informação que se deseja extrair da base de dados, porém, a complexidade dos dados inviabiliza que análises sejam feitas por especialistas (Han e Kamber, 2001). O processo de MD apresentado nesta dissertação apóia-se neste contexto, devido à necessidade de determinar um padrão que possa representar a identificação das fontes de correntes harmônicas presentes no sistema.

As tarefas realizadas pela MD geralmente dividem-se em: preditivas e descritivas (Han e Kamber, 2001). Quando aplica-se à mineração preditiva, dados que representem situações passadas do processo são apresentados com o intuito de se obter padrões que venham a representar situações atuais ou futuras do processo. Já a mineração descritiva que será empregada neste trabalho, é aplicada de modo a caracterizar os dados contidos na base de dados de forma geral, isto é, por meio deste tipo de mineração, determina-se apenas situações atuais do processo. 
Dada esta breve introdução aos aspectos necessários para que um sistema possa ser considerado uma MD, a seguir, apresenta-se o estado da arte e os fundamentos de RNAs.

\subsection{Redes Neurais Artificiais}

Conforme Haykin (1999), redes neurais são definidas como modelos matemático-computacionais inspirados no comportamento do cérebro humano. 0 cérebro humano possui um sistema de processamento da informação extremamente complexo, não linear e paralelo; ao passo que as redes neurais artificiais possuem um processamento paralelo que é distribuído pelas suas unidades de processamento, ou seja, os neurônios, que por sua vez são favoráveis ao armazenamento de conhecimento, de forma a disponibilizá-lo para uma posterior utilização.

Portanto, as redes neurais artificiais são parecidas ao cérebro em duas características:

- Seu conhecimento é adquirido por um processo de aprendizado e;

- As conexões entre seus neurônios são utilizadas para armazenar o conhecimento adquirido.

As RNAs possuem como principais características a capacidade de aprender por meio de exemplos e a generalização de informações aprendidas. A generalização está atrelada com a capacidade de a rede aprender pela apresentação de um conjunto reduzido de exemplos, onde a mesma deverá ser apta a fornecer respostas coerentes para dados que não tenham sido utilizados em sua etapa de aprendizado. Outras características como tolerância a falhas, auto- 
organização e capacidade de agrupar ou organizar dados também podem ser observadas em algumas arquiteturas de redes neurais.

Quanto à aplicação de RNAs, pode-se dizer que estas abrangem diversas áreas do conhecimento, como: física, matemática, engenharia, neurofisiologia etc. Com esta vasta quantidade de áreas de aplicação, pode-se perceber o potencial apresentado pelas RNAs no decorrer dos anos. Este foi um dos fatores que motivou a escolha da ferramenta para que viesse a ser empregada nesta dissertação.

\subsubsection{Estado da Arte de Redes Neurais Artificiais}

As RNAs são tópico de estudo desde 1943, quando o psiquiatra e neuroanatomista Warren McCulloch junto ao matemático Walter Pitts propuseram uma modelagem matemática que representasse o neurônio biológico. Em McCulloch e Pitts (1943), o modelo artificial do neurônio e suas capacidades computacionais são descritas, porém, sem nenhuma técnica de aprendizado. O modelo artificial do neurônio biológico proposto por McCulloch e Pitts pode ser visualizado na Figura 4.4, onde este é devidamente comparado a um neurônio biológico. 


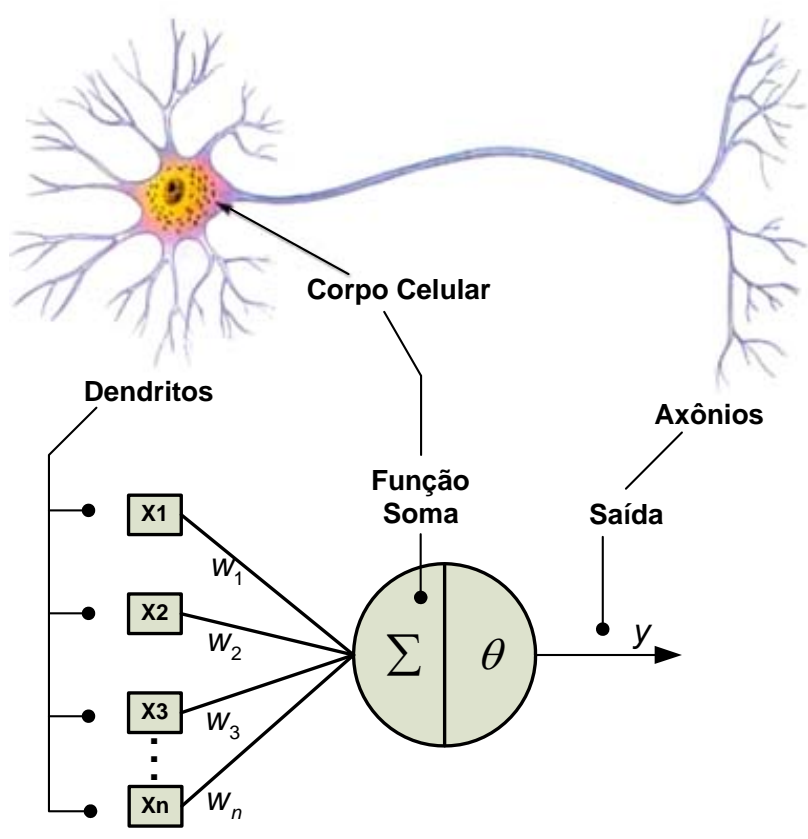

Figura 4.4 - Representação do neurônio artificial modelado por McCulloch e Pitts comparado a um neurônio biológico.

As técnicas de aprendizado começaram a ser estudadas anos depois, mais precisamente em 1949, quando Donald Hebb demonstrou que a variação dos pesos de entrada poderia tornar o neurônio artificial hábil ao aprendizado.

Em 1958, Frank Rosenblatt apresentou o Perceptron, sendo esta uma RNA constituída pelo neurônio artificial proposto por McCulloch e Pitts, porém, com algoritmo de treinamento que fazia uso dos pesos de entrada ajustáveis como demonstrado por Hebb. Entretanto, esta RNA apenas possibilitava o aprendizado de padrões linearmente separáveis. Paralelamente, Widrow e Hoff criaram uma regra de aprendizado conhecida como regra delta, que baseava-se no método do gradiente, de forma a minimizar o erro na saída da RNA.

Contudo, em 1969, Minsky e Papert demonstraram que o Perceptron era bastante limitado. Após este trabalho, o conexionismo teve um período de isolamento durante a década de 70. As pesquisas somente foram fortemente retomadas após a publicação do trabalho de John Hopfield em 1982. 
Em 1986, Rumelhart et al. (1986) descreveram o algoritmo de treinamento backpropagation, o qual contornaria as limitações apontadas por Minsky e Papert, pois agora as redes de perceptrons multicamadas eram passíveis de treinamento.

A partir de meados da década de 80 até os tempos atuais, as pesquisas e aplicações relacionadas às RNAs encontram-se em constante desenvolvimento, principalmente pelo avanço tecnológico, o qual proporciona o processamento de algoritmos que necessitam de maior poder computacional (Braga, Ludermir e Carvalho, 2000).

\subsubsection{Arquiteturas de Redes Neurais Artificiais}

A arquitetura de uma RNA relaciona-se diretamente com o algoritmo de aprendizado empregado para o treinamento da rede e com sua capacidade para resolução de determinados tipos de problemas. Alguns parâmetros como número de camadas, quantidade de neurônios por camada, tipo de conexão entre os neurônios e a topologia da rede devem ser levadas em consideração para determinar sua arquitetura.

Quanto ao número de camadas, pode-se categorizá-las em:

- Camada única ou;

- Múltiplas camadas.

Quanto aos tipos de conexão entre os neurônios, estes podem ser:

- Totalmente conectados ou;

- Parcialmente conectados.

Quanto à topologia da rede, estas podem ser principalmente divididas em:

- Feedforward e;

- Feedback. 
A quantidade de neurônios por camada normalmente não segue uma regra e são determinadas de forma experimental.

Outro fator que normalmente não é utilizado para a especificação da arquitetura de uma RNA, porém, está ligeiramente ligado à sua arquitetura é a função de ativação de cada neurônio. Em geral, utiliza-se a mesma função de ativação para os neurônios de uma dada camada.

Algumas das funções de ativação mais utilizadas têm seus cálculos e formatos gráficos mostrados nas Figuras de 4.5 a 4.11 :

- Degrau bipolar

$$
y(n)=\left\{\begin{array}{l}
y=1, \text { se } n>0 \\
y=0, \text { se } n=0 \\
y=-1, \text { se } n<0
\end{array}\right.
$$

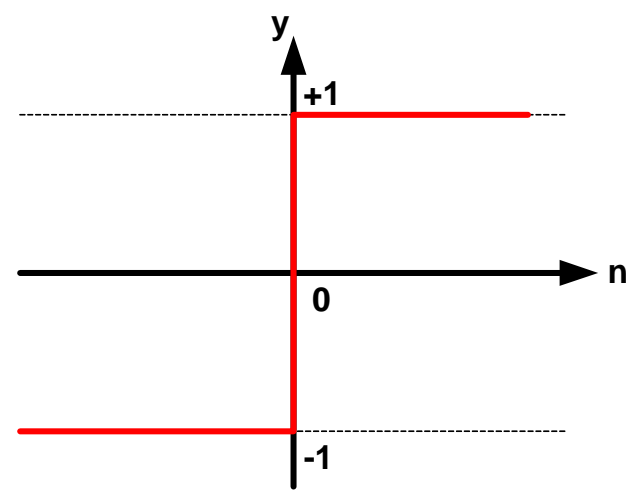

Figura 4.5 - Representação da função de ativação do tipo degrau bipolar.

- Degrau

$$
y(n)=\left\{\begin{array}{l}
y=1, \text { se } n \geq 0 \\
y=0, \text { se } n<0
\end{array}\right.
$$






Figura 4.6 - Representação da função de ativação do tipo degrau.

- Linear

$$
y(n)=n
$$

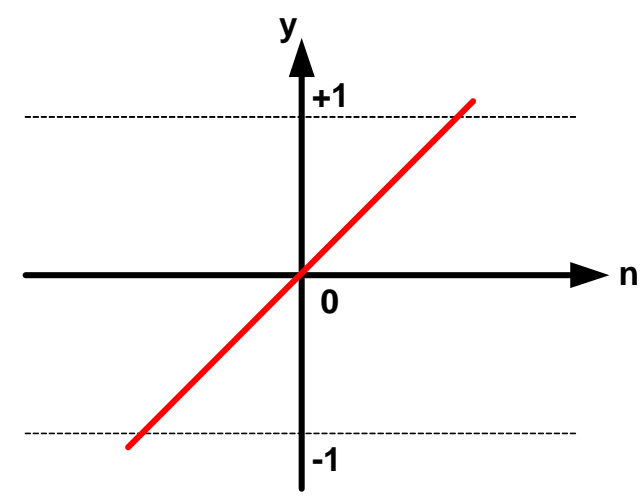

Figura 4.7 - Ilustração da função de ativação do tipo linear.

- Tangente hiperbólica

$$
y(n)=\frac{1-e^{-\beta n}}{1+e^{\beta n}} \text {, onde } \beta \text { é o parâmetro de excentricidade }
$$

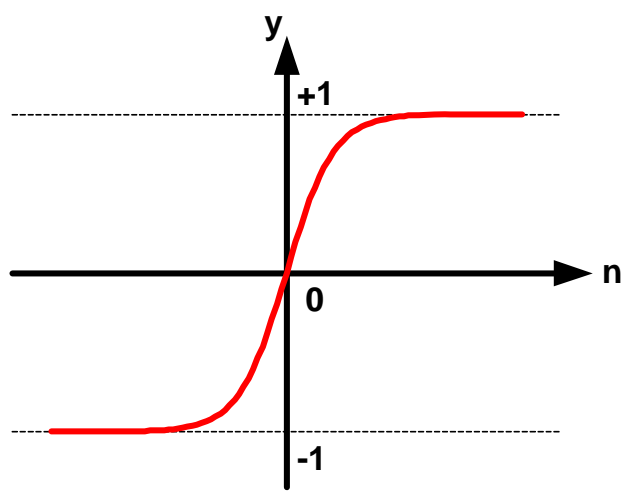

Figura 4.8 - Representação gráfica da função de ativação do tipo tangente hiperbólica. 
- Logística (sigmóide)

$y(n)=\frac{1}{1+e^{-\beta n}}$, onde $\beta$ é o parâmetro de excentricidade

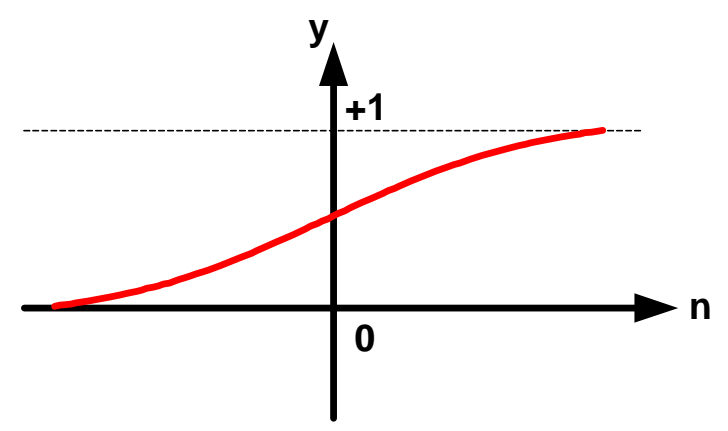

Figura 4.9 - Ilustração da função de ativação do tipo logística (sigmóide).

- Rampa

$$
y(n)\left\{\begin{array}{c}
y=1, \text { se } n>1 \\
y=n, \text { se }-1 \leq n \leq 1 \\
y=-1, \text { se } n<0
\end{array}\right.
$$

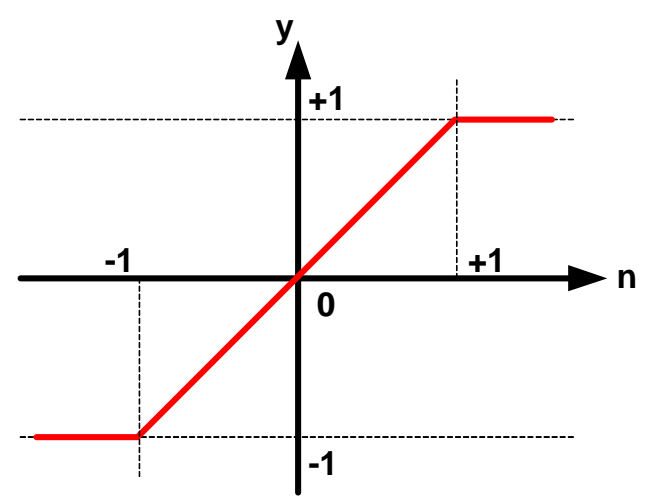

Figura 4.10 - Representação gráfica da função de ativação do tipo rampa.

- Base radial (gaussiana)

$$
y(n)=e^{-\left(\frac{(\sigma n)^{2}}{2 \sigma^{2}}\right)}
$$




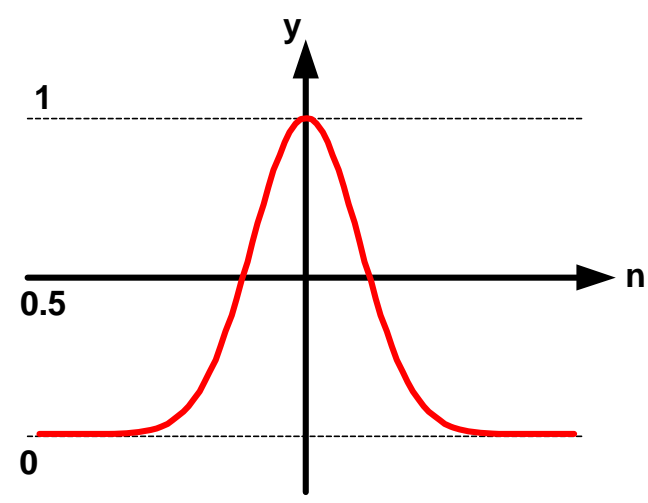

Figura 4.11 - Ilustração da função de ativação de base radial (gaussiana).

$\mathrm{Na}$ próxima seção analisam-se os aspectos inerentes à arquitetura feedforward da rede Perceptron de Múltiplas Camadas (do inglês, Multilayer Perceptron), a qual foi empregada nesta dissertação para a tarefa de extração dos padrões apresentados pelas assinaturas harmônicas das cargas.

\subsubsection{Perceptron de Múltiplas Camadas}

Como descrito por Haykin (1999), as redes MLP possuem arquitetura feedforward de múltiplas camadas, sendo constituídas pela camada de entrada, uma ou mais camadas neurais intermediárias e a camada neural de saída.

A camada de entrada recebe os sinais provenientes do processo, as camadas neurais intermediárias têm como função a extração e armazenamento do conhecimento e a camada neural de saída deverá emitir uma resposta coerente ao estímulo dado na entrada da rede.

Uma grande vantagem apresentada por esta arquitetura é a vasta quantidade de aplicações como: aproximador funcional, reconhecimento de padrões, otimização e controle de processos, entre outras.

Por utilizarem a topologia feedforward, seu fluxo de dados deve ser passado camada a camada, partindo-se da camada de entrada que irá receber um vetor 
contendo os sinais provenientes do sistema e que serão propagados aos neurônios das camadas intermediárias onde serão devidamente processados. Feito o processamento nas camadas intermediárias, estes são emitidos à camada neural de saída que fornecerá o parecer final da rede.

De forma, meramente ilustrativa, apresenta-se pela Figura 4.12 uma rede MLP com apenas uma camada intermediária.

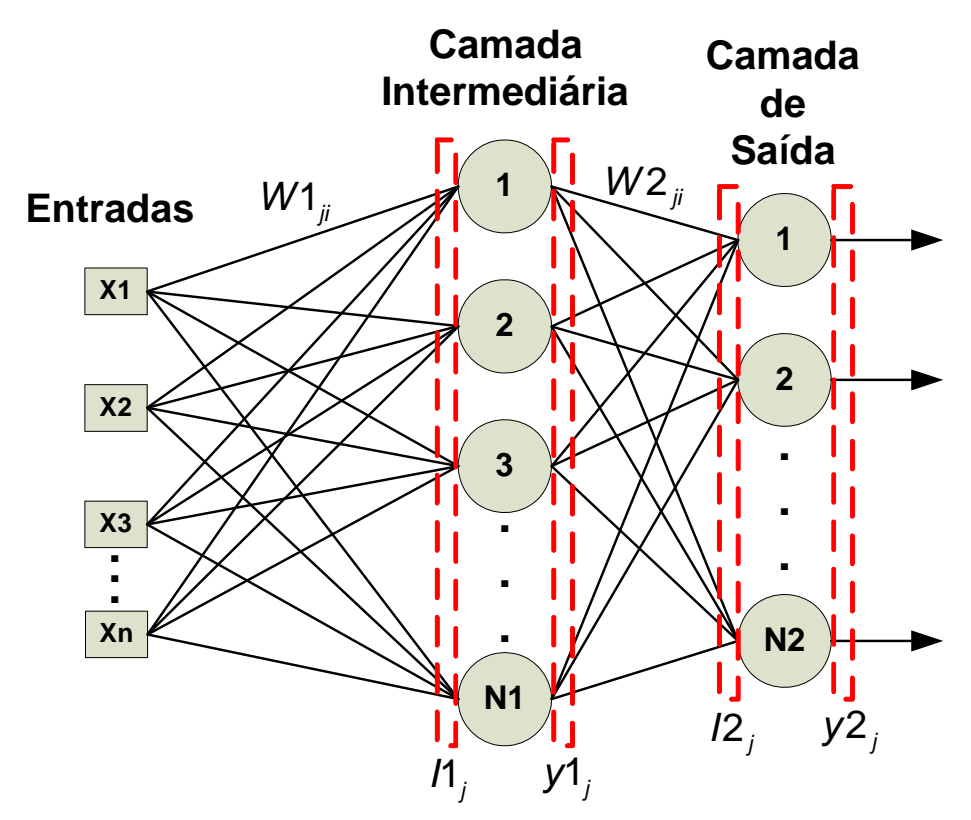

Figura 4.12 - Arquitetura de uma rede neural do tipo MLP.

Como pode ser visualizado na Figura 4.12, em redes do tipo MLP os neurônios de cada camada apenas são conectados aos neurônios da camada imediatamente superior, não existindo qualquer outro tipo de conexão entre neurônios. Todo o conhecimento obtido pelo processamento dos neurônios da camada intermediária será armazenado na forma de pesos sinápticos, representados por $W 1_{j i}, W 2_{j i}$.

Para representar como o conhecimento da rede neural do tipo MLP é obtido, as seções subseqüentes fornecem uma descrição conceitual e matemática dos 
métodos de treinamento supervisionado backpropagation e Levenberg-Marquardt (Hagan e Menhaj, 1994).

Porém, assim como uma diversidade de outros métodos para treinamento de redes neurais, o método de Levenberg-Marquardt baseia-se no algoritmo de backpropagation (retro-propagação). Por este motivo, apresentar-se-á primeiro o funcionamento do algoritmo de backpropagation, de forma a fornecer um maior embasamento aos aspectos conceituais e matemáticos do algoritmo de LevenbergMarquardt.

\subsubsection{Treinamento Backpropagation}

Para se treinar uma rede neural do tipo $M L P$ com o algoritmo de backpropagation, apresenta-se um exemplo de entrada, normalmente em formato vetorial que será propagado camada a camada até que a rede forneça uma resposta. Tal resposta deverá ser comparada a uma resposta desejada pré-definida para o exemplo de entrada. Portanto, para todos os exemplos utilizados no treinamento da rede neural, necessita-se de suas respectivas saídas desejadas.

Esta diferença entre a saída da rede e a saída desejada é realizada para se obter o erro quadrático produzido pela rede neural que será retropropagado com o intuito de melhor ajustar os pesos sinápticos. Com o erro quadrático obtido para cada um dos exemplos de treinamento, calcula-se então o erro quadrático médio (EQM) que será utilizado como critério de parada ao treinamento da rede neural. Enquanto o EQM não estiver dentro de um limite aceitável, todos os passos anteriores são repetidos.

Os cálculos necessários para o desenvolvimento do algoritmo de backpropagation serão definidos tomando-se como base a arquitetura da $M L P$ 
mostrada pela Figura 4.12. Antes de inicializarmos os cálculos do algoritmo backpropagation, algumas variáveis devem ser definidas:

- $n$ denota a quantidade de atributos contidos em cada exemplo que será apresentado à rede neural;

- j representa a quantidade de neurônios da camada corrente;

- i representa a quantidade de neurônios da camada anterior à camada corrente;

- $W 1_{j i}$ denota os pesos sinápticos entre a entrada e a camada neural intermediária;

- $W 2_{j i}$ denota os pesos sinápticos entre a camada neural intermediária e a camada neural de saída;

- $X$ representa o exemplo que será apresentado à rede com seus $n$ atributos;

- $\quad y 1_{j}$ denota a saída da camada neural intermediária;

- $\quad I 1_{j}$ representa a entrada da camada neural intermediária;

- $\quad y 2_{j}$ denota a resposta da camada neural de saída;

- 12 representa a entrada da camada neural de saída.

- $d_{j}$ representa a saída desejada.

Os cálculos para o algoritmo de backpropagation são apresentados a seguir, sendo divididos em duas etapas, forward e backward.

\section{ETAPA 1 - FORWARD}

Nesta etapa um exemplo é aplicado às entradas da rede e propagado camada a camada até a saída. 
Em um primeiro momento, os pesos sinápticos $W 1_{j i}$ e $W 2_{j i}$ devem ser inicializados (normalmente com valores aleatórios), onde $j$ denota a quantidade de neurônios na camada corrente, por exemplo, para $W 1_{j i}$ a variável $j$ determina a quantidade de neurônios da camada neural intermediária; enquanto $i$ representa a quantidade de entradas da rede.

Com os pesos sinápticos estabelecidos, propagamos os sinais de entrada para as próximas camadas e assim calculamos as saídas dos neurônios de cada camada como segue.

$$
\begin{gathered}
I 1_{j}=\sum_{i=0}^{n} W 1_{j i} * X_{i} \\
y 1_{j}=g\left(I 1_{j}\right) \\
I 2_{j}=\sum_{i=0}^{n} W 2_{j i} * y 1_{i} \\
y 2_{j}=g\left(I 2_{j}\right)
\end{gathered}
$$

Pelos cálculos anteriores, deve-se mostrar ainda como obter a função $g(x)$, a qual representa a ativação dos neurônios que compõem cada camada. Para isto foram apresentadas uma diversidade de funções de ativação na subseção 4.3.2. Entretanto, geralmente emprega-se nas camadas neurais intermediárias a função logística (sigmóide), tangente hiperbólica ou a base radial (gaussiana); e para a camada neural de saída a função linear.

Após determinar as saídas da rede, calcula-se o erro quadrático entre a saída atual e a saída desejada da seguinte forma: 


$$
E(k)=\frac{1}{2} \sum_{j=1}^{N 2}\left(d_{j}(k)-y 2_{j}(k)\right)^{2}
$$

Caso já tenhamos calculado o erro quadrático para as saídas de todos os exemplos de treinamento, calcula-se então o erro quadrático médio como segue:

$$
E Q M=\frac{1}{p} \sum_{k=1}^{p} E(k)
$$

onde $p$ denota a quantidade de padrões ou exemplos que serão dados como entrada para a treinamento da rede neural.

Obtidos os erros referentes às saídas da rede neural, executa-se a etapa backward.

\section{ETAPA 2 - BACKWARD}

Nesta etapa o erro quadrático obtido sobre a saída da rede deve ser retropropagado às camadas inferiores para que os pesos sinápticos sejam ajustados.

\section{Cálculo dos pesos da camada neural de saída}

Utilizando a regra da diferenciação em cadeia temos:

$$
\nabla E=\frac{\partial E}{\partial W 2_{j i}}=\frac{\partial E}{\partial y 2_{j}} \cdot \frac{\partial y 2_{j}}{\partial I 2_{j}} \cdot \frac{\partial I 2_{j}}{\partial W 2_{j i}}
$$

onde,

$$
\begin{gathered}
\frac{\partial E}{\partial W 2_{j i}}=y 1_{i} \\
\frac{\partial y 2_{j}}{\partial I 2_{j}}=g^{\prime}\left(I 2_{j}\right) \\
\frac{\partial E}{\partial y 2_{j}}=-\left(d_{j}-y 2_{j}\right)
\end{gathered}
$$

Substituindo (4.15), (4.16) e (4.17) em (4.14) obtemos: 


$$
\frac{\partial E}{\partial w 2_{j i}}=-\left(d_{j}-y 2_{j}\right) \cdot g^{\prime}\left(I 2_{j}\right) \cdot y 1_{i}
$$

Logo, o ajuste de $W 2_{j i}$ deve ser feito em direção oposta ao gradiente, ou seja:

$$
\begin{gathered}
\Delta W 2_{j i}=-\eta \cdot \frac{\partial E}{\partial W 2_{j i}} \\
\Delta W 2_{j i}=-\eta \cdot \delta 2_{j} \cdot y 1_{i}
\end{gathered}
$$

ou ainda:

$$
W 2_{j i}(t+1)=W 2_{j i}(t)+\eta^{*} \delta 2_{j}^{*} y 1_{i}
$$

onde $\eta$ denota a taxa de aprendizado do algoritmo e $\delta 2_{j}$ representa o gradiente local que é definido por:

$$
\delta 2_{j}=\left(d_{j}-y 2_{j}\right) \cdot g^{\prime}\left(I 2_{j}\right)
$$

\section{Cálculo dos pesos da camada neural intermediária}

Para a camada neural intermediária temos:

$$
\nabla E=\frac{\partial E}{\partial W 1_{j i}}=\frac{\partial E}{\partial y 1_{j}} \cdot \frac{\partial y 1_{j}}{\partial I 1_{j}} \cdot \frac{\partial l 1_{j}}{\partial W 1_{j i}}
$$

onde,

$$
\begin{gathered}
\frac{\partial I 1_{j}}{\partial W 1_{j i}}=X_{i} \\
\frac{\partial y 1_{j}}{\partial I 1_{j}}=g^{\prime}\left(I 1_{j}\right) \\
\frac{\partial E}{\partial y 1_{j}}=\sum_{k=1}^{N 2} \frac{\partial E}{\partial I 2_{k}} \cdot \frac{\partial I 2_{k}}{\partial y 1_{j}}
\end{gathered}
$$

No entanto, a Equação (4.26) pode ser reescrita como:

$$
\frac{\partial E}{\partial y 1_{j}}=\sum_{k=1}^{N 2} \frac{\partial E}{\partial I 2_{k}} \cdot W 2_{k j}
$$


Multiplicando a Equação (4.25) por (4.26) e inserindo o resultado em (4.27) obtemos:

$$
\frac{\partial E}{\partial y 1_{j}}=-\sum_{k=1}^{N 2} \delta 2_{k} \cdot W 2_{k j}
$$

Substituindo (4.24), (4.25) e (4.28) em (4.23) temos:

$$
\frac{\partial E}{\partial W 1_{j i}}=\left(-\sum_{k=1}^{N 2} \delta 2_{k} \cdot W 2_{k j}\right) \cdot g^{\prime}\left(I 1_{j}\right)+X_{i}
$$

Logo, o ajuste de $W 1_{j i}$ deve ser feito em direção oposta ao gradiente, ou seja:

$$
\begin{gathered}
\Delta W 1_{j i}=-\eta \cdot \frac{\partial E}{\partial W 1_{j i}} \\
\Delta W 1_{j i}=-\eta \cdot \delta 1_{j} \cdot X_{i}
\end{gathered}
$$

ou ainda:

$$
W 1_{j i}(t+1)=W 1_{j i}(t)+\eta \cdot \delta 1_{j} \cdot X_{i}
$$

onde $\delta 1_{j}$ representa o gradiente local definido por:

$$
\delta 1_{j}=g^{\prime}\left(I 1_{j}\right) \cdot \sum_{k=1}^{N 2}\left(\delta 2_{k} \cdot W 2_{k l}\right)
$$

\subsubsection{Treinamento Levenberg-Marquardt}

Como pôde ser visto na demonstração matemática anterior, o algoritmo de backpropagation utiliza a direção oposta ao gradiente para encontrar uma solução considerada ótima dentro do espaço de busca do problema, porém, este método além de não ser considerado tão favorável para a localização do ótimo global ainda requer um grande esforço computacional. Devido às características apresentadas 
pelo algoritmo de backpropagation, empregou-se neste trabalho o algoritmo de Levenberg-Marquardt que se sobrepõe a estas desvantagens.

Muitas técnicas para a otimização do treinamento de RNAs foram propostas na literatura, porém, a técnica de Levenberg-Marquardt que baseia-se no método dos mínimos quadrados destaca-se entre as que apresentam uma mais rápida convergência.

A seguir são apresentados os cálculos necessários para o desenvolvimento do algoritmo de treinamento.

Toda a etapa forward até as saídas da rede mostrada anteriormente para o algoritmo de backpropagation pode ser mantida sem alterações. Porém, o cálculo do erro quadrático e erro quadrático médio apresentados pelas Equações (4.12) e (4.13) serão expressos conjuntamente por:

$$
\begin{gathered}
V=\frac{1}{2 p} \sum_{k=1}^{p} \sum_{j=1}^{N 2}\left[d_{j}(k)-y 2_{j}(k)\right]^{2} \\
V=\frac{1}{2 p} \sum_{k=1}^{p}(d(k)-y 2(k))^{T} \cdot(d(k)-y 2(k)) \\
V=\frac{1}{2 p} \sum_{k=1}^{p} e^{T}(k) \cdot e(k)
\end{gathered}
$$

Portanto, pela Equação (4.36) pode-se dizer que $e(k)=(d(k)-y 2(k))$ e que o mesmo representa um vetor contento o erro para cada um dos $k$ exemplos de treinamento.

Como mostrado por Hagan e Menhaj (1994), o algoritmo de backpropagation representa um método de descida do gradiente, já o algoritmo de LevenbergMarquardt representa uma aproximação ao método de Newton.

Pelo método de Newton podemos verificar que a minimização de uma função objetivo $V(z)$ em relação a um vetor paramétrico $z$, é dada por: 


$$
\Delta z=-\left[\nabla^{2} V(z)\right]^{-1} \cdot \nabla V(z)
$$

onde, $\nabla^{2} V(z)$ denota a matriz Hessiana e $\nabla V(z)$ representa a matriz Jacobiana de $V(z)$. Partindo-se do pressuposto que $V(z)$ é uma função que realiza a operação de soma de funções quadráticas dada por:

$$
V(z)=\sum_{i=1}^{N} e_{i}^{2}(z)
$$

pela Equação (4.38) podemos obter:

$$
\begin{gathered}
\nabla V(z)=J^{T}(z) \cdot e(z) \\
\nabla^{2} V(z)=J^{T}(z) \cdot J(z)+s(z)
\end{gathered}
$$

onde, $J(z)$ é a matriz Jacobiana e $s(z)$ representa uma função vetorial que são respectivamente definidas por:

$$
\begin{gathered}
J(z)=\left[\begin{array}{cccc}
\frac{\partial e_{1}(z)}{\partial z_{1}} & \frac{\partial e_{1}(z)}{\partial z_{2}} & \ldots & \frac{\partial e_{1}(z)}{\partial z_{N}} \\
\frac{\partial e_{2}(z)}{\partial z_{1}} & \frac{\partial e_{2}(z)}{\partial z_{2}} & \ldots & \frac{\partial e_{2}(z)}{\partial z_{N}} \\
\ldots & \ldots & \ldots & \ldots \\
\frac{\partial e_{N}(z)}{\partial z_{1}} & \frac{\partial e_{N}(z)}{\partial z_{2}} & \ldots & \frac{\partial e_{N}(z)}{\partial z_{N}}
\end{array}\right] \\
s(z)=\sum_{i=1}^{N} e_{i}(z) \cdot \nabla^{2} e_{i}(z)
\end{gathered}
$$

Substituindo os resultados das Equações (4.40) e (4.39) em (4.37) obtém-se a equação iterativa do método de Newton:

$$
\Delta z=\left[J^{T}(z) \cdot J(z)+s(z)\right]^{-1} \cdot J^{T}(z) \cdot e(z)
$$

Desta forma, o método de Levenberg-Marquardt propõe modificações na Equação (4.43) apontadas a seguir:

$$
\Delta z=\left[J^{T}(z) \cdot J(z)+\mu \mathrm{I}\right]^{-1} \cdot J^{T}(z) \cdot e(z)
$$


onde, $\mu$ representa um parâmetro que ajusta a taxa de convergência do algoritmo e I denota a matriz identidade.

Visto que o cálculo da matriz Jacobiana representa a principal característica do algoritmo de Levenberg-Marquardt, incorporando-a ao algoritmo de backpropagation, esta passa a ser reescrita em função dos pesos sinápticos da rede com o intuito de melhor ajustá-los. Assim, a matriz Jacobiana passa a ser representada por:

$$
\begin{aligned}
& J(W 1)=\left[\begin{array}{cccccccccc}
\frac{\partial e(1)}{\partial W 1_{1,1}} & \ldots & \frac{\partial e(1)}{\partial W 1_{1, N}} & \frac{\partial e(1)}{\partial W 1_{2,1}} & \ldots & \frac{\partial e(1)}{\partial W 1_{2, N}} & \ldots & \frac{\partial e(1)}{\partial W 1_{\mathrm{N} 1,1}} & \ldots & \frac{\partial e(1)}{\partial W 1_{\mathrm{N} 1, N}} \\
\frac{\partial e(2)}{\partial W 1_{1,1}} & \ldots & \frac{\partial e(2)}{\partial W 1_{1, N}} & \frac{\partial e(2)}{\partial W 1_{2,1}} & \ldots & \frac{\partial e(2)}{\partial W 1_{2, N}} & \ldots & \frac{\partial e(2)}{\partial W 1_{\mathrm{N} 1,1}} & \ldots & \frac{\partial e(2)}{\partial W 1_{\mathrm{N} 1 N}} \\
\ldots & \ldots & \ldots & \ldots & \ldots & \ldots & \ldots & \ldots & \ldots & \ldots \\
\frac{\partial e(p)}{\partial W 1_{1,1}} & \ldots & \frac{\partial e(p)}{\partial W 1_{1, N}} & \frac{\partial e(p)}{\partial W 1_{2,1}} & \ldots & \frac{\partial e(p)}{\partial W 1_{2, N}} & \ldots & \frac{\partial e(p)}{\partial W 1_{\mathrm{N} 1,1}} & \ldots & \frac{\partial e(p)}{\partial W 1_{\mathrm{N} 1, N}}
\end{array}\right]
\end{aligned}
$$

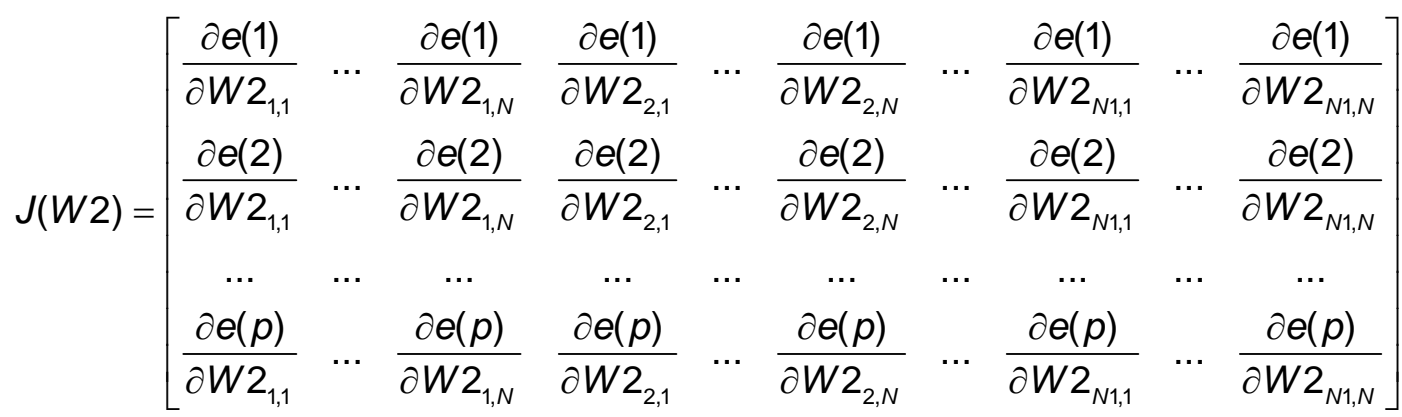

Partindo-se da Equação (4.44), a equação iterativa para o método de Levenberg-Marquardt será:

$$
\Delta z=\left[J^{T}(W) \cdot J(W)+\mu \mathrm{I}\right]^{-1} J^{T}(W) \cdot e(W)
$$

onde, $e(W)=\left[e_{1}(W), e_{2}(W), \ldots, e_{p}(W)\right]$ denota o vetor de erros referente aos $p$ exemplos de treinamento.

Com a atualização dos pesos sinápticos tem-se uma nova etapa backward, que como comprovado por Hagan e Menhaj (1994), apresenta melhor ajuste dos 
pesos e aumenta a velocidade de convergência quando comparado a um algoritmo de backpropagation convencional. 


\section{Identificação de Fontes de Harmônicas e Resultados}

\subsection{Metodologia Proposta}

Neste capítulo serão apresentados os aspectos referentes à metodologia proposta para a identificação das fontes de correntes harmônicas conectadas ao sistema, bem como os resultados obtidos no trabalho. Uma visão geral da metodologia proposta é ilustrada pela Figura 5.1.

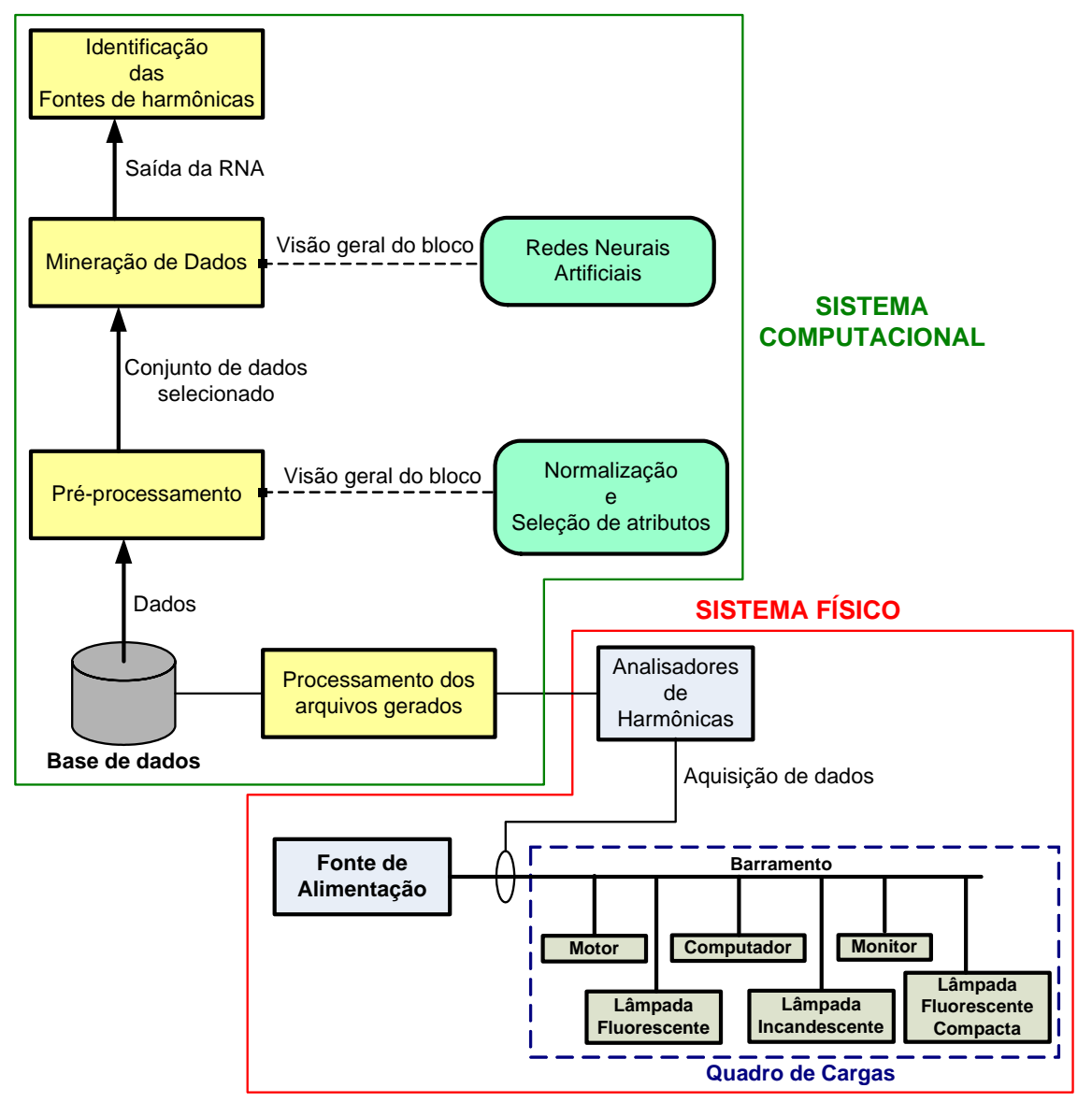

Figura 5.1 - Visão geral da metodologia proposta. 
Todo o procedimento experimental foi realizado com uma fonte de alimentação da California Instruments conectada ao quadro de cargas e configurada em $127 \mathrm{~V}$ eficaz com ângulo de fase em $90^{\circ}$ (utilizou-se $90^{\circ}$ ao invés de $0^{\circ}$ devido a aspectos de configuração do software do equipamento), sendo que esta configuração será adotada como condição ideal à operação do sistema. O quadro de cargas permite o acionamento individual ou combinatório das cargas, assim, para todas as 6 cargas ter-se-ão $2^{6}$ possíveis combinações ou 63 medições em condição ideal, visto que uma das combinações leva em consideração que nenhuma carga encontra-se conectada ao sistema.

Porém, estas 63 medições não eram suficientes para treinar e validar os sistemas neurais, desta forma, outras 378 medidas aleatórias foram realizadas sem que a fonte de alimentação estivesse em condição ideal. Neste caso, a tensão de saída da fonte foi variada entre $+15 \%$ e $-15 \%$; no entanto, para cada uma das medidas, dois analisadores de energia (Fluke e California Instruments) foram empregados fazendo com que o número de medidas dobrasse chegando a uma base de dados contendo um total de 882 aquisições. A utilização de analisadores de energia distintos garantiu que as assinaturas harmônicas obtidas fossem diferentes em poucos níveis percentuais, isto provavelmente devido à calibração dos equipamentos.

Vale ressaltar que todas as medidas apenas foram realizadas com as cargas em regime permanente, pois, o IEEE Std. 519-1992 estabelece este critério para que a real característica harmônica de uma carga seja extraída.

Os dados representando as assinaturas harmônicas das cargas individuais ou da combinação entre as mesmas continham correntes harmônicas de $1^{\mathrm{a}}$ a $25^{\mathrm{a}}$ ordens com suas respectivas amplitudes. O ângulo de fase não foi considerado 
devido à pesquisa de Varadan e Makram (1994) mostrar que este não é um atributo relevante para a identificação de cargas não lineares. Portanto, para cada medição foram extraídas 25 variáveis.

Com os dados adquiridos, houve ainda a necessidade de adequá-los, devido aos cabeçalhos contidos nos arquivos gerados pelos analisadores de energia como mostrado pelas Figuras 3.8 e 3.9.

Tendo em mãos os arquivos totalmente adequados, a base de dados pôde ser gerada, contendo 882 instâncias (amostras), e cada instância um total de 25 atributos.

Devido à grande quantidade de atributos que a base de dados possuía, isto tornava a mineração de dados feita pelas RNAs uma tarefa de alto custo computacional, além de muitos atributos não contribuírem efetivamente para a extração dos padrões de assinaturas harmônicas. Por isto, houve a necessidade de uma etapa de pré-processamento, onde foram analisados os três métodos para seleção de atributos citados no Capítulo 4. O desempenho de cada um desses métodos (Wrapper, CFS e CF) foi avaliado quanto aos atributos selecionados e ao tempo gasto para a execução da tarefa. Estes métodos de seleção de atributos foram empregados utilizando-se a ferramenta computacional Weka (C) (Waikato Environment Knowledge for Analisys), fornecida em domínio público e desenvolvida pela Universidade de Waikato (Witten e Frank, 2005).

Com os atributos selecionados, passou-se então a utilizar uma nova base de dados constituída apenas pelos atributos mais relevantes à identificação das fontes de harmônicas. Esta base de dados foi dividida em $70 \%$ para o conjunto de treinamento das redes e os 30\% restantes para o conjunto de validação. 
O conjunto de treinamento foi então apresentado às RNAs para que estas pudessem extrair pelo algoritmo de Levenberg-Marquardt os padrões de assinaturas harmônicas das cargas. Para isto foram empregadas seis RNAs, onde cada uma tornou-se especialista na identificação de determinado equipamento. Esta estratégia fez com que o desempenho da identificação das fontes de harmônicas fosse ainda melhor.

Após o treinamento das RNAs, estas foram submetidas ao processo de validação, onde o conjunto de validação foi apresentado às entradas de cada RNA para que viessem a identificar as cargas conectadas. Os resultados obtidos para todo processo descrito acima, desde a seleção de atributos até a validação das RNAs, serão melhor apresentados e explanados na seção subseqüente.

\subsection{Resultados Experimentais}

Em primeira instância, mostrar-se-á o desempenho dos métodos aplicados para a seleção dos atributos, isto é, a lista com as relevâncias de cada uma das ordens das harmônicas contidas na base de dados. As medidas de desempenho desses métodos podem ser visualizadas pela Tabela 5.1. 
Tabela 5.1 - Desempenho dos seletores de atributos do ponto de vista do esforço computacional e relevância dos atributos.

\begin{tabular}{|c|c|c|}
\hline \hline $\begin{array}{c}\text { Seletor } \\
\text { de } \\
\text { Atributos }\end{array}$ & $\begin{array}{c}\text { Ranking } \\
\text { de } \\
\text { Atributos }\end{array}$ & Tempo(s) \\
\hline & $01,03,05,07,09$, & \\
CFS & $\begin{array}{c}11,13,14,15,16, \\
18,19,20,22,24,\end{array}$ & 0,33 \\
& $25,02,04,06,08$, & \\
& $10,12,17,21,23$ & \\
\hline & $01,03,05,07,09$, & \\
CF & $11,13,14,15,16$, & \multirow{2}{*}{0,76} \\
& $18,19,20,22,24$, & \\
& $25,02,04,06,08$, & \\
& $10,12,17,21,23$ & \\
\hline & $01,03,05,07,11$, & \\
& $13,15,09,19,20$, & \multirow{2}{*}{ Wrapper } \\
& $22,25,18,16,24$, & $172311(\mathrm{rd})$ \\
& $14,23,02,04,10$, & \\
\hline & $17,12,06,21,08$ & \\
\hline
\end{tabular}

Pelos resultados obtidos, pode-se verificar que os quatro primeiros atributos do ranking foram os mesmos para os três métodos. Assim, apenas estes quatro primeiros atributos foram utilizados para compor a nova base de dados.

Outra característica que pode ser observada é o esforço computacional apresentado pelos algoritmos, onde o método Wrapper gastou aproximadamente dois dias para obter os atributos mais relevantes e os algoritmos CFS e CF, que são baseados em filtros, apresentaram respostas favoráveis em menos de um segundo. Também pode ser verificado e reafirmado que o método CF apresenta esforço computacional maior que o método CFS devido à utilização de um algoritmo de busca probabilística ao invés de uma busca heurística. Especificamente para esta dissertação, o esforço computacional apresentado pelos seletores de atributos é irrelevante, pois, são utilizados apenas na etapa de pré-processamento dos dados, os quais são posteriormente utilizados para o treinamento das RNAs. No entanto, caso a mesma metodologia fosse aplicada para sistemas onde as cargas são 
alteradas em um curto espaço de tempo, o esforço computacional dos métodos poderia fazer diferença e assim os métodos CFS e CF deveriam ser aplicados.

Com a aplicação das técnicas de seleção de atributos, o espaço de busca foi reduzido. De forma a exemplificar tal tarefa, foram gerados dois gráficos contendo apenas as 50 primeiras instâncias (amostras) da base de dados. Assim, pela Figura 5.2, ilustra-se um mero exemplo do espaço de busca original, isto é, o espaço de busca referente às 50 instâncias antes de seus atributos serem selecionados. E pela Figura 5.3, pode-se verificar o espaço de busca destas 50 instâncias, porém, após selecionados os atributos mais relevantes à identificação das cargas.

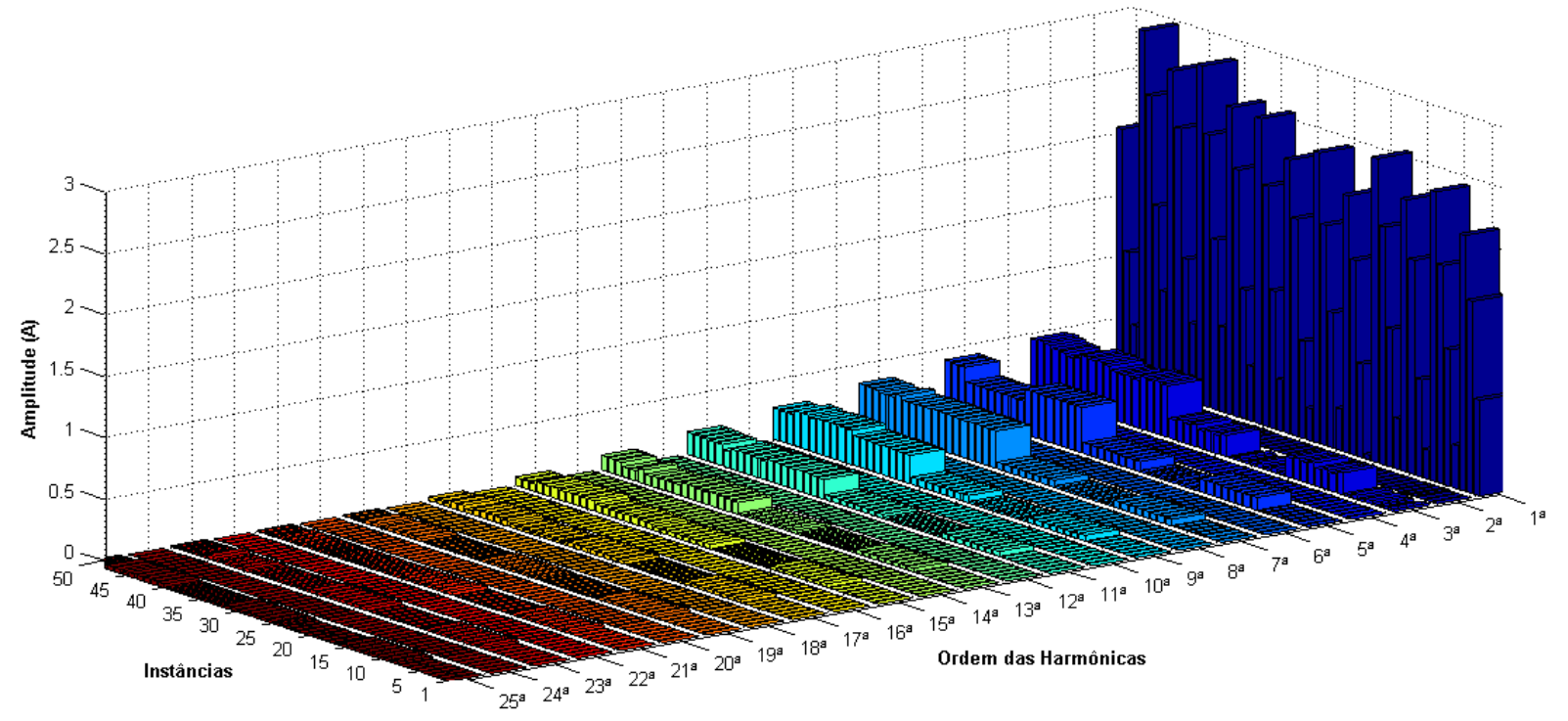

Figura 5.2 - Espaço de busca antes de selecionar os atributos mais relevantes. 


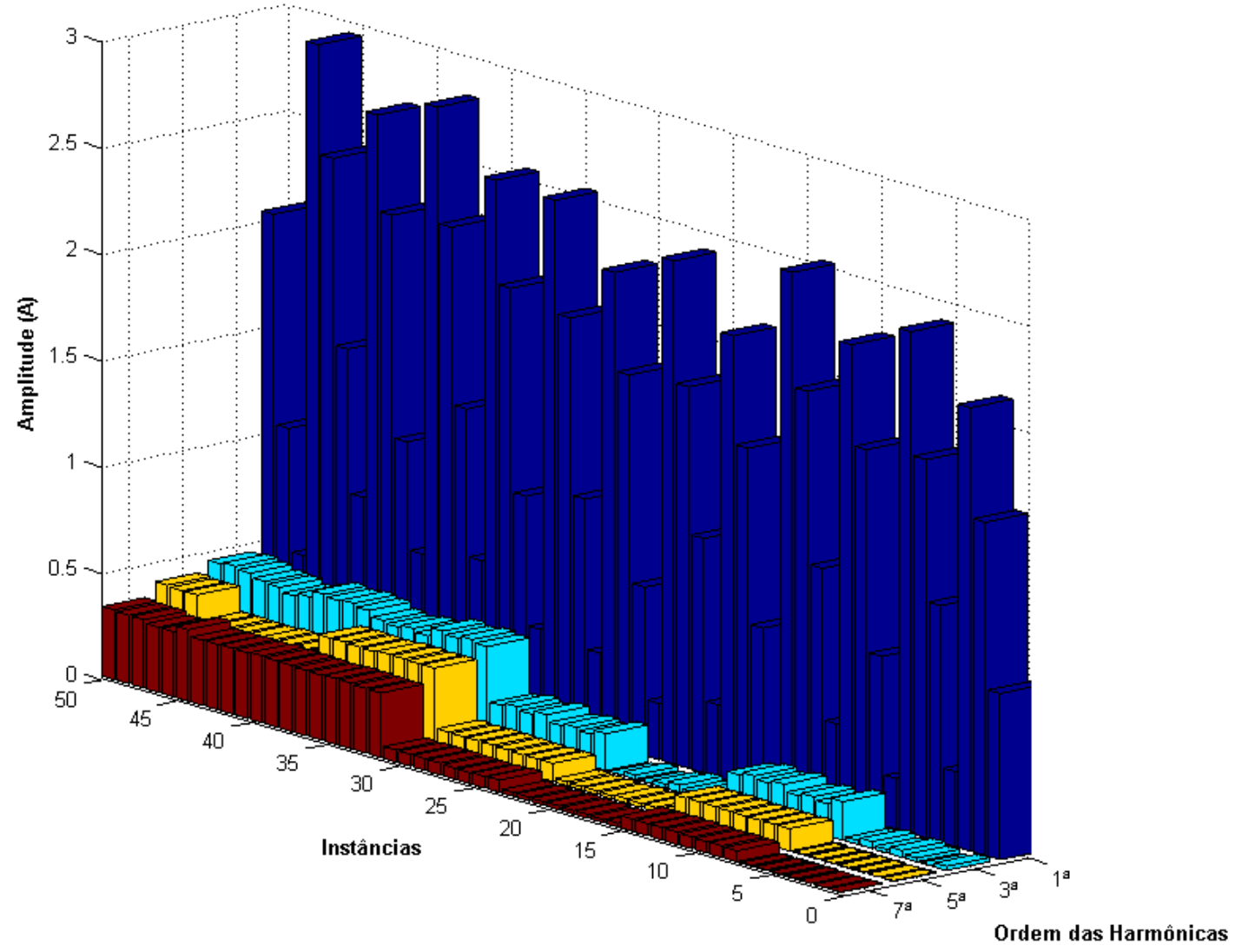

Figura 5.3 - Espaço de busca contendo apenas os atributos selecionados.

O próximo passo aplicado após a seleção dos atributos foi o treinamento das RNAs. Todas as RNAs empregadas nesta dissertação, bem como seus algoritmos de treinamento, foram configuradas utilizando-se o Toolbox da ferramenta computacional Matlab ${ }^{\circledR}$ (Demuth, Beale e Hagan, 2007). Assim, todas as seis RNAs foram projetadas de modo a possuírem a mesma configuração, sendo utilizadas duas camadas neurais intermediárias com respectivamente 26 e 12 neurônios; e apenas um neurônio na camada de saída. Quanto às funções de ativação dos neurônios, para as camadas intermediárias, utilizou-se a tangente hiperbólica, e para a camada de saída se empregou a função linear com limites em 1 e -1, representando assim o estado ao qual se encontra o equipamento (ligado ou desligado). A arquitetura das RNAs pode ser visualizada por meio da Figura 5.4. 


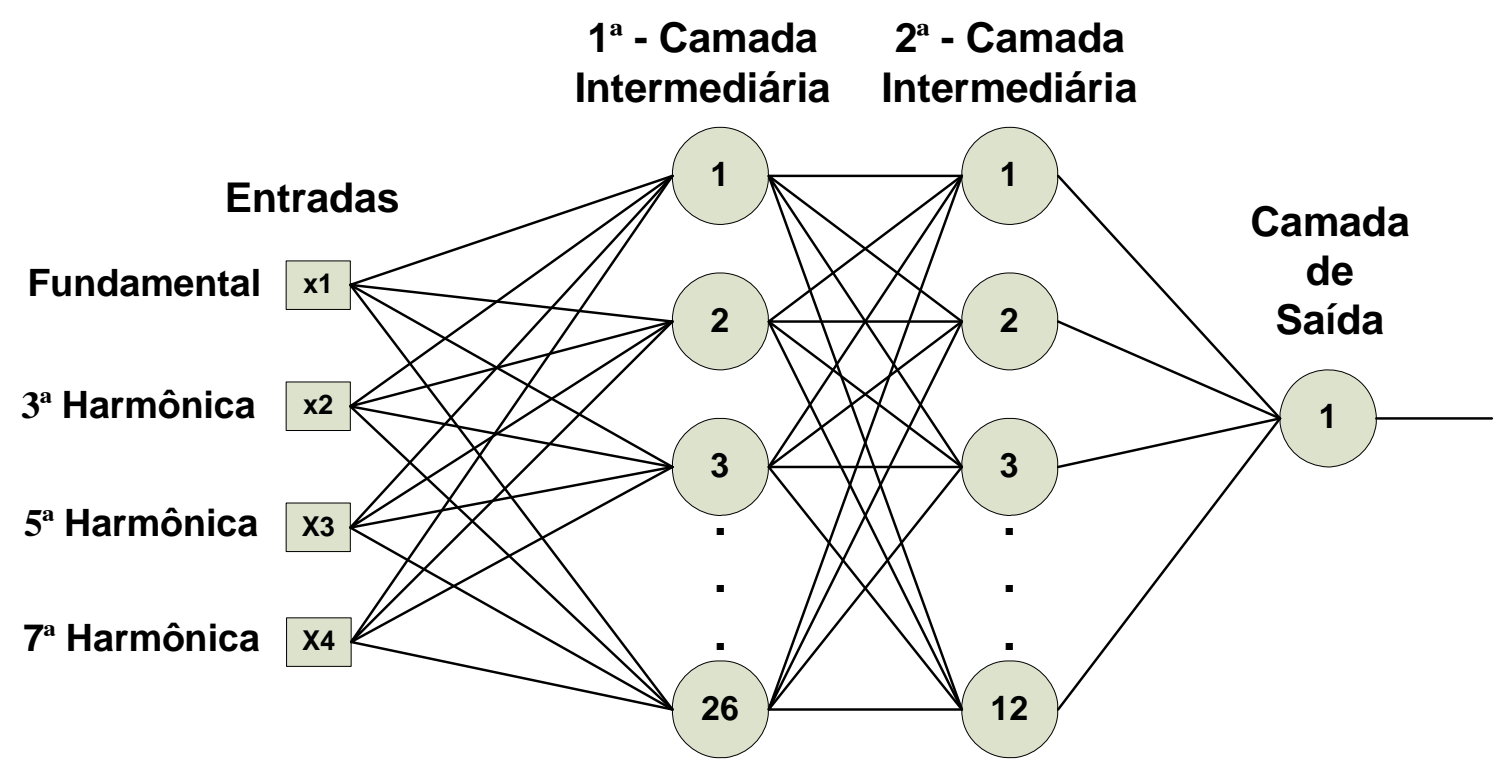

Figura 5.4 - Arquitetura das RNAs empregadas à tarefa de identificação das fontes de harmônicas.

Portanto, a seguir, apresenta-se na Figura 5.5 o gráfico do treinamento realizado pela RNA especializada na identificação do computador pessoal e, por meio da Figura 5.6, pode-se observar o treinamento da RNA especializada na identificação do Monitor.

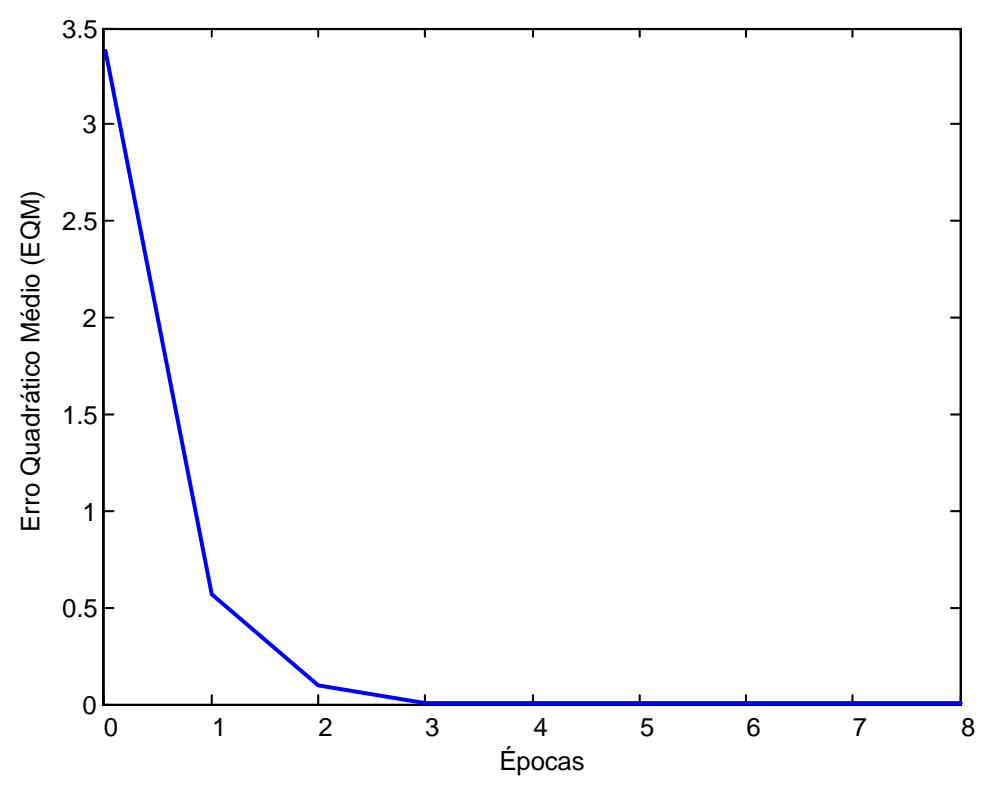

Figura 5.5 - Gráfico de treinamento da RNA especializada na identificação do computador pessoal. 


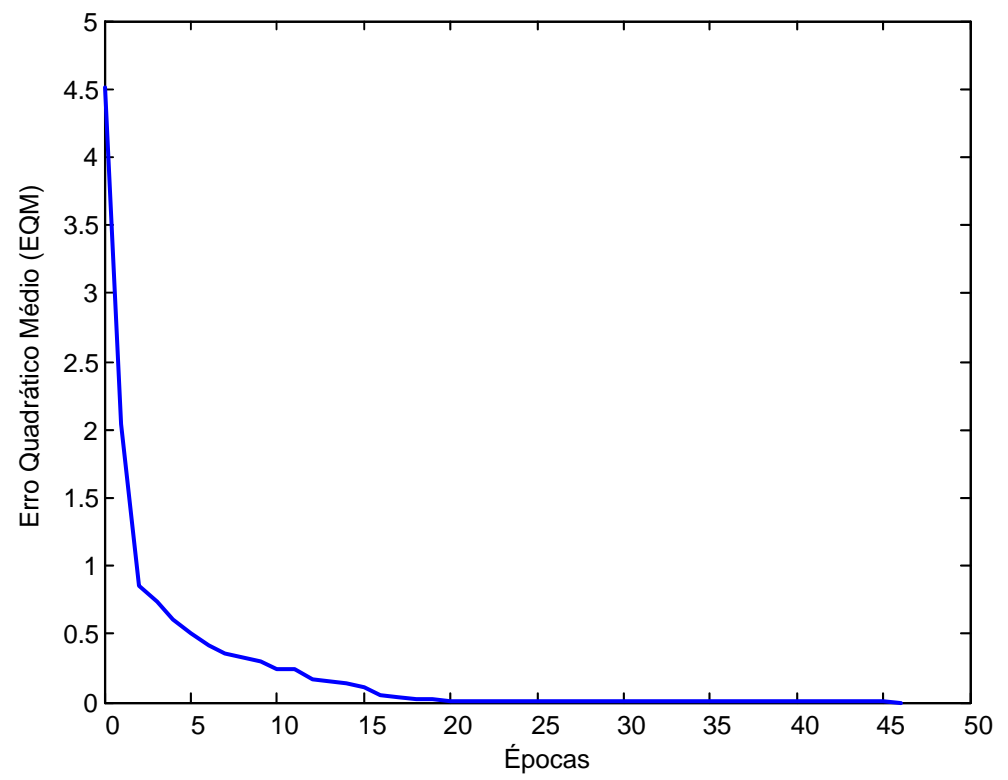

Figura 5.6 - Representação gráfica do treinamento realizado pela RNA responsável pela identificação do monitor.

O treinamento das RNAs especialistas na identificação das lâmpadas fluorescente, incandescente e fluorescente compacta são ilustrados pelas Figuras 5.7, 5.8 e 5.9 respectivamente.

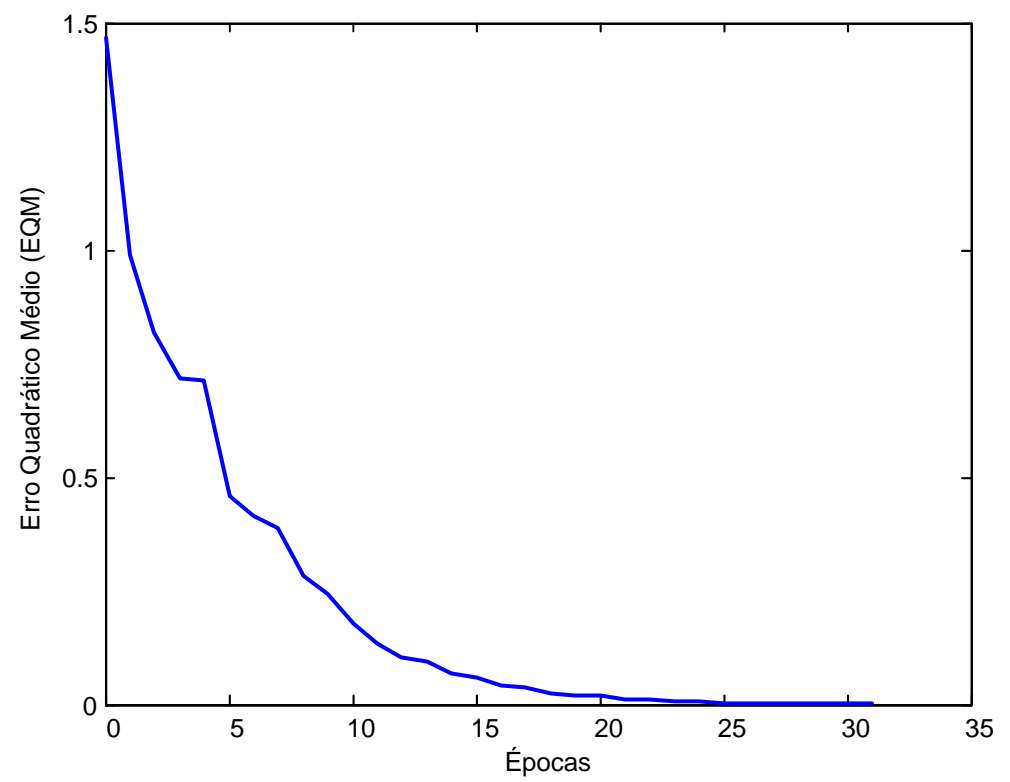

Figura 5.7 - Treinamento da RNA especializada na identificação da lâmpada fluorescente. 


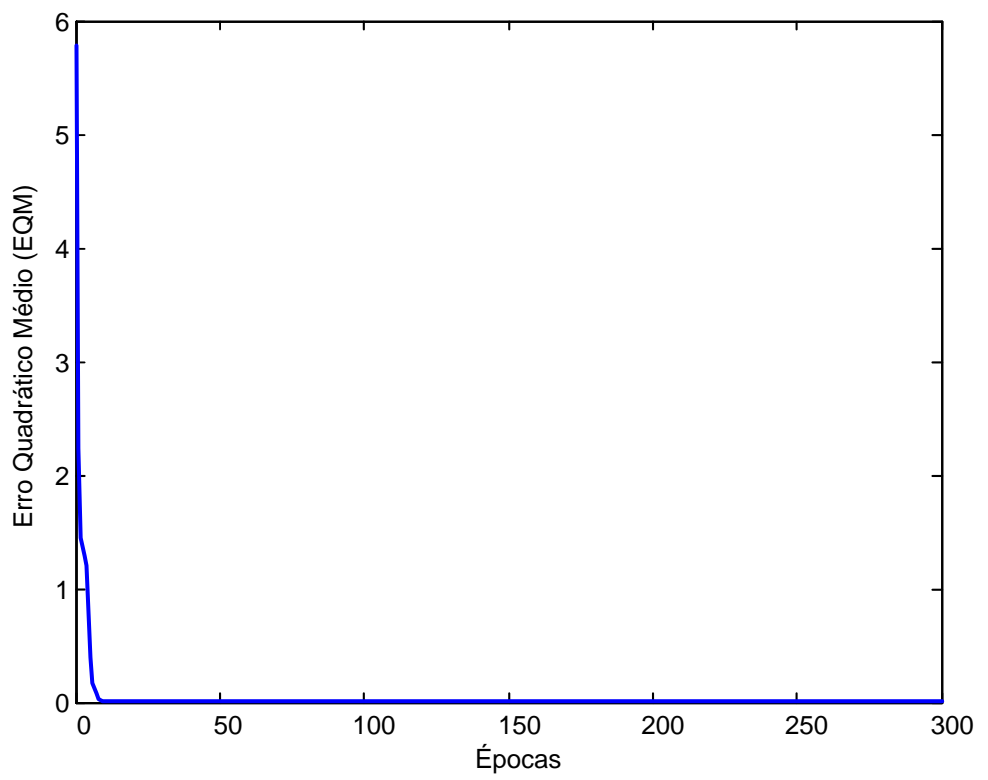

Figura 5.8 - Treinamento da RNA especialista na identificação da lâmpada incandescente.

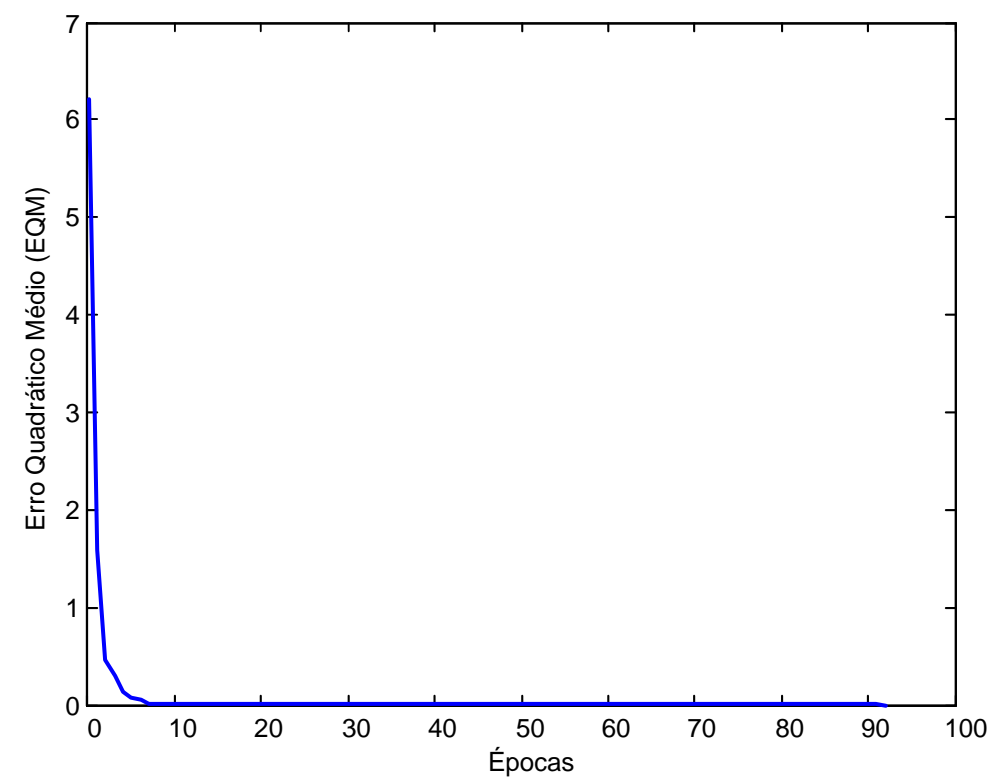

Figura 5.9 - Treinamento da RNA responsável pela identificação da lâmpada fluorescente compacta.

Já a RNA responsável pela identificação do motor tem seu treinamento apresentado pela Figura 5.10. 


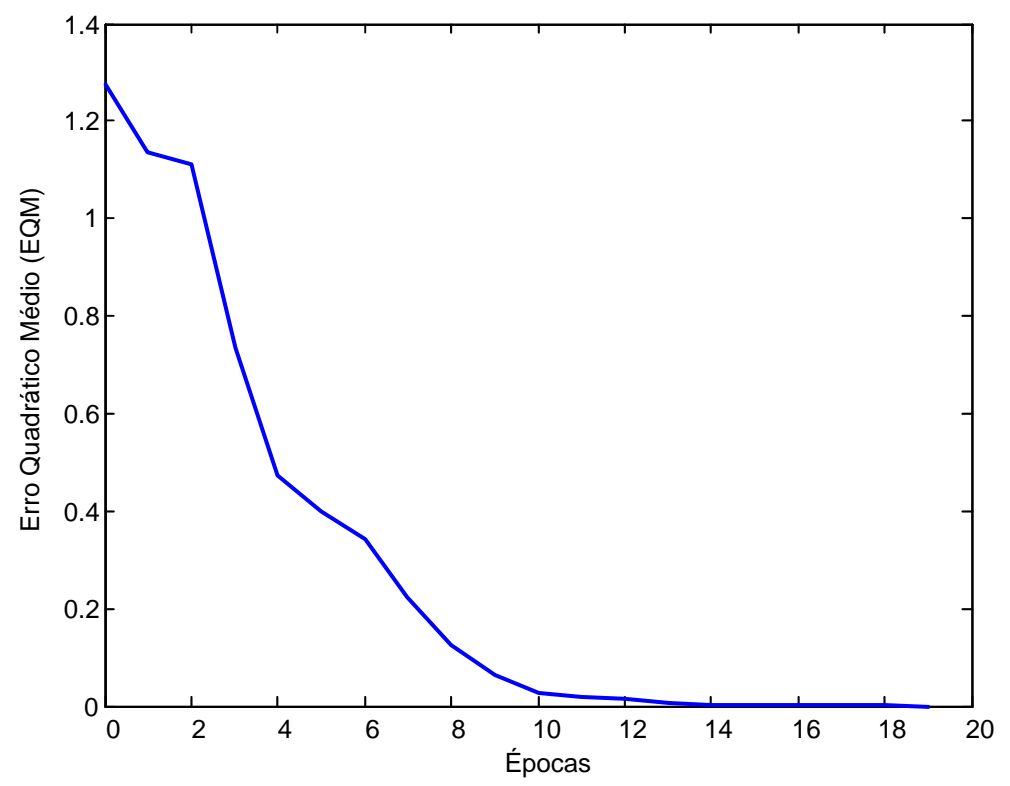

Figura 5.10 - Gráfico de treinamento da RNA especializada na identificação do motor.

Após o treinamento das RNAs, as mesmas foram submetidas a uma etapa de validação, utilizando-se para tanto o conjunto de validação composto por 265 medições que equivalem a cerca de $30 \%$ da base de dados.

A seguir podem ser visualizados por meio da Tabela 5.2 os resultados para a identificação de cada uma das cargas.

Tabela 5.2 - Desempenho das RNAs responsáveis pela identificação de cada carga.

\begin{tabular}{|cc|}
\hline \hline Carga & $\begin{array}{c}\text { Acerto } \\
\text { (\%) }\end{array}$ \\
\hline Lâmpada Incandescente & 100 \\
Lâmpada Fluorescente* & 99,25 \\
Lâmpada Fluorescente Compacta & 100 \\
Motor & 99,25 \\
Computador Pessoal & 100 \\
Monitor & 100 \\
\hline \hline
\end{tabular}

*reator convencional 
Por meio da tabela anterior, pode-se verificar que as RNAs responsáveis por identificar as lâmpadas incandescente e fluorescente compacta, bem como as RNAs especializadas na identificação do computador pessoal e do monitor, tiveram aproveitamento de 100\%, isto é, conseguiram identificar corretamente (para todas as instâncias) se a respectiva carga estava conectada ou não ao sistema elétrico.

Já no caso da lâmpada fluorescente e do motor, o aproveitamento foi aceitável, porém, com uma taxa de acerto de 99,25\%. As instâncias erradas pelas RNAs responsáveis por estes equipamentos são ilustradas pela Tabela 5.3.

Tabela 5.3 - Instâncias do conjunto de validação que as RNAs responsáveis pela lâmpada fluorescente e pelo motor apresentaram respostas errôneas.

\begin{tabular}{|c|c|c|c|c|c|c|c|c|c|c|c|c|}
\hline \multirow[b]{2}{*}{ \# Instâncias } & \multicolumn{6}{|c|}{ Saídas das redes } & \multicolumn{6}{|c|}{ Saídas desejadas } \\
\hline & PC & MON & LFC & LF & LI & MO & PC & MON & LFC & LF & LI & MO \\
\hline 206 & 0 & 0 & 0 & $\mathrm{O}$ & $x$ & 0 & $\mathrm{O}$ & $\mathrm{O}$ & 0 & 0 & $x$ & $\mathrm{X}$ \\
\hline 221 & 0 & $x$ & 0 & 0 & $x$ & 0 & 0 & $x$ & $\mathrm{O}$ & 0 & $x$ & $\mathrm{X}$ \\
\hline 260 & $X$ & $X$ & $X$ & $\mathrm{X}$ & $x$ & $\mathrm{O}$ & $X$ & $X$ & $X$ & 0 & $x$ & $\mathrm{O}$ \\
\hline 261 & $x$ & $x$ & $x$ & $x$ & $x$ & $x$ & $x$ & $x$ & $x$ & 0 & $x$ & $x$ \\
\hline
\end{tabular}

Para a análise da tabela acima algumas nomenclaturas foram utilizadas para se referir às RNAs responsáveis por cada equipamento, sendo PC (computador pessoal), MON (monitor), LFC (lâmpada fluorescente compacta), LF (lâmpada fluorescente com reator convencional), LI (lâmpada incandescente) e MO (motor).

Pela Tabela 5.3, verifica-se que os erros ocorreram em apenas quatro casos distintos, onde dois erros foram cometidos pela RNA responsável por identificar a lâmpada fluorescente e outros dois erros foram cometidos pela RNA responsável por identificar o motor monofásico. Quanto aos erros de identificação do motor, verificase que nas duas situações o mesmo encontrava-se ligado, porém, a rede neural identificou como desligado. Já no caso dos erros cometidos para identificação da 
lâmpada fluorescente, as duas situações foram inversas ao ocorrido com o motor, visto que a carga encontrava-se desligada e a rede neural identificou como ligada. 



\section{Conclusões Gerais e Trabalhos Futuros}

\subsection{Conclusões Gerais}

Nesta dissertação apresentou-se um estudo sobre a identificação de fontes de correntes harmônicas em sistemas elétricos residenciais, onde foi gerada uma base de dados a partir de ensaios laboratoriais. Os ensaios forneceram dados reais de cargas comumente utilizadas em residências, os quais possibilitaram o treinamento e validação dos sistemas neurais. Estes dados foram adquiridos com variações entre $+15 \%$ e $-15 \%$ na alimentação das cargas, pois, se fosse utilizado apenas dados representando a condição normal do sistema, a aplicação de redes neurais não seria uma alternativa viável devido ao pequeno conjunto de dados que seria apresentado ao treinamento das mesmas.

Por não haver como saber quais harmônicas seriam mais relevantes à identificação das cargas, foram obtidas harmônicas de $1^{\text {a }}$ à $25^{\mathrm{a}}$ ordens; no entanto, esta grande quantidade de harmônicas obtidas para cada assinatura harmônica das cargas e suas combinações faz com que o conjunto de dados tenha muitos atributos e também torna o espaço de busca mais complexo. Assim, técnicas para a seleção de atributos foram aplicadas para melhor preparar os dados à etapa de mineração que foi realizada pelas RNAs com o intuito de se extrair uma resposta eficiente que determinasse o comportamento dinâmico do sistema.

Esta etapa de preparação dos dados, além de reduzir o espaço de busca, garantiu um menor esforço computacional, visto que ao invés de se utilizar cerca de 
25 atributos como entrada às RNAs, apenas 4 atributos foram apresentados à entrada das mesmas.

Os resultados experimentais mostraram que as RNAs apresentam excelente desempenho sobre condições que extrapolam a normalidade do sistema elétrico, isto devido à sua capacidade de generalizar o conhecimento. Isto mostra o grande potencial das RNAs, podendo ser muito bem empregadas em problemas de identificação de fontes de harmônicas como alternativa aos métodos convencionais.

\subsection{Trabalhos Futuros}

Como trabalhos futuros, vislumbra-se a identificação das cargas em tempo real, por meio de placa para aquisição de dados.

Além da identificação em tempo real, este trabalho pode ser realizado com uma maior quantidade de cargas ou com equipamentos encontrados em diferentes tipos de consumidores residenciais e/ou industriais.

E por fim, pode-se aplicar este sistema baseado em mineração de dados para a identificação de fontes de tensões ou correntes harmônicas em sistemas de distribuição de energia, sendo este o tipo de aplicação comumente encontrado na literatura. 


\section{Referências Bibliográficas}

ALAMMARI, R. A., SOLIMAN, S. A. e EL-HAWARY, M. E. (2004). Identification of Individual Types of Harmonic Loads in an Electric Power System Bus. Electrical Power and Energy Systems, vol. 26, pp. 545-548.

ALMUALLIM, H. e DIETTERICH, T. G. (1991). Learning with many Irrelevant Features. Proc. of the $9^{\text {th }}$ National Conference on Artificial Intelligence.

ARRILLAGA, J., WATSON, N. R. e CHEN, S. (2000). Power System Quality Assessment. John Wiley \& Sons.

BRAGA, A. P., LUdermiR, T. B. e CARVAlHO, A. C. P. L. F. (2000). Redes Neurais Artificiais: Teoria e Aplicações. LTC.

CHAN, W. L., SO, A. T. P. e LAI, L. L. (2000). Wavelet Feature Vectors for Neural Network Based Harmonics Load Recognition. Proc. of the $5^{\text {th }}$ International Conference on Advances in Power System Control, Operation and Management (APSCOM), pp. 511-516.

DAS, J. C. (2002). Power System Analysis: Short-Circuit Load Flow and Harmonics, Marcel Dekker.

DEMUTH, H., BEALE, M. e HAGAN, M. (2007). "Neural Network Toolbox 5 - User's Guide", http://www.mathworks.com/access/helpdesk/help/toolbox/nnet/, Acessado em 05 de Janeiro de 2008.

DUGAN, R. C., McGRANAGHAN, M. F., SANTOSO, S. e BEATY, H. W. (2004). Electrical Power Systems Quality, McGraw-Hill. 
FAYYAD, U. M., PIATETSKY-SHAPIRO, G., SMYTH, P. e UTHURUSAMY, R. (1996). Advances in Knowledge Discovery and Data Mining, AAAI Press.

FERRERO, A., SALICONE, S, e TODESCHINI, G. (2007). A Fuzzy method for the identification of the sources reducing harmonic pollution in the electric network. Proc. of the Instrumentation and Measurement Technology Conference (IMTC), pp. 1-6.

HAGAN, M. T. e MENHAJ, M. B. (1994). Training Feedforward Networks with the Marquardt Algorithm. IEEE Transactions on Neural Networks, vol. 5, No. 6, pp. 989-993.

HALL, M. A. (1999). Correlation-based Feature Selection for Machine Learning, Ph.D. Thesis, The University of Waikato, Hamilton, NewZealand.

HALL, M. A. (2000). Correlation-based Feature Selection for Discrete and Numeric Class Machine Learning. Proc. of the $17^{\text {th }}$ International Conference on Machine Learning (ICML), pp. 359-366.

HALL, M. A. e HOLMES, G. (2003). Benchmarking Attribute Selection Techniques for Discrete Class Data Mining. IEEE Transactions on Knowledge and Data Engineering, vol. 15, No. 3, pp. 1-16.

HAN, J. e KAMBER, M. (2001). Data Mining: Concepts and Techniques, Morgan Kaufmann.

HAYKIN, S. (1999). Neural Networks - A Comprehensive Foundation, Prentice Hall. HEYDT, G. T. (1989). Identification of Harmonic Sources by a State Estimation Technique. IEEE Transactions on Power Delivery, vol. 4, No. 1, pp. 569-576.

IEEE Standard 519-1992 (Recommended Practices and Requirements for Harmonic Control in Electrical Power Systems). 
ISLAM, K. M. S. e SAMRA, A. H. (1997). Identification of Harmonic Sources in Power Distribution Systems. Proc. of the IEEE Southeastcon, pp. 301-303.

KOHAVI, R. e JOHN, G. H. (1997). Wrappers for Feature Subset Selection. Artificial Intelligence, pp. 273-324.

KUMAR, A., DAS, B. e SHARMA, J. (2004). Determination of location of multiple harmonic sources in a power system. Electrical Power and Energy Systems, vol. 26, pp. 73-78.

LEE, H. D. (2005). Seleção de Atributos Importantes para a Extração de Conhecimento de Bases de Dados, Tese de Doutorado, Universidade de São Paulo (USP/ICMC), São Carlos - SP.

LIN, H. C. (2007). Intelligent Neural Network-Based Fast Power System Harmonic Detection. IEEE Transactions on Industrial Electronics, vol. 54, No. 1, pp. 43-52.

LIN, W., LIN, C., TU, K. e WU, C. (2005). Multiple Harmonic Source Detection and Equipment Identification With Cascade Correlation Network. IEEE Transactions on Power Delivery, vol. 20, No. 3, pp. 2166-2173.

LIU, H. e MOTODA, H. (1998). Feature Selection for Knowledge Discovery and Data Mining, Kluwer Academic Publishers.

LIU, H. e MOTODA, H. (2001). Instance Selection and Construction for Data Mining, Kluwer Academic Publishers.

LIU, H. e SETIONO, R. (1996). A Probabilistic Approach to Feature Selection: A Filter Solution. Proc. of the $13^{\text {th }}$ International Conference on Machine Learning. MCCULLOCH, W. S. e PITTS, W. (1943). A Logical Calculus of the Ideas Immanent in Nervous Activity. Bulletin of Mathematical Biophysics, No. 5, pp. 115-133. NAScimento, C. F., JUNIOR, A. A. O., GOEDTEL, A., SILVA, I. N., MONTEIRO, J. R. B. A e AGUIAR, M. L. (2007). Harmonic Detection Based on Artificial Neural 
Networks for Current Distortion Compensation. IEEE International Symposium on Industrial Electronics (ISIE), pp. 2864-2869.

NAWI, S. M., JOHARI, J. e ABIDIN, A. F. (2003). A Fuzzy Logic Application for Identification of Harmonics Disturbances Sources. Proc. of the National Power and Energy Conference (PECon), pp. 27-31.

NGUYEN, M. T. e LEE, W. (2000). An Approach to Enhance the Harmonic Sources Identification Process. IEEE Industrial and Commercial Power Systems Technical Conference, pp. 127-132.

NIEKERK, C. R., RENS, A. P. J. e HOFFMAN, A. J. (2002). Identification of Types of Distortion Sources in Power Systems by Applying Neural Networks. Proc. of the IEEE Africon, pp. 829-834.

OLIVEIRA, S. R. (2004). De Dados a Conhecimento: Evolução e Desafios, Tese de Livre Docência, Universidade de São Paulo (USP/ICMC), São Carlos - SP.

RUMELHART, D. E. e MCCLELLAND, J. L. (1986). Parallel Distributed Processing, MIT Press.

SANKARAN, C. (2002). Power Quality, CRC Press.

SCHAFFNER (2006). "EMC - IEC 61000-3-2 Harmonics Standards Overview", http://www.schaffner.com/, Acessado em 21 de Maio de 2008.

SRINIVASAN, D., NG, W. S. e LIEW. A. C. (2006). Neural Network-Based Signature Recognition for Harmonic Source Identification. IEEE Transactions on Power Delivery, vol. 21, No. 01, pp. 398-405.

UMEH, K. e MOHAMED, A. (2005). Intelligent System for Identification of Harmonics Originating from Single Phase Nonlinear Loads. Proc. of the IEEE Southeastcon, pp. 137-142. 
VARADAN, S. e MAKRAM, E. B. (1994). Practical considerations in the application of neural networks to the identification of harmonic loads. Electrical Power Systems Research, vol. 30, pp. 103-106.

VARADAN, S. e MAKRAM, E. B. (1996). Harmonic load identification and determination of load composition using a least squares method. Electrical Power Systems Research, vol. 37, pp. 203-208.

WAKILEH, G. J. (2001). Power Systems Harmonics: Fundamentals, Analysis and Filter Design. Springer, Berlin, Germany.

WITTEN, I. H., e FRANK, E. (2005). Data Mining: Practical Machine Learning Tools and Techniques, 2nd ed., Morgan Kaufmann. 